\title{
Refinements in microvascular surgery
}

Citation for published version (APA):

De Lorenzi, F. (2003). Refinements in microvascular surgery. [Doctoral Thesis, Maastricht University]. Universiteit Maastricht. https://doi.org/10.26481/dis.20030620fd

Document status and date:

Published: 01/01/2003

DOI:

10.26481/dis.20030620fd

Document Version:

Publisher's PDF, also known as Version of record

\section{Please check the document version of this publication:}

- A submitted manuscript is the version of the article upon submission and before peer-review. There can be important differences between the submitted version and the official published version of record.

People interested in the research are advised to contact the author for the final version of the publication, or visit the DOI to the publisher's website.

- The final author version and the galley proof are versions of the publication after peer review.

- The final published version features the final layout of the paper including the volume, issue and page numbers.

Link to publication

\footnotetext{
General rights rights.

- You may freely distribute the URL identifying the publication in the public portal. please follow below link for the End User Agreement:

www.umlib.nl/taverne-license

Take down policy

If you believe that this document breaches copyright please contact us at:

repository@maastrichtuniversity.nl

providing details and we will investigate your claim.
}

Copyright and moral rights for the publications made accessible in the public portal are retained by the authors and/or other copyright owners and it is a condition of accessing publications that users recognise and abide by the legal requirements associated with these

- Users may download and print one copy of any publication from the public portal for the purpose of private study or research.

- You may not further distribute the material or use it for any profit-making activity or commercial gain

If the publication is distributed under the terms of Article $25 \mathrm{fa}$ of the Dutch Copyright Act, indicated by the "Taverne" license above, 
Refinements in microvascular surgery

\section{proefschrift}

ter verkrijging van de graad van doctor aan de Universiteit van Maastricht,

op gezag van de Rector Magnificus

Prof. Dr. A.C. Nieuwenhuijzen Kruseman,

volgens het besluit van het College van Decanen

in het openbaar te verdedigen

op vrijdag 20 juni 2003 om 14.00 uur

door

\section{Francesca de Lorenzi}

geboren op 13 november 1970 te Lucca in Italië 
Supervisor:

Co-supervisor

Degree Committee:
Prof. Dr. Willy D. Boeckx

Dr. René R. W. J. van der Hulst

Prof. Dr. J.L.H. Evers

Prof. Dr. M.J.H.M. Jacobs

Dr. J.J. Hage

Prof. Dr. Ph.E.V. Van Kerrebroeck

Prof. Dr. Sirpa Asko-Seliavaara

Prof. Dr. J.L.H. Evers

Financially supported by Emdaplast

ISBN 90 - 5681 - $169-X$ 
"It was like looking for the first time to the moon through a powerful telescope; a whole world of unrecognized detail was seen"

Jacobson, 1960 
Dedicated to my grandparents

In memory of my father 


\section{Table of contents}

1 Introduction 7

Solving technical problems:

2 Increasing the flow output by $Y$ shaped microvascular anastomosis 17

3 Interrupted micro-mattress sutures to solve vessel size discrepancy 27

4 VCS Auto Suture ${ }^{\circledR}$ Stapled Microvascular anastomoses in lower leg free flaps $\quad 35$

Solving clinical problems:

5 Free temporalis fascia transplantation as a treatment for wrist ankylosis $\quad 47$

6 Horseshoe expanded scapular free flap shows no venous congestion 57

7 The free TRAM procedure in breast reconstruction: $\begin{array}{ll}\text { choice of vascular receptor site } & 67\end{array}$

8 Free flaps in burn reconstruction $\quad 79$

9 Nostril reconstruction with ear helix free flap 93

10 Arterialised venous free flaps for soft tissue reconstruction of digits: a 40 cases series $\quad 99$

11 Development of a new arterialised venous flap in the rabbit ear 109

12 Discussion $\quad 121$

$\begin{array}{ll}\text { Summary } & 125\end{array}$

$\begin{array}{lr}\text { Acknowledgements } & 129\end{array}$

$\begin{array}{ll}\text { Curriculum vitae } & 131\end{array}$ 


\title{
Chapter 1 - Introduction
}

\begin{abstract}
History
During the last century the introduction of microsurgery has gained popularity and is applied in several surgical fields. The introduction of the microscope during surgery of the middle ear in 1921 by Nylen (1) was a key stone in further development of reconstructive surgery. In 1960 Jacobson and Suarez performed the first microsurgical anastomosis in a $3 \mathrm{~mm}$ small vessel ${ }^{(2)}$. Using microvascular anastomotic techniques created the possibility to replant digits as was performed for the first time by Tamai in $1965^{(3.4)}$. The first free flap in man was performed by Antia and Bunch in Bombay, India $1971^{(5)}$. Within one year after this first free tissue transfer McLean and Buncke used the omentum to repair a large scalp defect ${ }^{(6)}$. In 1973 Daniel and Taylor published there first series of free tissue transfers ${ }^{7,88}$. This was the birth of microsurgery. In the sixty's and seventy's microsurgical flaps were further developed $(9-16,56)$. Refinements in free flaps, selection, decreasing the bulk and optimising the quality of the tissues took place in the 1980 's ${ }^{(17-26)}$. Construction of prefabricated flaps with specific qualifications subsequently began in the ninety's ${ }^{(27-32)}$.
\end{abstract}

\section{Solving technical problems}

In several instances today's microsurgery still is confronted with problematic situations, especially regarding the basic microsurgical techniques. The data retrospectively collected by Glicksman et al. ${ }^{(57)}$ about 10.839 free flaps performed between 1990 and 1994 point out a success rate ranging between 93 an $95 \%$ using the 9 most commonly flaps. The success rate for digital replants was $81 \%$ for the lower extremity and $86 \%$ for the upper extremity. The vascular complications encountered consisted of venous occlusion (50\%), arterial occlusion (24\%), bleeding and/or haematoma (19\%) and vasospasm (5\%). The overall incidence of complications and flap failure is consistent with other series in the literature ${ }^{(55-67)}$. Improvement in the quality of the techniques, surgical skill, and problem solving, especially in small vessel microsurgery, is necessary. Novel developments in basic microvascular anastomosis techniques could improve the quality of the microvascular surgical reconstruction. Technical problems are encountered regarding vessel diameter, vessel quality, and local availability of recipient vessels.

Vessel diameter discrepancy can be seen in arteries as well as in veins. There are several solutions to this problem. The most simple is a more extensive dissection of the pedicle or the recipient vessels. However, this is not always possible. In addition, when the discrepancy in size is not significant, the smaller vessel can be easily expanded mechanically with dilator forceps or the stump of the smaller vessel can be cut obliquely to increase the circumference ${ }^{(33,34)}$. An alternative method is a longitudinal incision in the smaller vessel to spatulate its end ${ }^{\left({ }^{34}\right)}$ or performing a fish-mouth incision to expand the diameter of the smaller vessel, both in end-to-end and in end-to-side anastomoses ${ }^{(35)}$. Several other surgical solutions have been suggested to overcome more severe discrepancy. The wider vessel can be tapered to provide and end-to-end repair ${ }^{(36)}$. The sleeve anastomosis (or telescoped technique), consisting of end-to-end invaginating the 
smaller into the larger with sutures, might be used, although it is associated to a lower patency rate compared with the conventional interrupted suture technique in the rat femoral artery model ${ }^{(33,36)}$.

Performing an end-to-side anastomosis is another alternative. In experimental studies it was shown that in case of marked discrepancy end-to-side anastomosis have higher patency rate compared to end-to-end anastomosis ${ }^{(34,36,44)}$.

Although these solutions can be used in specific cases, it is known that they can decrease the patency of the anastomosis ${ }^{(33,36,68)}$.

Vessel quality of the recipient vessels is also an important variable during microsurgery. Arteriosclerosis is one of the risk factors for microvascular anastomosis ${ }^{\left({ }^{69}\right)}$. Vessels could also be damaged after radiotherapy and postoperative fibrosis, such as after infection or osteomyelitis. In these cases, selecting virgin recipient vessels can prove to be beneficial for the free flap feeding vessel.

Moreover, local availability may be impaired especially after cancer cancer surgery when surgical dissection of recipient vessels by previous non-microsurgically trained surgeons has been done, damaging recipient vessels.

In addition, flow patterns within the arteriovenous network in the flap itself can lead to postoperative failure. This can be due to a lack inflow, insufficient arteriovenous capillary network and lack of outflow (venous congestion).

Arterial inflow is impaired due to incongruent arteries, insufficient arterial supply as is some perforator flaps, diseased vessels as in arteriosclerosis or after radiotherapy.

An insufficient venous network is seen in case of compression of the low pressure component as seen at the dome of a conventional round shaped expanded flap. This is consistent with our previous experience with round shaped expanded flaps and with the data published by Russell et al. They observed marginal distant venous congestion and marginal distant necrosis in three out of 14 round expanded scapular flaps, not related to the microvascular anastomoses ${ }^{(70)}$. Also if the venous network is arterialised as in the venous flap, the arteriovenous network is insufficient.

Regarding the venous outflow in free flaps problems can arise when the axial venous return is compressed by an expander. Venous outflow is also decreased in small incongruent veins as seen in the lower leg, and the internal mammary vein. Also in perforator flaps (DIEP e.g.) insufficient drainage of the flap may occur due to the fact that only one or a few veins are used to drain an originally much larger vascular network.

In this thesis solutions regarding the above mentioned technical problems are suggested. The first step in solving incongruency of microvascular anastomoses is to look for a new vascular recipient vessels as is described in the example of the TRAM reconstruction (chapter 7). We explored the possibilities of various types of recipient vessels in the upper trunk area, especially for free TRAM or DIEP flap breast reconstructions and two satisfactory alternatives for the thoracodorsal vascular pedicle could be found in the external jugular vein and the cephalic vein. The use of the internal mammary vessels has facilitated breast reconstructions with free flaps ${ }^{(37-43)}$.

If finding more suitable vessels is not possible we have to look for alternative solutions. 
Recipient versus donor vessel size discrepancy creates microsurgical technical problems. The development of various microsurgical techniques solving the problem of vessel incongruency was a challenge. Although Godina in 1976 popularised the end-toside anastomosis ${ }^{(44)}$, for correction of vessel incongruency, this technique was rarely applicable in the head and neck or upper trunk's locations. Incongruent end-to-end anastomoses required inventive microsurgery. It let to the development of the mattress type as described in chapter 3 both for arterial and venous anastomoses ${ }^{(45)}$. However, in more extreme cases, especially in the internal mammary artery or lateral forearm flaps, extreme differences in diameters had to be overcome. The development of the $Y$ anastomosis proved to be a good advent and a good solution for extreme incongruencies in certain rarely found conditions. Upstream or downstream flow trough a $Y$ shaped anastomosis, in arterial or venous ones, is possible and could be used in large microsurgical anastomoses, such as internal jugular vein or cephalic vein, or in small anastomoses, such as the $0.3 \mathrm{~mm}$ testicular veins to deep inferior epigastric vein anastomosis. Although there is now a 25 year experience it is impossible to prove that the $\mathrm{Y}$ anastomosis will overcome the flow discrepancy or the incidence of venous congestion. To prove this a randomised prospective study would be necessary, which is impossible for ethical and practical reasons. However, we observed no increased anastomosing related complications in our series in comparison with current accepted data in the literature ${ }^{(57-67)}$.

Regarding technical problems, a mechanical anastomosing technique was recently developed. With this technique a ring type of mechanical anastomosis was only possible with predetermined diameters of vessels ${ }^{(46-51)}$. A major drawback was a significant decrease in vessel diameter so that in clinical practise only venous anastomoses could be performed with the Unilink/3M-coupling device. Arterial anastomoses did not provide sufficient vessel wall elasticity in order to allow sufficient dilatation and evertion of the vessel wall, required for temporary anchoring the everted vessel walls at the pin of the ring applicator. Recently, Kirsch ${ }^{(52)}$ has developed individual titanium staples in various sizes to perform, "stitch by stitch", staple by staple type of anastomosis and in chapter 4 we show our experience. This is in contrast to the predefined and not diameter adjustable type of anastomoses when using the Unilink/3M anastomotic device. The possibility to individually staple each small segment of an anastomosis, comparable to suture type anastomosis, allows to accurately adjust the everted edges of both vessel walls, improving the accuracy of the anastomosis between small vessels with $0.5 \mathrm{~mm}$ diameters ${ }^{(55)}$. Comparable $0.3 \mathrm{~mm}$ anastomoses were performed in a series of 30 patients where testicular autotransplantations were done when extremely high location of intra abdominal testis could not be treated by standard urological procedures. Only a microvascular repair to the deep inferior epigastric vessels gave a solution for this kind of problem ${ }^{(45)}$.

The problem of venous congestion is handled in an example of the expanded scapular flap in chapter 6 . After conventional expansion not resolvable venous congestion and marginal necrosis occur in about $21 \%$ of flaps ${ }^{(70)}$. A solution is suggested by expanding peripherally and thus avoiding an insufficient venous network at the dome of the round expanded flap and the subsequent lack of axial venous outflow. 


\section{Solving clinical problems}

The ideal reconstruction focussed on optimal functional, and cosmetic outcome in addition to durance and minimal donor site morbidity is still not achieved. In this thesis several examples to improve the outcome of each of these variables is discussed.

The use of implants in reconstructive and hand surgery is widely accepted. In general the types of prosthesis can be divided in two groups. The first consists of functional prosthesis as e.g. in joint replacement. The second group of implants is used to reshape body contours as in case of breast reconstruction after mastectomy. Although research in biomaterials is extensive ${ }^{(70-79)}$, there are still unsolved problems. Joint replacement implants are nowadays large used even if long-term complications, such as dislocation of the implant, infection and fractures, are described in the literature. Especially, total wrist arthoplasties show high long-term failure rate due to fractures, dislocations of the prosthesis and revision for pain relief. The durability and longevity of the prosthesis is limited and progressive X-ray deterioration and silicone synovialitis are the main shortcomings. Schill observed implant fracture in $31 \%$ of the patients, subsidence of the implant and significant reduction of carpal height in $82.5 \%$ of the prosthesis ${ }^{(80)}$. Other series in the literature show similar complication rates ${ }^{(81-85)}$.

In chapter 5 a new treatments for articular surface degenerative diseases is suggested. The temporalis fascia free flap is applied to replace the wrist joint. This is done in patients with severe arthritic disease, such as juvenile rheumatoid arthritis. Since transplantation of articular surfaces with vascularized tissues is not yet available in many instances, the development of a pseudo-articular surface, providing gliding tissues between bony surfaces was developed. In the future refinements of this technique by the combination of tissue engineering of cartilage cells and a vascular carrier can be developed. In this preliminary stage, however, prevention of an ankylosis of joints offers a major step forward in preventing joint stiffness and immobility in young patients leading to extreme disability. The conventional treatment is either arthodesis or the use of wrist implants. In comparison with wrist arthrodesis our technique seems to be superior concerning function. In comparison with implants the long term complications of this technique can be prevented. Also in cases of breast reconstruction with implants, still unsolved problems remain. The last generation, textured prosthesis still induce an individual body response that can let to a capsular contracture classified as Baker III or IV. It is responsible of implant dislocation, pain and anaesthetic results. Moreover, infection and implant rupture can occur requiring implant removal. Clough observed a pathological capsular contracture rate of 11 percent at 2 years after an immediate breast reconstruction and 15 percent at 5 years and an implant removal rate of 7 percent ${ }^{\left({ }^{86}\right)}$. The incidence of capsular contracture is higher if smooth implants are used or if a radiation treatment is required ${ }^{(87-90)}$. Even if no complication occurs in the postoperative period, all breast implants have a limited life and their change has to be planned especially in young patients. In conclusion, also breast implants have no life long guarantee. This is the reason why, in general, autologous breast reconstruction is superior to the use of implants. In chapter 7 refinements and modifications in autologous breast reconstructions are described, avoiding the use of implants. 
The most extreme example in which reconstructive surgery still has to evolve is in case of burns. The aim of reconstructive procedures in burn patients is to achieve functional and cosmetic outcomes, with long-life guarantee and low donor site morbidity. The "care as usual" includes the excision of burn eschar and split skin grafting in the majority of acute burn wounds ${ }^{(53)}$ followed by an adequate pressure therapy. Also keratinocyte cultures are largely used thanks to the extensive research in biomaterials. Although these efforts, in cases of deep burn injuries these conventional therapy are insufficient and a functional impairment is expected if vital tissues, as vessels, bones, tendons and joints, are exposed. It requires the resurfacing with a flap. Moreover, severe functional and aesthetic deformities can secondly occur after conventional therapies, due to scar contraction. In chapter 8 the indications for free flap resurfacing in burn patients are discussed. They play a marginal role among more conservative therapies, such as grafting and skin expansion ${ }^{(54)}$.

Donor site morbidity remains a major drawback in reconstructive surgery. How to overcome this problem is discussed in several chapters in this thesis. In chapter 10 the use of arterialised venous flaps in clinical practise makes it possible to transfer free tissues without using an artery. Although the venous flap reduced donor site morbidity, it is related to venous congestion in the early postoperative period. To investigate this phenomenon we developed an animal model which is described in chapter 11. In chapter 6 a primary closure of the donor area with no tension is achieved after flap expansion.

\section{References}

1. Nylen CO. The otomicroscope and microsurgery 1921 - 1971. Acta Otolaryngol 73: 453, 1972.

2. Jacobson JH, Suarez EL. Microsurgery in anastomosis of small vessels. Surg. Forum 11: 243, 1960.

3. Tamai S, Sarauchin N, Hori Y, Tatsumi Y, Okuda H. Microvascular surgery in Orthopaedics and traumatology. J Bone Joint Surg 54B: 637, 1972.

4. Tamai S. Digital remplantation. Clin Plast Surg 5:195, 1978.

5. Antia NH, Bunch IV. Transfer of an abdominal dermo-fat graft by direct anastomosis of blood veseels. Br J Plast Surg 24: 15, 1971.

6. McLean DH, Buncke HJ Jr. Autotransplant of omentum to a large scalp defect with microsurgical revascularization. Plast Reconstr Surg 49: 268, 1972.

7. Daniel RK, Taylor Gl. Distant transfer of an island flap by microvascular anastomosis. A clinical technique. Plast Reconstr Surg 52: 111, 1973.

8. Daniel RK, Williams HB. The free transfer of skin flaps by microvascular anastomoses. Plast Reconstr Surg 52: 16, 1973.

9. Daniel RK, Cunningham D, Taylor GI. The deltopectoral flap: an anatomical and hemodynamic approach. Plast Reconstr Surg 55: 275, 1975.

10. Daniel RK, Terzis J, Schwarz G. Neurovascular free flaps. Plast Reconstr Surg 56: 13, 1975. 
11. McCraw J, Furlow L. The dorsalis pedis arterialized flap. Plast Reconstr Surg 55: 177, 1975.

12. Ohmori K, Harii K. Free groin flaps: their vascular basis. Br J Plast Surg 28: 238, 1975.

13. Taylor GI, Daniel RK. The anatomy of several free flap donor sites. Plast Reconstr Surg 56: 243 , 1975.

14. Terzis J. Functional aspects of reinnervation of free skin grafts: a clinical extension of microvascular techniques. Plast Reconstr Surg 58: 142, 1976.

15. Harii K, Ohmori K, Sekiguchi J. The free musculocutaneous flap. Plast Reconstr Surg 57: 294, 1976.

16. Schenck R. free muscle and composite skin transplantation by microneurovascular anastomoses. Orthop Clin North Am 8: 367, 1977.

17. Harii K, Ohmori K, Torii S. Free gracilis muscle transplantation with microneurovascular anastomoses for the treatment of facial paralysis: a preliminary report. Plast Reconstr Surg 57: 133, 1976.

18. Bonney G, Birch R, Jamieson AM, Eames RA. Experiences with vascularized nerve graft. In: Terzis JK, ed. Clin Plast Surg. Symposium on peripheral nerve microsurgery. Philadelphia: WB Sanders, 137, 1984.

19. Cormack GC, Lamberty BGH. The arterial anatomy of skin flaps. Edinburgh, London, Melburne, New York: Churchill Livingstone, 1986.

20. Ikuta Y. Autotransplant of omentum to cover large denudation of the scalp. Case Report. Plast Reconstr Surg 55: 490, 1975.

21. Ikuta Y, Kubo T, Tsuge K. Free muscle transplantation by microsurgical technique to treat severe Volkmann's contracture. Plast Reconstr Surg 58: 407, 1976.

22. Gilbert A. Vascularized sural nerve graft. Clin Plast Surg 11: 73, 1984.

23. Mathes SJ, Nahai F. Clinical applications for muscle and musculocutaneous flaps. St Louis, Toronto, London: The CV Mosby Company, 1982.

24. McCraw JB, Arnold PG. Atlas of muscle and musculocutaneous flaps. Norfolk, Virginia, USA: Hampton Press Pub Co, 1986.

25. Rose EH, Kowalski T. Restoration of sensibility to anaesthetic scarred digits with free vascularized nerve grafts from the dorsum of the foot. J Hand Surg 10A: 514, 1985.

26. Terzis JK. Microreconstruction of nerve injuries. Philadelphia, USA: WB Saunders CO, 1987.

27. Khouri RK, Upton J, Shaw WW. Principle of flap prefabrication. Clin Plast Surg 19: 763, 1992.

28. Baudet J, Rivet D, Martin D, Boileau R. Prefabricated free flap transfers. Presented at the 3rd Annual Meeting of the American Society for Reconstructive Microsurgery. San Antonio, Texas: Sept. 12- 13, 1987.

29. Hirase J, Valauri FA, Buncke HJ, Newlin LY. Customized prefabricated neovascularized free flaps. Microsurgery 8: 218, 1987.

30. Hirase J, Valauri FA, Buncke HJ. Prefabricate sensate myocutaneous and osteomyocutaneous free flaps. An experimental model. Preliminary report. Plast Reconstr Surg 82: 244, 1988.

31. Khouri RK, Upton J, Shaw WW. Prefabrication of composite free flaps through staged microvascular transfer: an experimental and clinical study. Plast Reconstr Surg 87: 108, 1991.

32. Hyakusoku H, Okubo M, Umeda T, Fumiiri M. A prefabricated hair-bearing island flap for lip reconstruction. Br J Plast Surg 40: 37, 1987.

33. Pho RWH. General principles of microsurgery. In Pho RWH: Microsurgical technique in 
orthopaedics. Butterworths \& Co. Ltd, 1988.

34. Hidalgo DA, Shaw WW, Romita MC, Godfrey NV. Anastomotic technique and vein grafts. In Shaw WW, Hidalgo DA: Microsurgery in trauma. New York: Futura Publishing Company, Inc, 1987.

35. Harashina T, Irigaray A. Expansion of smaller vessel diameter by fish-mouth incision in microvascular anastomosis with marked size discrepancy. Plast Reconstr Surg 65(4): 502, 1980.

36. O'Brien McC B, Morrison WA. End-to-end anastomosis. In O'Brien McC B, Morrison WA: Reconstructive microsurgery. Churchill Livingstone, 1987.

37. Clark CP, Rohrich RJ, Copit S, Pittman CE, Robinson J. An anatomic study of the internal mammary veins: clinical implications for free-tissue-transfer breast reconstruction. Plast Reconstr Surg 99: 400, 1997.

38. Feng LJ. Recipient vessels in free-flap breast reconstruction: a study of the internal mammary and thoracodorsal vessels. Plast Reconstr Surg 99: 405, 1997.

39. Ninkovic M, Anderl H, Hefel L, Schwabegger A, Wechselberger G. Internal mammary vessels: a reliable recipient system for free flaps in breast reconstruction. Br J Plast Surg 48: 533, 1995.

40. Arnez ZM, Valdatta L, Tyler MP, Planinsek F. Anatomy of the internal mammary veins and their use in free TRAM flap breast reconstruction. Br J Plast Surg 48: 540, 1995.

41. Hefel L, Schwabegger A, Ninkovic M, Wechselberger G, Moriggl B, Waldenberger P, Anderl $H$. Internal mammary vessels: anatomical and clinical considerations. $\mathrm{Br} \mathrm{J}$ Plast Surg 48: 527, 1995.

42. Dupin $\mathrm{CL}$, Allen RJ, Glass CA, Bunch R. The internal mammary artery and vein as a recipient site for free-flap breast reconstruction: a report of 110 consecutive cases. Plast Reconstr Surg 98: 685, 1996.

43. Blondeel Ph, Boeckx W. Refinements in free flap breast reconstruction: the free bilateral deep inferior epigastric perforator flap anastomosed the internal mammary artery. Br J Plast Surg 47: 495, 1994.

44. Godina M. Preferential use of end-to-side arterial anastomoses in free flap transfers. Plast Reconstr Surg 64: 673, 1979.

45. Boeckx W, Vereecken R, Depuydt K. Microsurgery for intra-abdominal testicular retention. Eur J Obstet Gynaecol 81: 191, 1998.

46. Joji S, Muneshige H, Ikuta Y. Experimental study of mechanical microvascular anastomosis with new biodegradable ring device. Br j Plast Surg 52: 559, 1999.

47. Nakayama K, Tamiya T, Yamamoto K, Akimoto S. A simple new apparatus for small vessel anastomosis. Surgery,52: 918, 1962.

48. Berggren A, Ostrup LT, Lidman D. Mechanical anastomosis of small arteries and veins with the Unilink apparatus: a histologic and scanning electron microscopic study. Plast Reconstr Surg 80: 274, 1987.

49. Berggren A, Ostrup LT, Ragnarsson R. Clinical experience with the Unilink/3M Precise microvascular anastomotic device. Scand J Plast Reconstr Surg 27: 35, 1993.

50. Kimura H. Mechanical anastomosis using an absorbable ring. Hiroshima Med J 3: 65,1995.

51. Ragnarsson R, Berggren A, Ostrup LT, Gilbert RW. Arterial end-to-side anastomosis with the Unilink system. Ann Plast Surg 22: 405, 1989. 
52. Kirsch WM, Zhu YM, Hardesty RA, Chapolini R. A new method for microvascular anastomosis: report of experimental and clinical research. Am Surg 58: 722, 1992.

53. Platt AJ, McKiernan MV, McLean NR. Free tissue transfer in the management of burns. Burns 22(6):474-476, 1996.

54. Adant JP, Bluth F, Jacquemin D. Reconstruction of neck burns. A long term comparative study between skin grafts, skin expansion and free flaps. Acta Chir Belg; 98(1):5-9, 1998.

55. Boeckx W, Darius O, Van den Hof B, Vandevoort M. Scanning electron microscopic analysis of the stapled microvascular anastomosis in the rabbit. Ann Thorac Surg 63: 128, 1997.

56. Boeckx WD, De Coninck A, Vanderlinden E. Ten free flap transfers: use of intra-arterial dye injection to outline a flap exactly. Plast Reconstr Surg 57: 716, 1976.

57. Glicksman A, Ferder M, Casale P, Posner J, Kim R, Strauch B. 1457 years of microsurgical experience. Plast Reconstr Surg 100(2): 355, 1997.

58. Hallock GG. Both superficial and deep extremities veins can be used successfully as the recipient site for free flaps. Ann Plast Surg 44(6): 633, 2000.

59. Serletti JM, Higgins JP, Moran S, Orlando GS. Factors affecting outcome in free-tissue transfer in the elderly. Plast Reconstr Surg 106: 66, 2000.

60. Rasheed T, Lewis HG, Gordon DJ. A review of 100 consecutive free tissue transfers. Ulster Med J 69: 14, 2000.

61. Chaivanichsiri P. Influence of recipients vessels on free tissue transplantation of the extremities. Plast Reconstr Surg 104: 970, 1999.

62. Disa JJ, Cordeiro PG, Hidalgo DA. Efficacy of conventional monitoring techniques in free tissue transfer: an 11-yera experience in 750 consecutive cases. Plast Reconstr Surg 104: 97, 1999.

63. Yuen JC, Feng Z. Microsurgical flaps for limb salvage in children. J Ark Med Soc 95: 387, 1999.

64. O’Brien CJ, Lee KK, Stern HS, Traynor SJ, Bron L, Tew PJ, Haghighi KS. Evaluation of 250 freeflap reconstructions after resection of tumours of the head and neck. Aust N Z J Surg 68: 698, 1998.

65. Amin AA, Baldwin BJ, Gurlek A, Miller MJ, Kroll SS, Reece GP, Evans GR, Robb GR, Schusterman MA. Second free flaps in head and neck reconstruction. J Reconstr Microsurg 14: $365,1998$.

66. Kaplan I, Ada S, Ozerkan F, Bora A, Ademoglu Y. Reconstruction of soft tissue and bone defects in lower extremity with free flaps. Microsurgery 18: 176, 1998.

67. Aitasalo K, Relander M, Virolainen E. The success rate of free flaps after preoperative irradiation in head and neck reconstruction. Ann Chir Gynaecol 86: 311, 1997.

68. Hamilton RB, O'Brien MB. An experimental study of microvascular patency using a continuous suture technique. Br J Plast Surg 32: 153, 1979.

69. Kanoh N, Dai CF, Ikeda N, Mimura O. Parameters for the preoperative evaluation of arteriosclerosis for free flap transfers in head and neck surgery. Clin Otolaryngol 25: 135, 2000.

70. Russell RC, Khouri RK, Upton J, Jones TR, Bush K, Lantieri LA. The expanded scapular flap. Plast Reconstr Surg 96: 884, 1995.

71. Aswood- Smith MJ. Preservation of mouse bone marrow at $-79^{\circ} \mathrm{C}$ with dimethylsulphonide. Nature 190: 1204, 1961.

72. Blondet R et al. Skin preservation by programmed freezing. Br J Plast Surg 35: 530, 1982.

73. Bravo D et al. Effect of storage and preservation methods on viability in transplantable human 
skin allografts. Burns 26: 367, 2000.

74. Bugbee WD, Convery FR. Ostheochondral allograft transplantation. Clin Sport Med 18(1): 67, 1999.

75. Dingman RO, Grabb WC. Costal cartilage homograft preserved by irradiation. Plast Reconstr Surg 28: 562, 1961.

76. Farrant $\mathrm{J}$. Mechanism of cell damage during freezing and thawing and its prevention. Nature 205: 1284, 1965.

77. Freedlander E et al. Skin banking in the UK: the need for proper organization. Burns 24: 19, 1998.

78. Howard W. Bone banking. Aut Nurs J 6: 1, 1999.

79. Wormack GN et al. Supplying commercial biomedical companies from a human tissue bank in an NHS hospital : a view from personal experience. J Clin Pathol 52: 254, 1999.

80. Schill S, Thabe H, Mohr W. Long-term outcome of Swanson prosthesis management of the rheumatic wrist joint. Handchir Mikrochir Plast Chir 33: 198, 2001.

81. Allieu Y. Development of surgical indications in the treatment of rheumatoid wrist. Report on experience based on 603 surgical cases. Ann Chir Main Memb Super 16. 179, 1997.

82. Stanley JK, Tolat AR. Long-term results of Swanson silastic arthroplasty in the rheumatoid wrist. J Hand Surg (Br) 18: 381, 1993.

83. Lundkvist L, Barfred T. Total wrist arthroplasty. Experience with Swanson flexible silicone implants, 1982-1988. Scand J Plast Surg Hand Surg 26: 97, 1992.

84. Jolly SL, Ferlic DC, Clayton ML, Dennis DA, Stringer EA: Swanson silicone arthroplasty of the wrist in rheumatoid arthritis: a long-term follow-up. J Hand Surg (Am) 17: 142, 1992.

85. Divelbiss BJ, Sollerman C, Adams BD. Early results of the Universal total wrist arthroplasty in rheumatoid arthritis. J Hand Surg (Am) 27: 195, 2002.

86. Clough KB, O’Donoghue Jm, Fitoussi AD, Nos C, Falcou MC. Prospective evaluation of late cosmetic results following breast reconstruction: I. Implant reconstruction. Plast Reconstr Surg 107: 1702, 2001.

87. Fagrell D, Berggren A, Tarpila E. Capsular contracture around saline-filled fine textured and smooth mammary implants: a prospective 7.5 year follow up. Plast Reconstr Surg 108: 2108, 2001.

88. Duskova M, Sosna B, Kletensky J, Vrtiskova J. Capsular contracture in augmentation mammaplasty. Acta Chir Plast 42: 79, 2000.

89. Collis N, Coleman D, Foo IT, Sharpe DT. Ten-year review of a prospective randomised controlled trial of textured versus smooth subglandular silicone gel breast implants. Plast Reconstr Surg 106: 786, 2000.

90. Contant CM, Van Geel AN, Van der Holt B, Griep C, Tjong Joe Wai R, Wiggers T. Morbidity of immediate breast reconstruction (IBR) after mastectomy by a subpectorally placed silicone prosthesis: the adverse effect of radiotherapy. Eur J Surg Oncol 26: 344, 2000. 
Chapter 2 - Increasing the flow output by Y-shaped microvascular anastomosis

W. Boeckx, F. De Lorenzi, R. van der Hulst

J Reconstr Microsurg 2002 July; 18(5): 381-6 


\section{Abstract}

In this paper we present a new type of microvascular anastomosis to overcome two major inconveniences in microsurgery: "flow discrepancy" and vessel size discrepancy between the donor and the recipient vessels.

An $Y$ shaped anastomosis is an end-to-end anastomosis between three vessels: two small ones on one side and a larger vessel on the opposite site. Both arterial and venous anastomoses can be performed in this way. The blood flow can go across the anastomosis in both directions. Hemodynamically, it increases the blood output through the anastomosed vessels.

The surgical technique and main clinical applications of the $Y$ anastomosis are described in details. Indications and advantages are discussed. 


\subsection{Introduction}

During the last 30 years microvascular techniques have considerably improved and free flap reconstructions have become a primary tool of the reconstructive surgeon. Donor tissues with a constant pedicle have been defined and suturing techniques have been refined. Technical and pharmacological advances have decreased the incidence of thrombotic occlusion of the anastomosed vessels. In addition, postoperative management and monitoring of free transfers have been improved. This resulted in a very high microvascular transfer success rate ${ }^{(1-4)}$. However, although the risk of free flap complications has greatly decreased in the recent years, complications still occur and may even cause the failure of the free flap.

It is well known that at least a feeding vessel and a draining one have to be anastomosed to the recipient side in free flap surgery.

In most clinical cases only one artery and only one vein are anastomosed at the recipient area achieving good vascularization and drainage of the flap.

In some cases there is a discrepancy in size and number of vessels between the pedicle of the flap and the recipient side. Two small arteries or veins can be present at the recipient side and a big one in the pedicle, or vice versa. Most of the time it is unknown which one of the smaller vessels has to be preferred to make the anastomosis. If one vessel is used for anastomosis, the less damaged or the vessel with expected highest flow is used. However, it is rarely known which vessel is less damaged or has a high flow. The most simple way to overcome size discrepancy is a more extensive dissection of the pedicle or the recipient vessels. It is not always possible to overcome the discrepancy in size and number of vessels by performing only two microvascular anastomoses: one vein and one artery. The flow through these anastomosed vessels can be not sufficient. When venous outflow is inadequate, venous congestion of the flap can occur. It is due to a decreased venous drainage. On the other hand, if there is an arterial insufficiency the flap can not be vascularized satisfactorily and is not "well bleeding" after the microvascular anastomoses have been performed, even if the anastomoses are patent (intraoperative "empty-and-refill" test).

Both of these complications/inconveniences occur because the blood output through the draining and feeding anastomosed vessels is not enough and not related to the demand of the flap.

In this paper we present a new type of microvascular anastomosis to overcome the problem of "flow discrepancy" when only two microvascular anastomoses are performed to transfer a free flap. We describe surgical details and clinical applications and discuss indications and advantages.

\subsection{Operative technique}

The $Y$ shaped anastomosis is an end-to-end anastomosis between three vessels: two small vessels on one side and a large one on the other side. It is performed according 

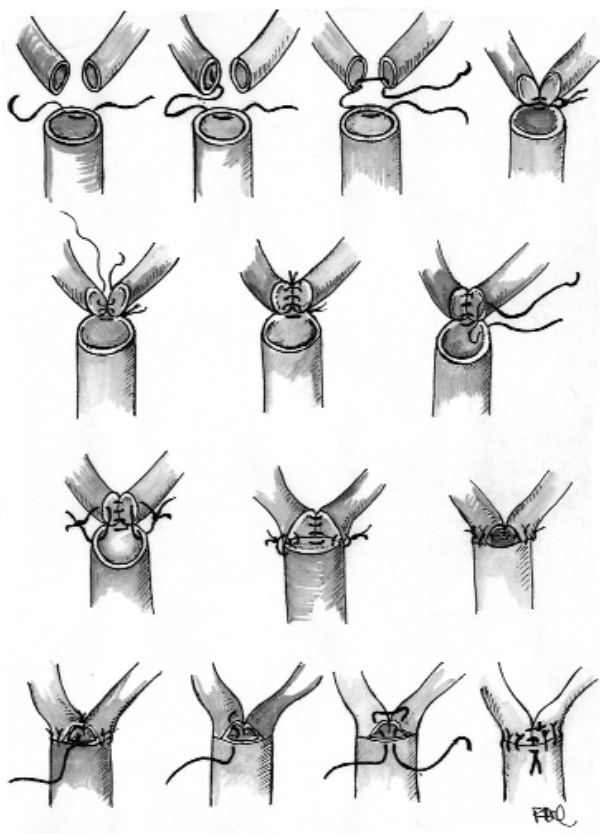

Fig. 1a Schematic drawing of $Y$ shaped microvascular anastomosis. to "posterior wall first" technique of anastomosing ${ }^{(5-6)}$.

The $Y$ anastomosis is begun by placing the first suture through the middle of the posterior wall of the larger size vessel and the inferior ends of the posterior wall of the two smaller vessels (fig. 1a).

The second and third sutures are placed between the posterior (and medial) borders of the smaller vessels, from outside-in in one vessel and inside-out in the other. The sutures must be sufficiently close to the first suture to make the anastomosis waterproof. The fourth and fifth stitches are placed on each side of the first suture, between the lateral walls of the smaller vessels and the larger one. Also these stitches have to be sufficiently close to the first suture to make a watertight anastomosis. The sixth and seventh sutures are placed adjacent to the fourth and fifth sutures advancing anteriorly in both directions (fig. 1b) (fig. 1c).
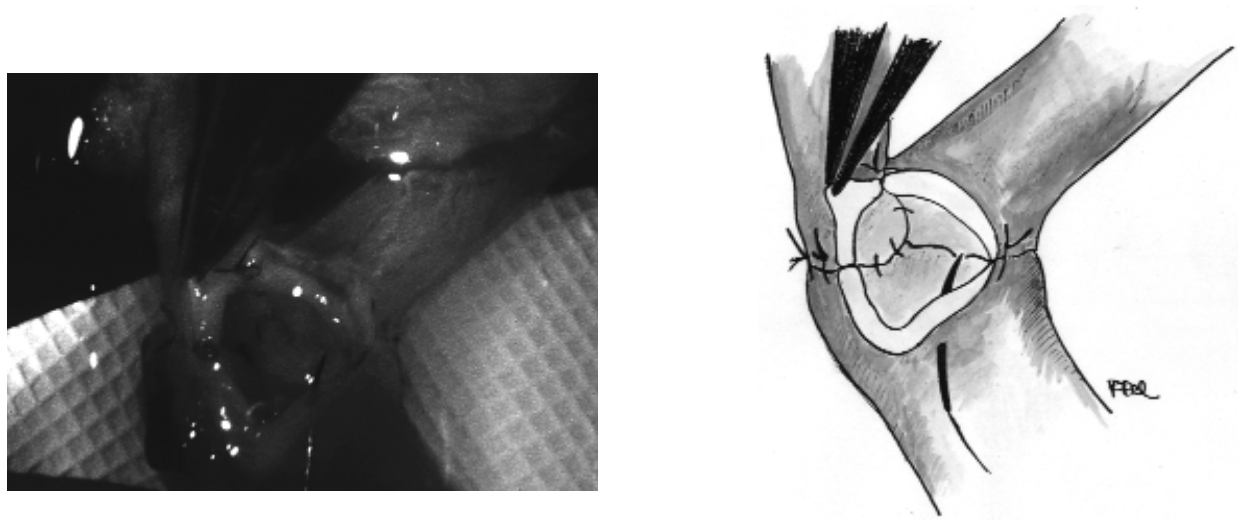

Fig. $1 \mathrm{~b}$ Stitches placed on the anterior wall, between one smaller vessel and the larger one. 

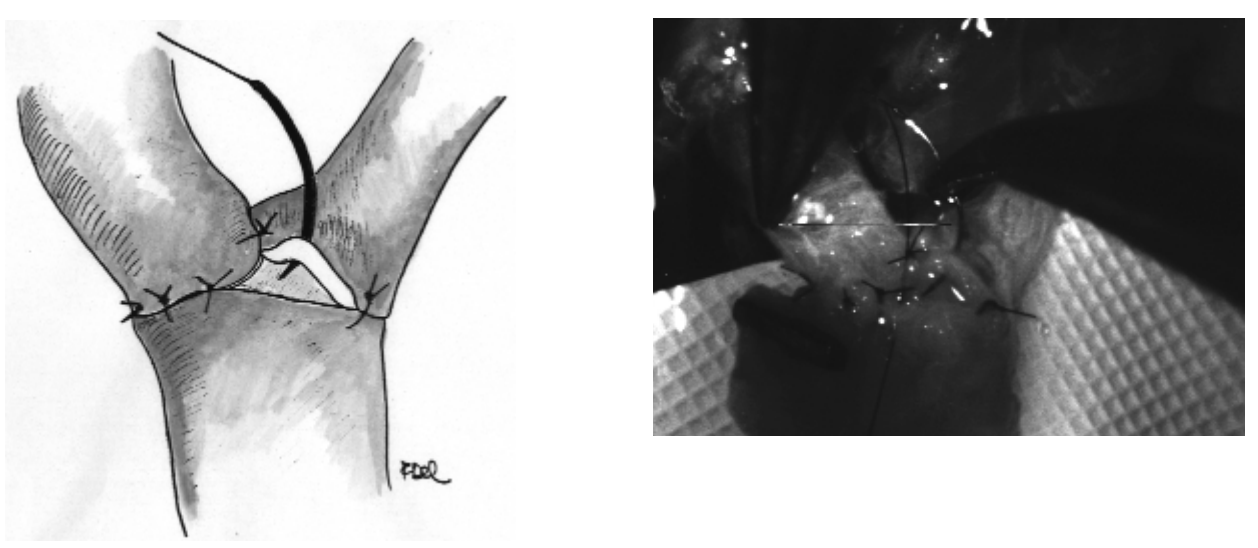

Fig. 1c Further stitches between one smaller vessel and the larger one. The suture advances anteriorly.

The last stitch is a mattress suture placed on the anterior wall, at the cross point between the two small vessels and the larger one. It is placed in the large vessel from outside-in and inside-out in both the smaller vessels. The anastomosis is now complete (fig. 1d). The same technique is used in arterial and venous anastomoses.
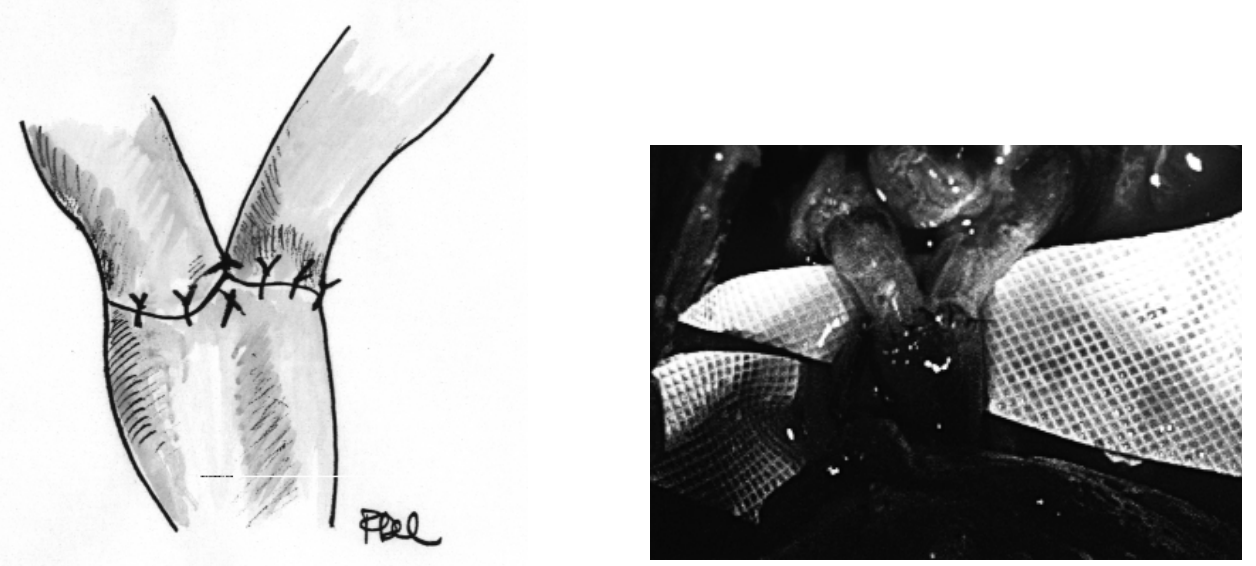

Fig. 1d Complete $Y$ shaped anastomosis. 


\subsection{Materials and methods}

Clinical applications of $Y$ anastomosis are summarised in Table 1 and 2, with the anastomotic technique mostly used for venous anastomoses rather than arterial ones.

\begin{tabular}{llll} 
Type of flap & Successful Y & Failure Y & Total Y \\
Chinese flap (2 comitant veins pedicle) & 3 & - & 3 \\
Gracilis flap (2 veins pedicle) & 7 & 1 & 8 \\
Latissimus dorsi (2 veins pedicle or 2 recipient vv) & 1 & - & 1 \\
Rectus abdominis flap (2 veins pedicle) & 2 & - & 2 \\
S-GAP flap (2 veins pedicle) & 1 & - & 1 \\
TRAM flap (2 recipient veins- internal mammary v) & 14 & 1 & 15 \\
Testis (2 veins pedicle) & 29 & 1 & 30 \\
\hline TOTAL & 57 (95\%) & 3 & 60
\end{tabular}

Tab. 1 Clinical applications of venous $Y$ anastomosis

$\begin{array}{llll}\text { Type of flap } & \text { Successful } Y & \text { Failure } Y & \text { Total Y } \\ \text { S-GAP flap (2 arteries pedicle) } & 1 & - & 1\end{array}$

Table 2. Clinical application of arterial Y anastomosis.

\subsection{Discussion}

We first described $Y$ shaped microvascular anastomosis between two smaller donor veins and one larger recipient vein in $1976{ }^{(5)}$. Since then, few technical refinements have been performed and several new clinical applications have been developed.

In our early experience with this type of anastomosis, the medial borders of the smaller vessels were sutured first forming a common wall. Secondly the anterior wall was sutured prior to suturing the posterior wall. Today we perform this anastomosis according to "posterior wall first" technique (5-6). The main idea and peculiarity of this anastomosis are not changed, but in our opinion posterior wall first technique is more save because the vessel lumen is continuously visualised during the suturing.

The $\mathrm{Y}$ anastomosis was performed in more than 40 arterial and venous anastomoses in different clinical situations (Tab. 1-2).

With regard to venous anastomoses, we performed this technique both in lower leg and head and neck region. In lower leg reconstructions, two different anatomic patterns were present: one large recipient vein and two smaller veins in the pedicle of the flap or one large vein in the pedicle and two small veins as recipient vessels. In one case, for instance, a latissimus dorsi muscle flap was planned to repair a large defect of the distal leg. No superficial veins were available for the anastomosis due to extensive fibrosis of 
the surrounding tissues. Thus, we performed a $Y$ anastomosis between the thoracodorsal vein and the two comitant veins of posterior tibial artery.

In another patient we performed a gracilis muscle flap for osteomyelitis of the distal third of the tibia. The pedicle contained two small veins which were anastomosed to a superficial vein with a large diameter. In head and neck reconstructions, the most frequent anatomic pattern consisted of a large recipient vein and two smaller donor vessels. We performed facial palsy reanimation with a gracilis muscle flap by using the two veins of the pedicle which were anastomosed to the facial vein in a $Y$ shaped fashion. The Chinese flap, the scapular flap and the lateral arm flap have been used to reconstruct head and neck defects anastomosing the two small veins of the pedicles to the external jugular vein by using $Y$ anastomosis.

With regard to arterial anastomoses, a superior gluteal artery perforator flap was planned for breast reconstruction. The internal mammary vessels were chosen as recipient site at the 4th intercostal space. A Y anastomosis was performed between internal mammary artery and medial and lateral superior gluteal perforators. Two venous end-to-end anastomoses were performed between the two internal mammary veins and the two flap veins $^{(7)}$.

In testicular auto-transplantation two 0,3 $\mathrm{mm}$ diameter testicular veins are anastomosed to the deep inferior epigastric vein ${ }^{(8)}$.

In our hands $\mathrm{Y}$ shaped anastomosis showed comparable reliability and patency rate as conventional techniques. Hemodynamically, blood flow can go across the $Y$ anastomosis in both directions: from the large vessel to the smaller ones and vice versa. Various numerical models and experimental investigations of blood flow trough a $Y$ shaped bifurcation have been developed in the literature, simulating in vivo situations, including both arterial ${ }^{(9)}$ and venular bifurcations ${ }^{(10)}$. In microvessels, mechanical interactions between red cells and tube walls generally result in the formation of a plasma layer or a region of reduced hematocrit adjacent to the wall, and increased concentration of red cells near the center of the tube. At diverging branch of the microvasculature, the blood flow in a parent vessel is divided as it enters two daughter vessels. Blood is a two-phase fluid (red cells and plasma) and these components may be distributed non-proportionally between the daughter vessels, one receiving a higher hematocrit than that of the parent vessel, and the other receiving a lower hematocrit ${ }^{(11)}$. Vice versa, when the two streams of blood with different hematocrits converge, the streams tend to retain original hematocrit without significant mixing. An interface is formed between the continuos phases of blood from the two different branches. The diffusion of red cells across this interface is very slow. Velocity profiles in the stratified flow are generally asymmetric and blunted, with the less viscous fluid having the highest radial velocity gradients ${ }^{(10)}$. Moreover, several clinical applications of $Y$ shaped vascular beds or grafts are described in the literature ${ }^{(12,13,14)}$.

After a 25 years experience with this type of anastomosis, we would like to emphasise and discuss the main indications and advantages of $Y$ microvascular anastomosis.

The most important indications are essentially two: "flow discrepancy" and vessel size discrepancy. 
Nowadays it is well known that the blood flow through anastomosed vessels is equally important as patency ${ }^{(15,16)}$. It is inversely proportional to the total resistance provided by the microcirculatory beds downstream. Because different tissues possess different vascular resistances, some flaps may display more favourable haemodynamics than others. Thus, especially when a flap with high resistance (for example fascial and fasciocutaneous flaps harvested from the extremities) has to be anastomosed at the recipient site, it is important to preserve a sufficient inflow. On the contrary, a sufficient outflow is necessary when a large flap with high blood input is planned to prevent venous congestion.

Venous congestion can occur in two different situations: when only one of the two small veins of the flap pedicle is anastomosed to the recipient vein or when the draining vein of the flap is anastomosed to a lower flow recipient vein (one of the two small veins present at the recipient site). In both cases the output draining the flap is insufficient. $Y$ shaped anastomosis overcomes this inconvenience increasing the blood outflow through the anastomosed vessels. In fact, by performing only one microvascular anastomosis, it is possible to preserve the individual output of both the smaller vessels. Venous congestion and stasis predispose to intravascular thrombosis. Moreover, venous congestion is also the first sign of venous thrombosis. Thus, performing $Y$ anastomosis and decreasing the incidence of venous congestion, we can avoid secondary surgical revisions of the anastomosed vessels required when venous congestion occurs.

A comparable pathophysiological mechanism occurs on the arterial side. The blood input in the flap can be insufficient compared to the demand when only one of the two feeding arteries has been anastomosed to the recipient vessel. The flap doesn't show a normal capillary filling and a surgical revision of the anastomoses might be required.

When flow volume discrepancy is not present, vessel size discrepancy still represents the second main indication for performing $Y$ shaped anastomoses. If vessels with dissimilar diameters are not satisfactorily anastomosed, the risk of free flap failure is increased. Different surgical techniques have been developed to overcome this problem. When the discrepancy in size is not significant, the smaller vessel can be expanded mechanically with dilator forceps or the stump of the smaller vessel can be cut obliquely to increase the circumference ${ }^{(17,18)}$. An alternative method is cutting longitudinal the smaller vessel to spatulate its end ${ }^{(18)}$. Also, the sleeve technique (or telescoped technique), consisting of invaginating sutures might be used. This technique showed a lower patency rate compared with the conventional interrupted suture technique in the rat femoral artery model ${ }^{(17,19)}$. A fish-mouth incision has been described to expand the diameter of the smaller vessel in end-to-end and end-to-side anastomoses ${ }^{(20)}$ and perioperative dilation using a percutaneous transluminal angioplasty catheter has been performed in animals ${ }^{(21)}$. Performing an end to side anastomosis is another alternative in to overcome vessel discrepancy. In experimental studies it was shown that in case of marked discrepancy end-to-side anastomosis have higher patency rates compared to end-to-end anastomosis ${ }^{(18,19,22)}$.

No one method has become the overwhelming favourite and nowadays the choice of the microvascular anastomotic technique is still an item of debate. 
We propose the following protocol: if the recipient vessel is not interrupted by previous surgery, our first choice is usually an end-to-side anastomosis to preserve the vessel continuity. If the recipient vessel has already been cut, the first choice is an end-to-end anastomosis. In the ideal condition, there is no size discrepancy. With minimal discrepancy the vessels are adjusted stitch by stitch. When the size discrepancy is less than 1.5-2:1 we perform mattress anastomosis ${ }^{(8)}$. Using this type of anastomosis, the larger diameter is decreased compared to the smaller one.

When a vessel discrepancy exists more than 2-3:1 ratio, we plan a $Y$ shaped anastomosis. Another solution is to perform a so called "blind" end-to-side anastomosis. In this case the larger vessel is closed at the end and an end to side anastomosis is performed proximally to this blind end. Haemodynamically the interrupted blood flow at the blind end of the larger vessel increases the risk of intravascular thrombosis, developing turbulence and stasis.

\subsection{Conclusion}

In conclusion, there are different factors influencing the choice of microvascular anastomosis: the anatomy of the recipient area, the anatomy of the flap pedicle and the flow volume of the flap. No microvascular technique can be used in all clinical situations, but the surgeon can choose the more suitable method for every different anatomic and functional condition. In our opinion $Y$ shaped anastomosis is a reliable technique to add to the armamentarium of the microsurgeon. It is a new instrument in our hands to make microsurgery more versatile.

\subsection{References}

1. Serletti JM, Higgins JP, Moran S, Orlando GS. Factors affecting outcome in free-tissue transfer in the elderly. Plast Reconstr Surg 106(1): 66, 2000.

2. Yuen JC, Feng Z. Microsurgical flaps for limb salvage in children. J Ark Med Soc 95(9); 387, 1999.

3. Hidalgo DA, Disa JJ, Cordeiro PG, HU QY. A review of 716 free flaps for oncologic surgical defects: refinement in donor-site selection and technique. Plast Reconstr Surg 102(3): 722, 1998.

4. Glicksman A, Ferder M, Casale P, Posner J, Kim R, Strauch B. !457 years of microsurgical experience. Plast Reconstr Surg 100(1): 355, 1997.

5. Boeckx W. Clinical micro-surgery. In Marquet R, Hess F, Kort W, Boeckx W: Micro-surgery. Experimental techniques in the rat and clinical applications. Ghent, Belgium: European Press, 1976.

6. Harris GD, Finseth F, Buncke HJ. Posterior-wall-first microvascular anastomotic technique. $\mathrm{Br}$ J Plast Surg 34: 47, 1981.

7. Banic A, Boeckx WD, Greulich M, Guelinckx P, Marchi A, Rigotti G, Tschopp H. Late results of 
breast reconstruction with free TRAM flaps: a prospective multicentre study. Plast Reconstr Surg 95: 1203, 1995.

8. Boeckx W, Vereecken R, Depuydt K. Microsurgery for intra-abdominal testicular retention. Eur J Obstet Gynaecol 81:191,1998.

9. Feuerstein IA, El Masry OA, Round GF. Arterial bifurcation flows - effects of flow rate and area ratio. Can J Physiol Pharmacol 54(6): 795, 1976.

10. Das B, Enden G, Popel AS. Stratified multiphase model for blood flow in a venular bifurcation. Ann Biomed eng 25: 135, 1997.

11. Pries AR, Secomb TW, Gaehtgens P. Biophysical aspects of blood flow in the microvasculature. Cardiovascular Research 32: 654, 1996.

12. Rajaii-Khorasani A: Bifurcated anastomosis. Ann Thorac Surg 63: 1189, 1997.

13. Yilmaz AT, Ozal E, Gunay C, Arslan M, Tatar H. Extended use of radial artery with Y-graft technique for complete arterial revascularization. Ann Thorac Surg 72: 636, 2001-12-14.

14. Parodi JC, Ferreira M. Relocation of the iliac artery bifurcation to facilitate endoluminal treatment of abdominal aortic aneurysms. J Endovasc Surg 6:342, 1999.

15. Sasmor MT, Reus WF, Straker DJ, Colen LB. Vascular resistance considerations in free-tissue transfer. J Reconstr Microsurg 8(3): 195, 1992.

16. Samaha FJ, Oliva A, Buncke GM, Bunke HJ, Siko PP. A clinical study of end-to-side techniques for microvascular anastomosis. Plast Reconstr Surg 99(4): 1109, 1997.

17. Pho RWH. General principles of microsurgery. In Pho RWH: Microsurgical technique in orthopaedics. Butterworths \& Co. Ltd, 1988.

18. Hidalgo DA, Shaw WW, Romita MC, Godfrey NV. Anastomotic technique and vein grafts. In Shaw WW, Hidalgo DA: Microsurgery in trauma. New York: Futura Publishing Company, Inc, 1987.

19. O’Brien McC B, Morrison WA. End-to-end anastomosis. In O'Brien McC B, Morrison WA: Reconstructive microsurgery. Churchill Livingstone, 1987.

20. Harashina T, Irigaray A. Expansion of smaller vessel diameter by fish-mouth incision in microvascular anastomosis with marked size discrepancy. Plast Reconstr Surg 65(4): 502, 1980.

21. Yuksel E, Safak T, Ozcan G, Kecik A, Shenaq SM. Perioperative dilation for vessel-size discrepancy using a percutaneous transluminal angioplasty catheter. J Reconstr Microsurg 15(1): 31, 1999.

22. Godina M. Preferential use of end-to-side arterial anastomoses in free flap transfers. Plast Reconstr Surg 64(5): 673, 1979. 


\section{Chapter 3 - Interrupted micro-mattress sutures solve} vessel size discrepancy

F. De Lorenzi, R. van der Hulst, W. Boeckx

(Accepted for publication in Journal of Reconstructive Microsurgery) 


\section{Abstract}

Although technical refinements have improved microvascular techniques, the problem of vessel size discrepancy between donor and receptor vessels is still unsolved and can decrease the success rate of free tissue transfer. In fact, if vessels with incongruent diameters are not adequately anastomosed, the risk of free flap failure is increased.

In this paper we present a new type of microvascular anastomosis to overcome the problem of vessel size discrepancy. Interrupted mattress sutures are placed in end-toend anastomosis narrowing the wider diameter and compensating for the diameter incongruency.

The surgical technique and main clinical applications of the interrupted micro-mattress sutures are described in detail. Indications and advantages are discussed. 


\subsection{Introduction}

During the last decades free flap transfers have become increasingly popular and are widely applied in reconstructive surgery. Microvascular techniques have considerably refined and new free flaps (characterised by different diameter and length of the pedicle) have been described, offering several "choices" according to the anatomic characteristics of the recipient site. However, many times a vessel size discrepancy between the donor and the recipient vessels is present. This inconvenience still represents a technical problem for the microsurgeon, because if vessels with dissimilar diameters are not adequately anastomosed, the risk of free flap failure is increased.

The most simple way to overcome vessel size discrepancy is a more extensive dissection of the pedicle or the recipient vessels. However, this is not always possible. In addition, when the discrepancy in size is not significant, the smaller vessel can be easily expanded mechanically with dilator forceps or the stump of the smaller vessel can be cut obliquely to increase the circumference ${ }^{(1,2)}$. An alternative method is a longitudinal incision in the smaller vessel to spatulate its end ${ }^{(2)}$ or performing a fish-mouth incision to expand the diameter of the smaller vessel, both in end-to-end and in end-to-side anastomoses ${ }^{(3)}$.

Several other surgical solutions have been suggested to overcome more severe discrepancy. The wider vessel can be tapered to provide and end-to-end repair ${ }^{(4)}$. The sleeve anastomosis (or telescoped technique), consisting of end-to-end invaginating the smaller into the larger with sutures, might be used, although it is associated to a lower patency rate compared with the conventional interrupted suture technique in the rat femoral artery model ${ }^{(1,4)}$.

Performing an end-to-side anastomosis is another alternative. In experimental studies it was shown that in case of marked discrepancy end-to-side anastomosis have higher patency rate compared to end-to-end anastomosis ${ }^{(2,4,5)}$.

No single method has become favourite and can be performed in all different clinical situations. The surgeon personally makes the choice of microvascular anastomotic technique in cases of vessel size discrepancy, according to his skills and experience with different techniques and anatomic characteristics of the vessels which have to be anastomosed.

In this paper we present our protocol which we use in case of incongruent anastomoses. In addition a new type of microvascular anastomosis used in mild discrepancy is described. Interrupted mattress sutures are placed in end-to-end anastomoses to narrow the wider diameter and compensate for the diameter incongruency. We describe surgical details and clinical applications and discuss indications, advantages and results. 


\subsection{Operative technique}

The end-to-end anastomosis is performed according to "posterior wall first" suturing technique ${ }^{(6,7)}$ which provides continuous visualisation of the vessel lumen during the suturing and avoids rotation of the vessels. The posterior wall is sutured first with interrupted stitches at the 7 o'clock, 6 o'clock and 5 o'clock positions to perform the posterior wall anastomosis. To compensate for the diameter incongruency interrupted mattress sutures are placed on the lateral and anterior walls. The larger diameter vessel is approximated and decreased in diameter using a horizontal micro-mattress suture, while the narrower diameter vessel is entered with a vertical type mattress stitch.

These sutures are repeated so many times as necessary, progressively tapering the larger vessel diameter to a match (fig.1, fig a-d).

The sutures must be sufficiently close to each other to make a watertight anastomosis. Stitches are positioned on the 9 o'clock, 5 o'clock, 11 o'clock, 3 o'clock and so on till 12 o'clock.

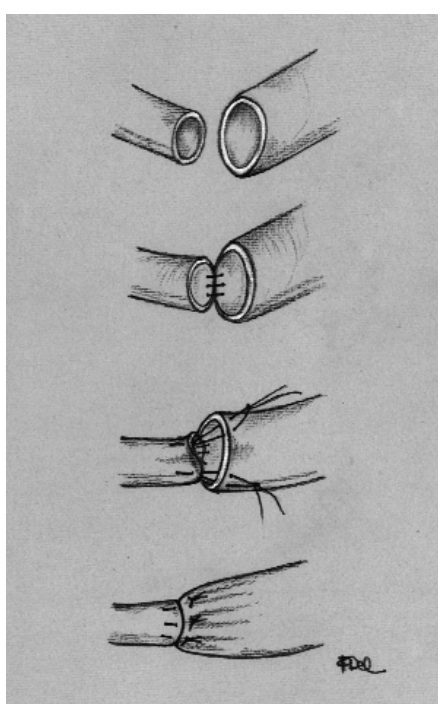

Fig. 1 Schematic drawing of micromattress anastomosis.

The same technique is used in arterial and venous anastomoses.

Vessel patency is checked with the downstream milking test and later with the Doppler flow probe.
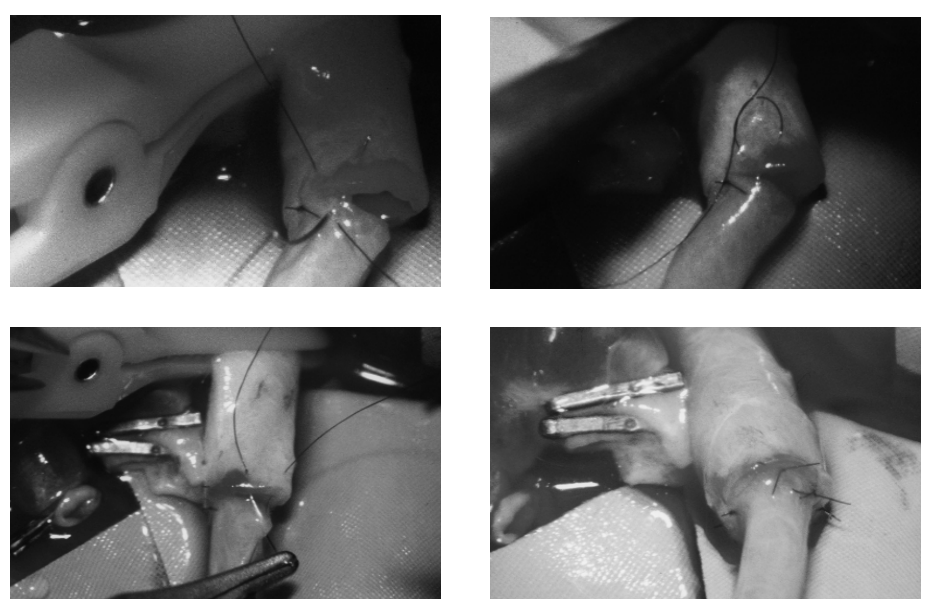

Fig. a-d.

Intraoperative views of mattress stitches. 


\subsection{Material and methods}

Since 1983 we have performed 190 interrupted micro-mattress sutures in free flap reconstructions overcoming vessel size discrepancy between donor and recipient vessels. We used mattress stitches in 59 arterial anastomoses, in 36 venous anastomoses and in 95 free transfers both the arterial and venous anastomoses have been performed using this technique.

The number of incongruent anastomoses we observed is obviously larger because different anastomotic techniques have been used according to different sizes in diameter between the donor and the recipient vessels. More details about the mattress suturing technique, arterial and/or venous anastomoses and their success rate are shown in table 1. Free flap transfers included head and neck coverage, lower limb and breast reconstructions and testis autotransplantations.

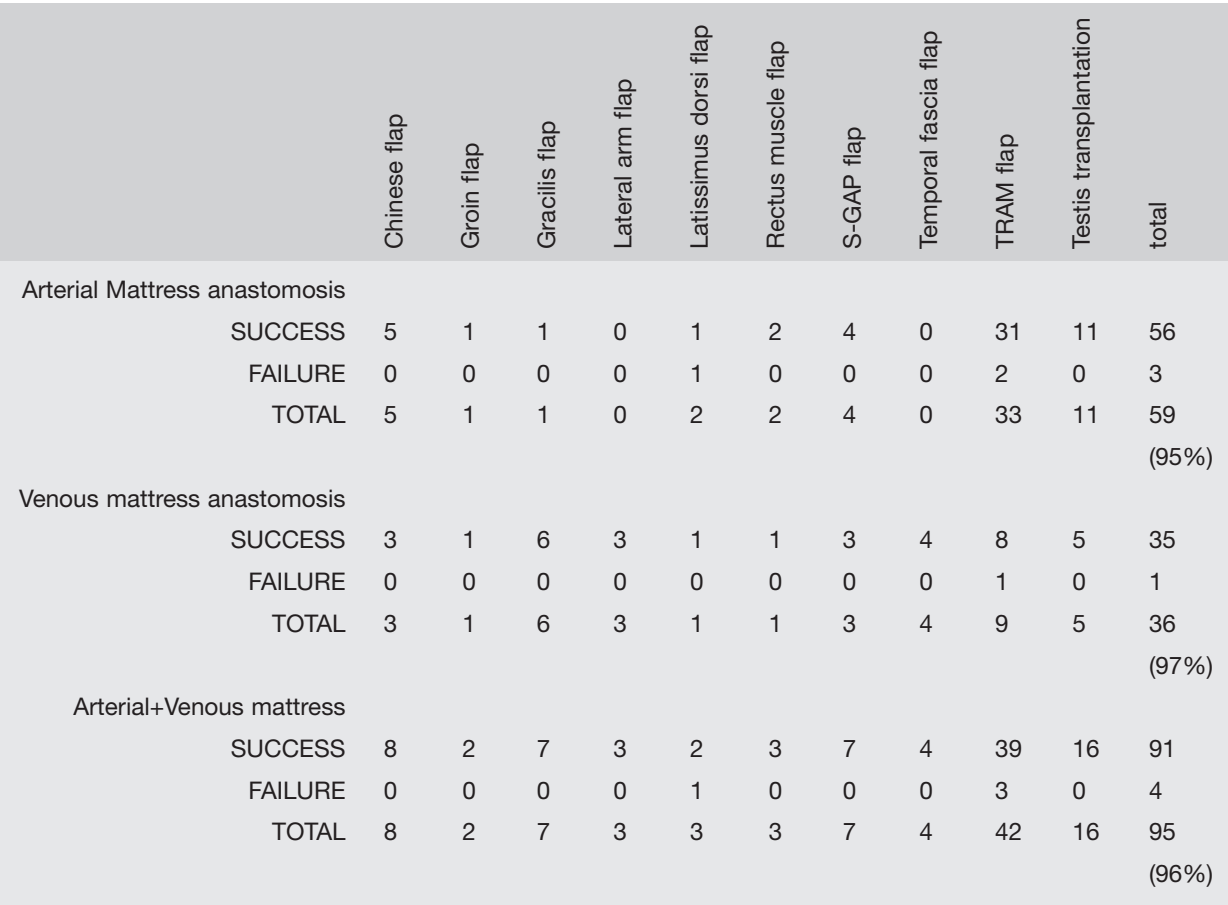

Table 1. Different free transfers and success rate of the mattress anastomosis. 


\subsection{Results}

Free flap failure rate was $5 \%$ (3 out 59 flaps) when the arterial anastomosis was performed using the mattress suturing technique; it was 3\% (1 out 36 flaps) when the venous anastomosis was performed with this technique. In the cases in which both the arterial and venous anastomoses were performed with mattress stitches, free flap failure rate was $4 \%$ (4 out 95 flaps). In this group, we observed thrombosis at the site of the anastomosis or in the artery or in the vein.

\subsection{Discussion}

We first described the use of interrupted mattress sutures in microvascular end-to-end anastomoses in $1982{ }^{\left({ }^{\circ}\right)}$. Since then, this type of anastomosis has been largely performed without any significant technical refinement in more than 170 free flaps, both for arterial and venous anastomoses.

Paying attention to several technical points facilitates its application. First, the posterior wall is anastomosed according to conventional "posterior wall first" suturing technique. Secondly, on the anterior and lateral walls, vessel size discrepancy is corrected by applying interrupted micro-mattress stitches. We advise not to apply micro-mattress sutures to the posterior wall, because it is technically difficult.

We do recommend applying as many small mattress stitches as possible to smooth out irregularities at the stitches. In fact, each mattress suture creates an irregularity, which is more significant if a bigger diameter reduction is performed with each stitch. Thus, more small stitches are better than less large sutures. Moreover, if more stitches are applied, the gap between two adjacent stitches is smaller and leakage avoided, and interference with blood flow is less significant.

Since our first experience with this suturing technique several different clinical applications have been developed. We extensively performed micro-mattress sutures in head and neck free flap reconstructions after oncologic resections ${ }^{(9)}$. In most cases recipient vessels were stiffed, with decreased diameters within irradiated fields. We carefully transected the vessel, being afraid of intima dehiscence. Side branches were clipped and not ligated and minimal adventiectomy was performed. We preferred endto-end mattress suturing anastomoses to end-to-side repair in case of mild vessel size discrepancy because by performing end-to-side anastomoses between such small vessels we were afraid of vessel kinking. Moreover, a sufficient intima eversion is required if an end-to-side anastomosis is planned and this is difficult to achieve with irradiated stiffed vessels. This technique is applied in a majority of free TRAM breast reconstructions to the internal mammary vessels.

In testicular autotransplantations for intra-abdominal testicular retention we performed micro-mattress sutures to overcome the incongruency between testicular and inferior epigastric vessels in end-to-end way of anastomosing ${ }^{(8)}$.

With regard to lower leg reconstructions, we frequently solved the inconvenience of 
vessel size discrepancy between donor and recipient vessels by performing mattress sutures in end-to-end microvascular anastomoses.

Nowadays, in case of mild discrepancy, mattress suturing technique is our first choice. In our hands the use of interrupted mattress sutures showed comparable reliability and patency rate as conventional techniques. As previously shown, we observed thrombosis at the site of the mattress anastomosis in $4,2 \%$ of anastomoses.

After a 18 years experience with this type of suturing technique, we would like to emphasise and discuss its main indications and advantages.

The main indication of mattress suturing technique is mild vessel size discrepancy. We propose the following protocol in case of incongruent anastomoses (tab 2).

\begin{tabular}{|rl|}
\hline 1,5:1 ratio & End-to-end anastomosis \\
\hline 2:1 ratio & Mattress sutures \\
\hline 3:1 ratio & Y shaped anastomoses \\
\hline
\end{tabular}

Table 2 Incongruent anastomoses

If the recipient vessel has already been cut during previous surgery, the first choice is an end-to-end anastomosis. In the ideal condition, there is no size discrepancy. With minimal discrepancy the vessels are adjusted stitch by stitch or the smaller vessel is mechanically dilated with dilator forceps or the smaller end obliquely incised. When discrepancy is between 1.5-2:1 ratio we perform mattress anastomosis ${ }^{(8)}$.

When a vessel discrepancy exists for more than 2:1 until 3:1 ratio, we plan an $Y$ shaped anastomosis or an end-to-side repair. An $Y$ shaped anastomosis is an end-to-end anastomosis between three vessels: two smaller on one side and a bigger one on the other side ${ }^{(6)}$. The other solution is a so-called "blind" end-to-side anastomosis. In this case the larger vessel is closed at the end and an end to side anastomosis is performed proximally to this blind end. Hemodynamically the interrupted blood flow at the blind end of the larger vessel increases the risk of intravascular thrombosis, developing turbulence and stasis.

The interrupted mattress suturing technique is a quick, safe, effective and reliable solution for mild incongruent end-to-end anastomoses. Specific advantages of this technique include the ability to avoid end-to-side repairs in difficult conditions (stiffed small irradiated vessels, difficulties in achieving a sufficient intima eversion, risk of kinking with small vessels) and interpositional vein grafts. A vein graft can be used to overcome a size discrepancy problem but it can be inconvenient especially in case of arterial anastomosis. In fact, vein wall does not include the thick arterial muscle layer which may result in loss of blood flow pulse through the vein graft.

The main particular disadvantage of the presented technique might be the difficulty of backhand suturing under microscope magnification To our opinion however, every microsurgeon should be able to perform the backhand stitch technique, and it should be included in the microsurgical training program. 


\subsection{Conclusion}

In conclusion, different methods are suggested to overcome the inconvenience of vessel size discrepancy. No single one can be used in all clinical situations. The surgeon can choose the more suitable solution for every different anatomic and functional condition. In our opinion the use of interrupted mattress sutures in microvascular end-to-end anastomosis is a new technique which should be add to the armamentarium of surgical solutions because it is an easy, quick and reliable technique.

\subsection{References}

1. Pho RWH. General principles of microsurgery. In Pho RWH: Microsurgical technique in orthopaedics. Butterworths \& Co. Ltd, 1988.

2. Hidalgo DA, Shaw WW, Romita MC, Godfrey NV: Anastomotic technique and vein grafts. In Shaw WW, Hidalgo DA: Microsurgery in trauma. New York: Futura Publishing Company, Inc, 1987.

3. Harashina T, Irigaray A. Expansion of smaller vessel diameter by fish-mouth incision in microvascular anastomosis with marked size discrepancy. Plast Reconstr Surg 65(4): 502, 1980.

4. O'Brien McC B, Morrison WA. End-to-end anastomosis. In O'Brien McC B, Morrison WA: Reconstructive microsurgery. Churchill Livingstone, 1987.

5. Godina M. Preferential use of end-to-side arterial anastomoses in free flap transfers. Plast Reconstr Surg 64(5): 673, 1979.

6. Boeckx W. Clinical micro-surgery. In Marquet R, Hess F, Kort W, Boeckx W: Micro-surgery. Experimental techniques in the rat and clinical applications. Ghent, Belgium: European Press, 1976.

7. Harris GD, Finseth F, Buncke HJ. Posterior-wall-first microvascular anastomotic technique. Br J Plast Surg 34: 47, 1981.

8. Boeckx W, Vereecken R, Depuydt K. Microsurgery for intra-abdominal testicular retention. Eur J Obstet Gynecol 81:191,1998.

9. Boeckx W, Fossion E, Guelinckx P, Demey R, Dewilde R. Free flaps in head and neck surgery. Acta Chir Belg 82(3): 219, 1982. 


\section{Chapter 4 - VCS Auto Suture ${ }^{\circledR}$ Stapled Microvascular} anastomoses in lower leg free flaps

F. De Lorenzi, R. R. W. J. van der Hulst, W. D. Boeckx.

Plast Reconstr Surg 2002 May: 109(6): 2023-30 


\section{Abstract}

We present our series of 26 free flaps in which end-to-side and end-to-end stapled microvascular anastomoses have been performed successfully. Only in 13\% of the anastomoses the VCS $®$ staples were not applicable. The use of a Sliding Everting Forceps $(\mathrm{SEF} \otimes)$ is required to provide optimal alignment of the vessel walls. This is essential to achieve a patent and a watertight anastomosis. A highly skilled microsurgeon can achieved good results using the VCS $®$ staples. 


\subsection{Introduction}

Suture anastomosis of small vessels is time-consuming and tedious and demands long training if high patency rates are to be achieved. Vascular Surgeons have developed non-suture techniques of vessel anastomosis, but unfortunately many of these mechanical devices are intended for larger vessels ${ }^{(1,2)}$. More recently, Plastic Surgeons have developed several mechanical non-suture systems (3-8) for microvascular anastomoses. The main advantage of using these devices is rapidity, if compared with conventional interrupted suture technique. We performed experimental trials using an individual titanium non-penetrating staple device type VCS Auto Suture ${ }^{\circledR}$ microclip as non-suture technique for microvascular anastomosis ${ }^{(3)}$. Based on these results and advantages, 26 clinical free flaps have been performed using an end-to-end and end-toside vessel anastomosis VCS Auto Suture ${ }^{\circledR}$ microclip stapling technique with follow-up results up to three years. In this study we discuss the results and the advantages of this non-suture technique, its indications and limitations in clinical applications, pointing out few important aspects of the correct operating procedure.

\subsection{Material and methods}

Device description: VCS Auto Suture ${ }^{\circledR}$ Titanium Microclips are individual staples of 0.9 $\mathrm{mm}$ (small) and $1.4 \mathrm{~mm}$ (medium) in size, non perforating the vessel wall ${ }^{\left({ }^{9}\right.}$. Thus, no foreign material inside vessel lumen is present. They are mounted on a self reloading application forceps, holding 25 pieces (Fig.1).
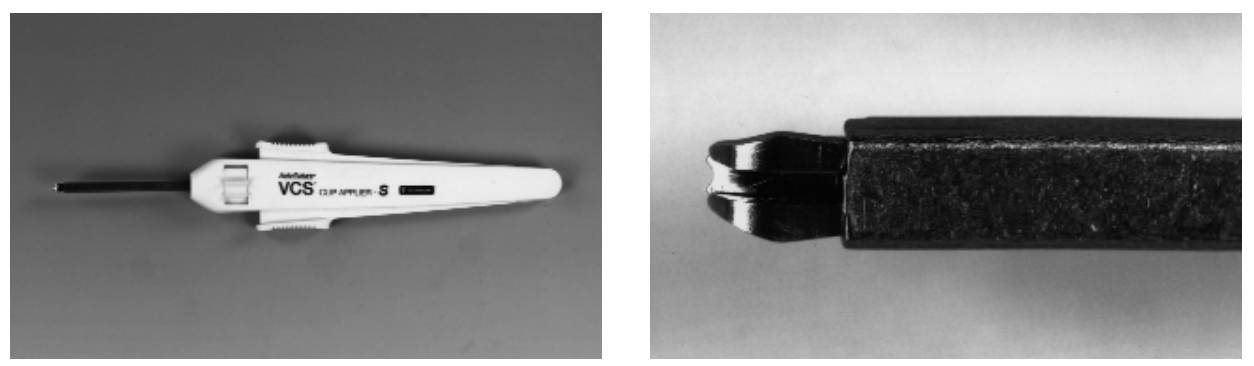

Fig. 1 a, application forceps; $b$, the top.

Eversion of intima and media and approximation of vessel walls is essential for clip application. It's accomplished with a special Sliding Everting Forceps (SEF® Warm Co. Mechelen. Belgium) (Fig. .2 a-b). This forceps allows eversion of the vessel edges. Before squeezing together both vessel walls, one wall can be lifted or pushed back relative to the other. This allows perfect alignment of both vessel walls, an essential condition for accurate clip application. 
Malaligned clips can be easy removed by squeezing under the clip arms with a special derived clip releasing forceps.

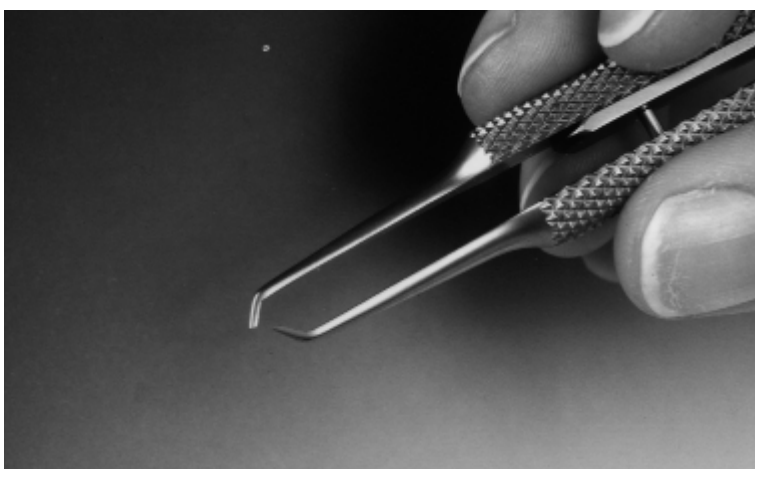

Fig. $2 a-b$

Sliding Everting Forceps (SEF® Warm

Co. Mechelen. Belgium).

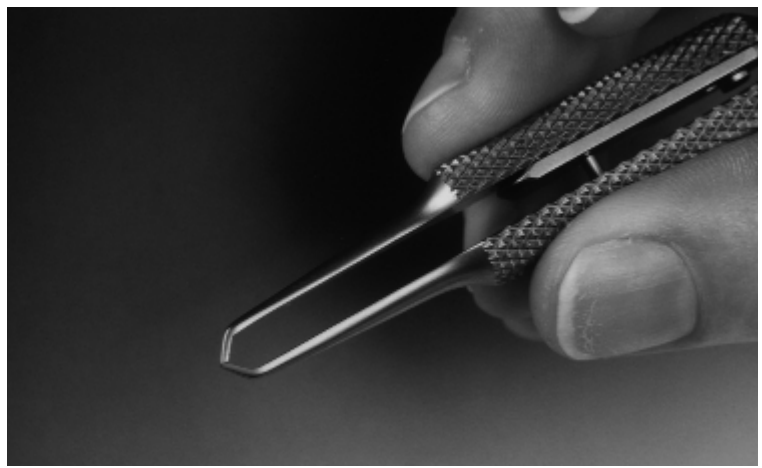

Operating procedure: Both end-to-end and end-to-side vessel anastomosis can be performed using the $\mathrm{VCS} \circledast$ technique.

When doing the end-to-end anastomosis, one approximation-stay suture at 6 o'clock position is placed in order to rotate up the posterior wall for clip application and stabilise the vessel walls.

The suture line of the anastomosis must be positioned in such a way that it is running in a direction from the top left corner of the operative field to the bottom right, as seen through the operative microscope.

While the assistant holds the stay suture and applies moderate traction toward himself, the surgeon uses the SEF $®$ in the left hand to align and to evert vessel ends. The surgeon then applies the clips with his right hand starting from the right to the left, until the entire circumference of the vessel is stapled. The stay suture is released after completion of microclip anastomosis (Fig. 3). Further details concerning the operating procedure have been described ${ }^{(3)}$. 


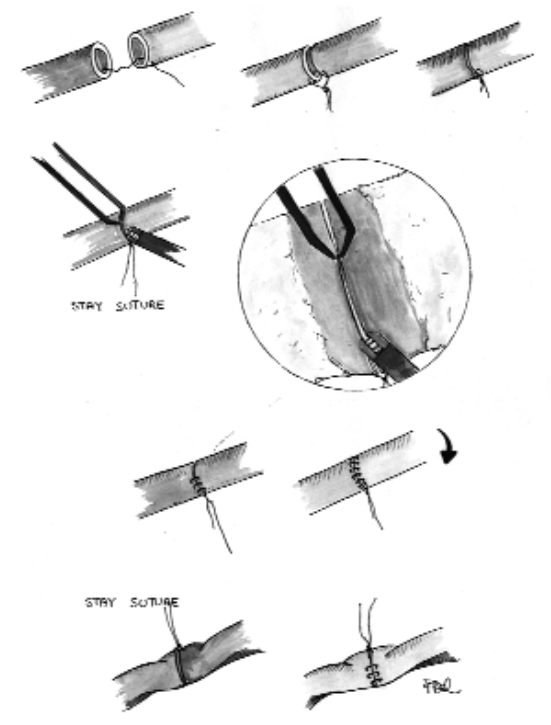

Fig. 4-a, A longitudinal arteriotomy slightly longer than the donor vessel diameter is performed with a knife. No vessel wall is resected. $b$, Bringing together the two prawns of the double microvascular clamps makes the vessel bulging and everting the longitudinally slit vessel wall, thereby everting the intima.

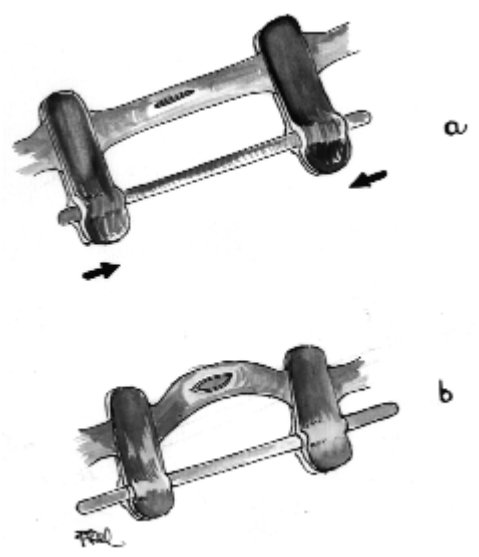

When doing the end-to-side anastomosis, we perform an oblique end-to-side anastomosis, after longitudinal arteriotomy of the recipient vessel, without any resection of the vessel wall (Fig. 4). One approximation stitch is placed at the top and at the heel of the anastomosis (Fig. 5) ${ }^{(5)}$ in order to lift the vessel and to apply microclips to the posterior wall first. The stitch may be released after completion of stapled anastomosis.

Fig. 3 End-to-end Stapled anastomosis.

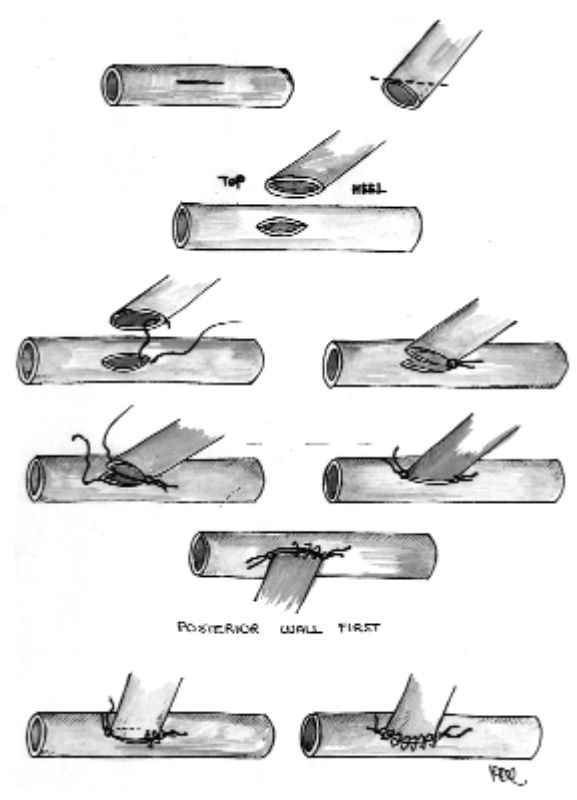

Fig. 5 End-to-side Stapled anastomosis. 
Clinical applications: Between August 1995 and December 1996 we performed 26 free flaps using the VCS Auto Suture $®$ microstapler technique for lower leg defects (21) and some other locations (5). Patients ranged in age from 20 to 61 years (Table 1).

\begin{tabular}{|ll|}
\hline$<20$ years & 1 \\
\hline $21-40$ years & 10 \\
\hline $41-60$ years & 11 \\
\hline$>60$ years & 4 \\
\hline
\end{tabular}

Table 1. Age of patients

More frequent indications were soft tissue cover of fractures, osteomyelitis and crush injuries of the lower leg (Table 2).

\begin{tabular}{ll}
\hline Indications: & Type of flap: \\
\hline Lower leg (21): & 11 gracilis muscle \\
10 fractures & 3 latissimus dorsi muscle \\
5 crush injuries & 3 rectus abdominis myocutaneous \\
5 osteomyelitis & 3 temporalis fascia \\
1 Pressure ulcer & 1 venous flap \\
& 1 gracilis muscle \\
Other sites $(5):$ & 1 latissimus dorsi muscle \\
2 electric burns & 1 temporalis fascia \\
1 squamous carcinoma & 1 TRAM \\
1 breast reconstruction & 1 venous flap \\
1 hand crush &
\end{tabular}

Table 2. Indications for free flap repair and type of flap used.

The recipient vessels of free transfers are showed in Table 3.

$\begin{array}{ll}\text { Lower leg (21): } & \text { Other sites (5): } \\ \begin{array}{ll}15 \text { tibialis posterior vessels } & 2 \text { ulnar vessels } \\ 2 \text { dorsalis pedis vessels } & 1 \text { radial vessels } \\ 1 \text { gastrocnemius muscle vessels } & 1 \text { internal mammary vessels } \\ 2 \text { superficial femoral vessels } & 1 \text { occipital vessels } \\ 1 \text { vein graft } & \end{array}\end{array}$

Table 3. Recipient vessels for VCS Auto Suture ${ }^{\circledR}$ Stapled Microvascular anastomosis. 
We performed 13 end-to-side arterial VCS $尺$ Stapled anastomoses $(50 \%)$ and 8 end-toend arterial VCS $₫$ Stapled anastomoses (31\%). In five cases we used conventional 9/0 interrupted suture technique (19\%) for arterial anastomosis. 24 end-to-end venous VCS $®$ Stapled anastomoses (92\%), two conventional 9/0-interrupted suture (4\%) were performed for venous anastomoses (Table 4).

\begin{tabular}{ll} 
Arteries: & Veins: \\
\hline 13 VCS $\AA$ end-to-side $(50 \%)$ & 0 VCS $尺$ end-to-side \\
8 VCS $₫$ end-to-end $(31 \%)$ & 24 VCS $\circledast$ end-to-end $(92 \%)$ \\
$59 / 0$ suture $(19 \%)$ & $29 / 0$ suture $(4 \%)$
\end{tabular}

Table 4. Type of microvascular anastomosis.

We use small staples three times for venous anastomoses and only once for arterial anastomosis; in all other cases we used medium size microclips (Table 5). The choice of clip size depends on the thickness of the vessel wall and not according to the vessel diameter. In fact, if small clips are applied to thick vessel walls, the clip arms can not hold and evert the walls, which is necessary for appropriate intima to intima contact. For this reason we used smaller clips in venous anastomosis, with a thinner wall than the arterial one. Eight to twelve microclips were required for a blood-tight anastomosis, slightly higher than the number of interrupted microsutures required when using conventional 9/0 suture technique. In order to prevent vascular spasm, pure papaverine solution was dropped on the vessels during their dissection and removal of adventitia. Heparined saline was used for flushing the vessel lumen. Vessel patency was tested under microscope magnification using downstream squeeze test.

$\begin{array}{ll}\text { Arteries } & \\ \text { - Small } & 1 \\ \text { - Medium } & 20 \\ \text { Veins } & \\ \text { - Small } & 3 \\ \text { - Medium } & 23\end{array}$

Table 5. VCS® size.

\subsection{Results}

All anastomoses, VCS Auto Suture ${ }^{\circledR}$ stapled and 9/0 sutured were patent after completion of the procedure. All free flaps survived, we had no failures, no surgical revisions were required. No partial necrosis was found. VCS Auto Suture ${ }^{\circledR}$ Staples were not applicable in $13 \%$ of vessel anastomoses (7/52 vessels). In three cases of end-toend anastomosis vessel rotation was not possible, due to important arteriosclerosis and 
vessel rigidity or due to longitudinal dissection of the recipient vessel, especially with very short vessel stumps. In these cases a conventional interrupted 9/0 suture, posterior wall first, was performed. In four cases of end-to-side anastomosis VCS $®$ Staples were not applicable because of small size of the vessels (two cases) and inadequate eversion of vessel wall achieved (two cases) (Table 6). Here the eversion of the small lateral opening in the recipient vessel resulted in decreasing the transverse diameter of the arteriotomy, thereby occluding the vessel lumen from the exterior side. When insufficient blood vessel diameter increase could be achieved, the VCS staples were too thick and exerted external pressure on the terminal donor vessel wall thereby occluding the flap vessel (Fig. 6).

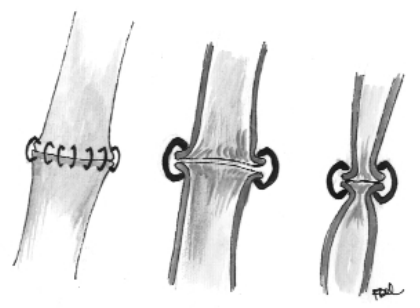

Fig. 6 Sufficient vessel diameter allowing sufficient transverse vessel wall for eversion without decreasing the vessel diameter. Insufficient vessel diameter not providing sufficient length at the anastomosis for adequate vessel length to be held by the VCS staple.

$\begin{array}{ll}\text { End-to-end anastomoses } & \text { End-to-side anastomoses } \\ 1 \text { radial artery: rotation not possible } & 4 \text { tibialis posterior arteries: } \\ 1 \text { tibialis posterior vein: rotation not possible } & 2 \text { not adequate eversion } \\ 1 \text { internal mammary vein: rotation not possible } & 2 \text { too small vessels }\end{array}$

Table 6. VCS $®$ Auto Suture Staples not applicable.

Blood leakage between the clips was corrected with additional clip at the time of vessel clamp release. This was necessary in about $25 \%$ of the cases. No extra sutures were required to achieve a waterproof anastomosis.

\subsection{Discussion}

VCS Auto Suture ${ }^{\circledR}$ non-penetrating clips stapled anastomosis technique is a safe and quick technique, with high success rate. However, an intima to intima contact and a perfect alignment of vessel walls are essential for correct placement of microclips. Thus, the key to successful application of VCS Auto Suture ${ }^{\circledR}$ Staples are the Sliding Everting Forceps (SEF®). They allow an eversion of vessels ends for intima to intima contact and an accurate alignment of vessels ends to avoid overlapping (one vessel end slips out of VCS $®$ Staple). Moreover, the Sliding Forceps can lift one vessel end relative to the other. 
Only after perfect alignment is achieved the clips will be applied. As in conventional sutured micro anastomoses a variable number of clips can be used to perform the anastomosis, depending on the vessel diameter. Only vessel diameter congruency is required. If vessel diameters are incongruent an end-to-side anastomosis can overcome this problem. This is in contrast to other mechanical anastomotic devices such as the UNILINK, for which patency and water-tightness depends on vessel diameter-clip size match. Especially the thicker-walled arteries (as compared to veins) do evert only a little bit. This results in the inability to anastomose arteries with the UNILINK System. In addition, the VCS ${ }^{\circledR}$ clip only holds $0.2-0.3 \mathrm{~mm}$ of vessel wall in its jaws. Therefore only limited vessel wall stretch is required to evert the vessel wall $90^{\circ}$ relative to its longitudinal axis. Therefore stenosis of the anastomosis is a very rare finding only occurring in stiff arteriosclerotic vessels. With the UNILINK System our personal experience in arteries has shown that vessel wall eversion has to be extensive up to $90^{\circ}$, in order to allow the vessel wall to be hooked on the pins holding the vessel everted before the two UNILINK rings can be compressed to seal the anastomosis. In this system the complete vessel edge has to be opened and stretched maximally, giving the risk of tearing and leakage. In the $\operatorname{VCS}{ }^{\circledR}$ system only one tenth of the vessel circumference is stretched and everted to apply one single clip. After its application, the vessel wall retracts again allowing the next staple to be applied after eversion of that part of the vessel. At no instance has the whole vessel end to be everted for "single shot application of all staples", as required in the UNILINK System. This results in a lack of stenosis at the site of the anastomosis.

To facilitate easy vessel intima and media eversion we prefer to perform a longitudinal incision in the longitudinal vessel when performing end-to-side anastomosis. This is in contrast to the end-to-side sutured micro anastomosis where we do resect a longitudinal elliptical segment of anterior vessel wall to open up the vessel widely. To future improve the vessel wall eversion in end-to-side anastomosis we do apply a double adjustable O'Brien Gilbert type of microvascular clamp on the longitudinal vessel, which is dissected free over an additional length. After proximal and distal vessel wall occlusion the vessel clamps are slid together enabling the occluded segment to bulge (Fig. 4). This bulging facilitates opening up the arteriotomy, widening of its diameter and eversion of its media and intima. Especially the proximal and distal ends of the arteriotomy evert nicely when doing this manoeuvre. Evertion is further promoted by placing two stay sutures at the heel and toe of the anastomosis. We try to perform an oblique end-to-side anastomosis to avoid right angle types of anastomosis. This does obscure the visibility of the vessel walls in the end-to-side anastomosis as the terminal vessel sits in the middle of the optical axis of the operation microscope field of vision.

Using the SEF® Sliding Everting Forceps the vessel wall alignment can be adjusted for each individual staple. Comparable to a sutured anastomosis this allow us to accurately position each individual staple, squeeze the vessels together and apply the single staple. This process is repeated for each staple individually allowing repeated possibilities to perform an accurate vessel wall alignment. This avoids part of the vessel wall slipping out of the jaws of the staple, a problem encountered in the ring type mechanical anastomoses. 
Patency rate of VCS Auto Suture ${ }^{\circledR}$ Stapled anastomoses has been found $100 \%$ in our series. Various patency rates have been described ${ }^{(6,8)}$ using a mechanical device for microvascular anastomosis of arteries, being the average rate $96 \%$. In our previous experimental trial we found no difference between sutured and stapled groups of anastomoses and it has been found $100 \%$ with both VCS Auto Suture ${ }^{\circledR}$ stapled technique and conventional interrupted suture. This compares favourably with the UNILINK System ${ }^{(7,8)}$. The high success rate of the VCS ${ }^{\circledR}$ stapled anastomosis can be explained by several factors. First there is no size reduction at the anastomosis. No circumferential rings are prohibiting vessel wall expansion at the systolic phase of the heart beat. No thick and short rings that can kink along the longitudinal axis thereby compressing the vessel diameter from outside. In addition, as showed in our experimental trial ${ }^{(3)}$ and demonstrated also by using other mechanical devices ${ }^{(7,8)}$, a faster re-epithelialisation has been found at the anastomotic place if compared with conventional sutured anastomoses. It's probably due to an absence of foreign material in the intima and vessel lumen. No contact of it with blood stream occurs and no migration of leukocytes to the anastomotic site has been observed, no exposition of sub-endothelial connective tissue because of minimal damage of endothelial has been found in our previous study. Thus, using VCS Auto Suture ${ }^{\circledR}$ microclip the two main inducers of the thrombogenesis - endothelial damage and highly thrombogenetic exposed subintimal connective tissue - can be minimised or almost excluded, resulting in safer anastomosis.

An additional advantage of the VCS technique is rapidity. In comparison with $9 / 0$ conventional interrupted technique, where the procedure in our hands takes the mean time of 22 minutes, the required time for stapling microvascular anastomosis technique was found at the mean of 8 minutes. A substantial time saving has been realised. This operation time saving can probably decrease operating time costs, compensate VCS Auto Suture $\AA$ instrument expenses and could leave a profit. We think that microclip anastomosis technique can give additional possibilities in complex microvascular reconstruction when several anastomoses have to be done in one operation session. This often happens in inferior limb reconstruction and under limited tourniquet time.

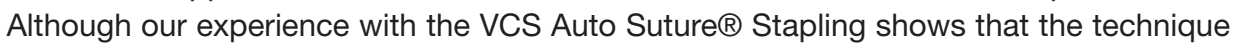
is a safe, others have encountered some problems. Yamamoto et al. ${ }^{(9)}$ reported a rupture of the stapled anastomosis in a infected wound 11 days after the operation. This may be due to a technical problem related to the lack of appropriate vessel wall alignment. In his series no SEF® was used.

Although the advantages discussed above, VCS Auto Suture $®$ Stapled microvascular anastomoses can not always be performed in clinical applications. A normal vessel wall is required with an elastic expandable media and intima. No arteriosclerotic vessels can be anastomosed. In arteriosclerotic vessels, intima dehiscence can occur when trying to evert the vessel wall. No possibility is available to compress the intima against the media. Intima dehiscence may have the risk of aneurysm formation or rupture of the anastomosis as recently reported by Yamamoto et al. ${ }^{(10)}$. Media calcification also gives risk of vessel wall rupture when compressed by a staple or tearing of the vessel wall. 
These were the reason why in our series in 13\% of vessels the clips weren't applicable, requiring a conventional $9 / 0$ interrupted suture because of small vessel size, inadequate vessel rotation and inadequate wall eversion achieved. We do think however that applicability is higher than UNILINK, especially for arterial repair.

\subsection{Conclusion}

In conclusion, in our opinion, a mechanical non-suturing technique for microvascular anastomosis may eliminate the conventional procedure in optimal cases. They prove to be quick, safe and with high success rate in normal vessels. However, a superior microvascular expertise is required to apply the staples accurately. Only in damaged vessel walls or important vessel diameter mismatch the sufficient eversion of the vessel wall leads to an inappropriate diameter of the vessels, also due to the fact that, especially in end-to-side anastomosis, the height of the clip has to be accommodated for (Fig. 6).

\subsection{References}

1. Nakayama K, Tamiya T, Yamamoto $\mathrm{Y}$, et al. A simple new apparatus for small vessel anastomosis Surgery. 52: 918, 1962.

2. Inokuchi K. Stapling device for end-to-side anastomosis of blood vessel. Arch. Surg. 82: 337, 1961.

3. Boeckx W, Darius O, Van de Hof B, Vandervoort M. Scanning electron microscopic evaluation of the microvascular anastomosis performed by non-penetrating vascular stapling: comparison with conventional microsuture t.echnique. In Proceedings of the 12th Symposium of International Society of Reconstructive Microsurgery, Singapore, February 6-10, 1996.

4. Joji S, Muneshige H, Ikuta, Y. Experimental study of mechanical microvascular anastomosis with new biodegradable ring device. Br J Plast Surg, 52: 559, 1999.

5. Kirsch WM, Zhu YH, Boukouvalas Z, Hardesty, RA. Microvascular anastomoses: surgical technique. In Sun Lee (Eds), Color Atlas of Microsurgery, 1st Ed. St. Louis Tokyo: Ishiyaku Euro America, Inc, 1993.

6. Kirsch WM, Zhu YH, Hardesty RA, Chapolini RA. New method for microvascular anastomosis: report of experimental and clinical research. Am Surg, 12: 722, 1992.

7. Nylander G, Ragnarsson R, Berggren A, Ostrup, LT. The UNILINK system for mechanical microvascular anastomosis in hand surgery. J Hand Surg, 14A: 44, 1989.

8. Ragnarsson R, Berggren A, Ostrup LT, Gilbert RW. Arterial end-to-side anastomosis with the UNILINK system. Ann Plast Surg 22: 405, 1989.

9. Zeebregts CJ, Van de Dungen JJ, Kalicharan D, Cromheecke M, Van der Want J, Van Schilfgaarde R, Non penetratingvascular clips for small-caliber anastomosis. Microsurgery 20 : 131, 2000.

10. Yamamoto N, Nakai H, Satoh Y, Oshima Y. Clinical application of a non penetrating micro vascular stapling device for vascularized free tissue transfer. Ann Plast Surg, 42(1): 49, 1999. 
Chapter 5 - Free temporalis fascia transplantation as a treatment for wrist ankylosis

W. D. Boeckx, F. De Lorenzi, R. R. W. J. van der Hulst, J. H. Sawor

J Reconstr Microsurg 2002 May; 18(4): 269-74 


\section{Abstract}

The temporalis fascia is well vascularized and for this reason its use in reconstructive surgery is versatile. It can be used as an island flap in defects of head and neck or as a free flap in reconstructions of different anatomic regions. As a "living" spacer in the treatment of wrist ankylosis its use is not yet described.

In this paper we present the transfer of the free temporalis fascia into the wrist as a treatment of wrist ankylosis in patients affected by severe rheumatoid arthritis.

Four flaps in three patients were performed. Preoperative flexion/extension in the wrist was absent or almost absent and painful, resulting in severely impaired daily activities. After resection of distal ulna, distal radius and the proximal surfaces of the proximal row of the carpal bones was performed, the free fascia was used to replace the wrist joint. Postoperative wrist flexion/extension was 45-50 degrees in average. Moreover in all patients, this procedure allowed painless motion of the wrist and daily activities were improved. A two years follow-up showed no recurrence of wrist problems and a maintained articular space.

In conclusion, in the treatment of wrist ankylosis the use of the free temporalis fascia offers a good alternative to arthrodesis, maintaining sufficient function for daily activities. 


\subsection{Introduction}

Rheumatoid arthritis is a systemic condition affecting synovial tissue and involving several joints. The wrist is affected by this degenerative process in 65 to $85 \%$ of cases ${ }^{(1)}$. The hypertrophied synovial tissue alters its surroundings: it destroys articular cartilage, invades subchondral bone and stretches soft tissues (ligaments and tendons) that support the involved joint. Frequently in the rheumatoid synovitis, the earliest involved structures are the ulnar styloid, the ulnar head and the midportion of the scaphoid ${ }^{(2)}$. In case of mild to moderate disease several surgical options are now available to prevent the progression of the disease, to provide pain relief and to reconstruct the partially affected joint ${ }^{2}{ }^{2}$. . In case of severe wrist involvement characterised by fixed deformity without joint changes and articular destruction, classified as stage III and IV by MillerBreslow at al. ${ }^{(4)}$, arthrodesis and total wrist arthroplasties are indicated. Arthrodesis being the procedure of choice for the end-staged rheumatoid wrist. Although wrist fusion provides pain relief and improves hand function, wrist motion is lost, which itself is a disability ${ }^{(5)}$. Total wrist arthroplasties have been used with inconsistent results, due to long-term complications, such as dislocation of the implant, infection and fractures requiring surgical revisions ${ }^{(2,6)}$.

Therefore, we propose a new procedure to reconstruct the end-staged rheumatoid wrist by replacing the destroyed joint with a vascularized transfer of the superficial fascia temporalis. This to provide pain relief and improve wrist motion. This is a new indication for the temporoparietal fascial flap, which has been largely used in defects of head and neck $^{(7)}$ and for coverage of other anatomical regions as a free flap ${ }^{(8,9)}$.

\subsection{Material and methods}

Between August 1998 and December 1999 we performed four free fascia temporalis flaps for severe wrist rheumatoid arthritis. Three patients were included, two women and one man, with one bilateral procedure in a young woman. They were affected by juvenile, erosive and progressive rheumatoid arthritis, as demonstrated by histological examination. The average age at the time of surgery was 32 years with a range of 20 to 51,5 years. The average duration of rheumatoid arthritis was 9,7 years (8 to 11 years). Three times the left wrist and in one case the right wrist was operated. There was no preoperative instability and or subluxation. Although patients had received corticoid steroid treatment there were no significant skin problems nor in the scalp area nor in the hand.

X-ray's were taken before surgery and at follow-up. The patient's level of pain was recorded and range of motion was measured. Disease of the thumb, fingers and elbow was also considered to evaluate the involvement of the upper extremity. 


\subsection{Technique}

The operation is performed under general anaesthesia and no associated procedures (as repair of ruptured tendons, denervations, metacarpophalangeal joint arthrodesis or arthroplasty) are performed except for synovectomy.

The patient is placed in the supine position. A two team approach is used: the first team is harvesting the superficial temporalis fascia flap on its pedicle (superficial temporal vessels), the second team is working on the affected wrist.

Under tourniquet, a transverse skin incision is made over the dorsal surface of the wrist (fig. 1).

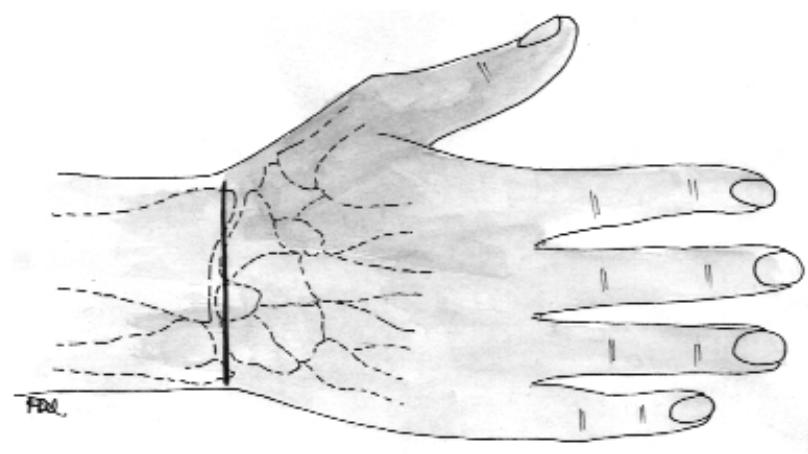

Fig. 1. Transverse skin incision over the dorsal surface of the wrist.

The dorsal nerves and veins are carefully retracted. The extensor retinaculum is incised diagonally (fig. 2 a-b) and extensor tendons exposed. Synovectomy of all extensor tendons is then performed.
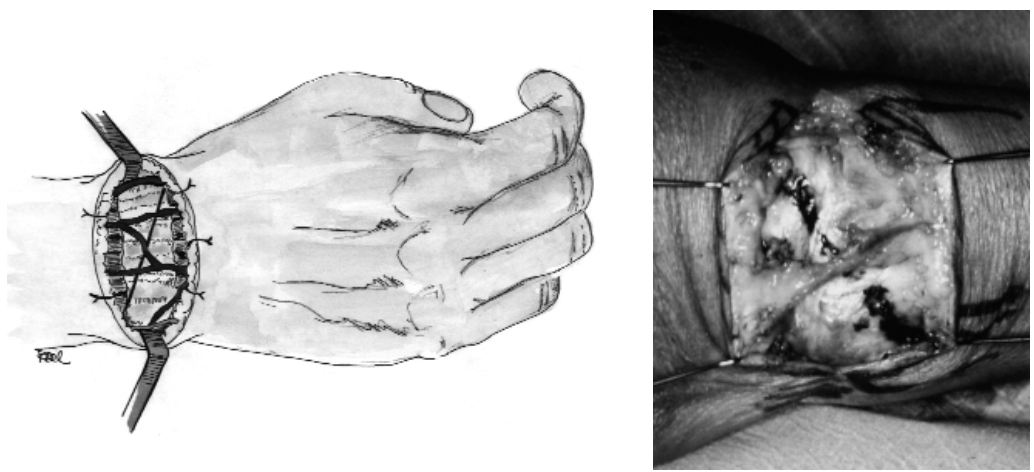

Fig. 2 a-b. Diagonal incision of the extensor retinaculum 
The tendons are carefully retracted and the carpus is exposed by preserving and reflecting the dorsal ligament of the wrist joint (fig.3 a-b).

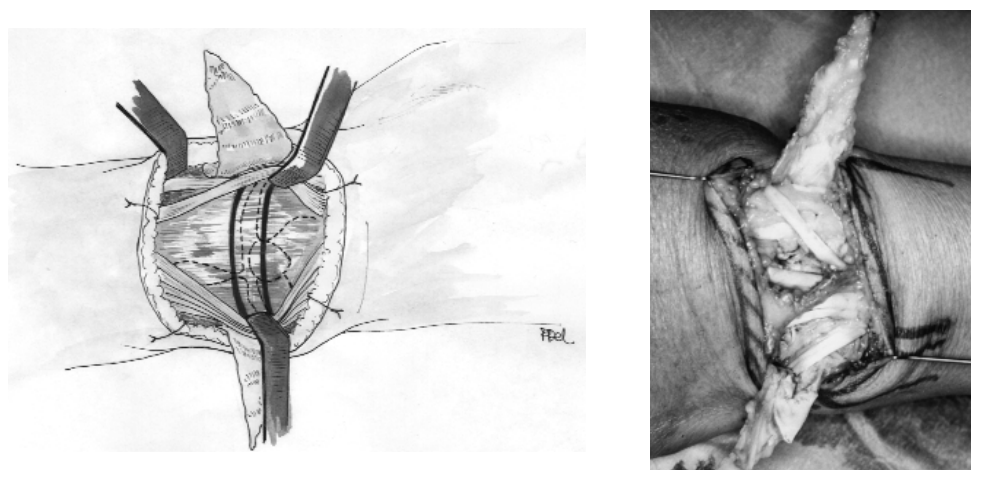

Fig. 3 Extensor tendons are retracted and the carpus is exposed.

The distal ulna, distal radius and the proximal articular surfaces of the first row of the carpal bones are resected using an oscillating saw (fig. 4 a-b). The triangular fibrocartilage complex and the radiocarpal ligaments are left intact to preserve wrist stability (fig. 5). The amount of bone resected depends on the severity of the disease as well as the abnormal anatomy of the wrist joint, such as the presence of osteophytes.

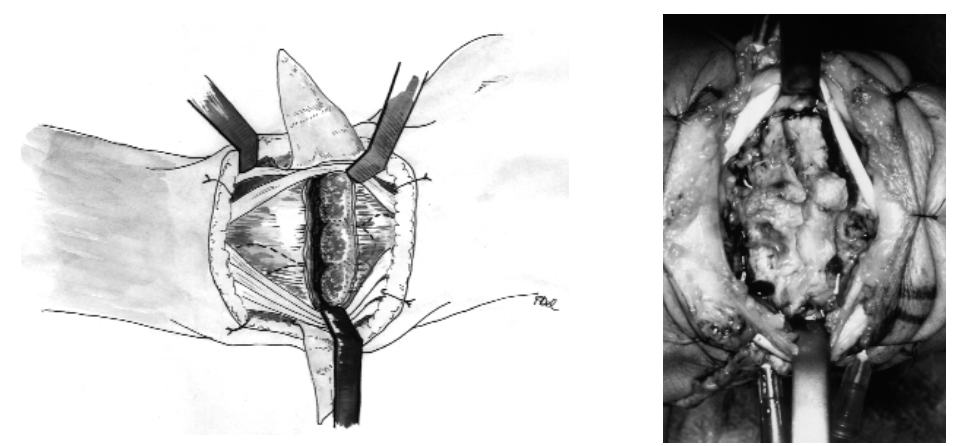

Fig. 4. Resection of the distal ulna, distal radius and proximal articular surfaces of the first row of the carpal bones.

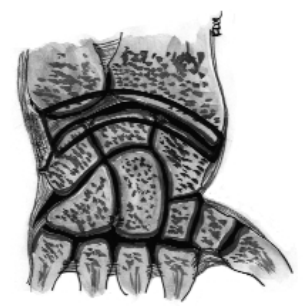

Fig. 5. Schematic view of bone resection 
A small skin incision is then made over the anatomic box and the radial artery is exposed and dissected free. It will be the recipient artery for microvascular anastomosis. As a recipient vein the vena cephalica or one of the dorsal veins were used (fig. 6). The tourniquet is realised and hemostasis controlled.

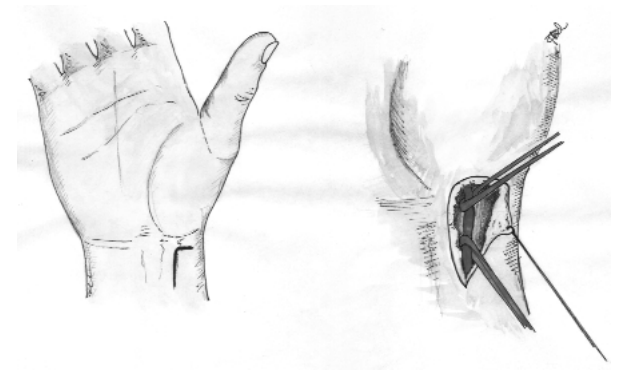

Fig. 6. Recipient artery.

The superficial temporalis fascia is now carefully inserted between the distal ends of ulna and radius and the proximal denuded surfaces of the carpal bones in a double layer fashion, with the smooth gliding surface inside (fig. 7 a-b). Transfixing stay sutures fix the temporal fascia on the volar surface inside. The superficial temporal artery is tunnelled to the anatomic box and anastomosed to the radial artery using end-to-side technique ("posterior wall first" technique) (10, 11).

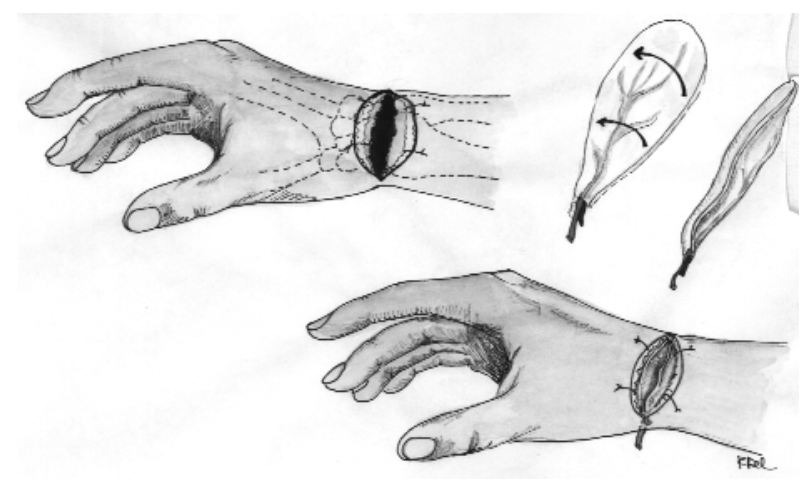

Fig. 7. The superficial temporalis fascia is placed in the wrist in a double layer fashion.

The superficial temporal vein is anastomosed to the cephalic vein using end-to-end technique ("posterior wall first" technique) ${ }^{(10,11)}$. A Redon drain is used and placed under the flap. The dorsal ligament is replaced in its original position. The extensor retinaculum is then replaced across the wrist above all extensor tendons. The skin is closed and a 
bulky compression dressing is applied. There is no additional fixation used to stabilize the wrist postoperatively. Postoperative monitoring of the free flap is performed by Doppler probe analysis of the pulsate flow through the anastomoses. Antibiotics and Reomacrodex $30 \mathrm{ml} /$ hour are given to the patient for five days. At three days a thinner dressing is applied. Hand therapy allowing full range of motion is initiated as quickly as possible, mostly being within one week after surgery.

\subsection{Results}

Mean follow up was 17 months (range 7 to 24 months). Postoperative X-ray's showed a joint space of 3-4 mm (fig. 8).
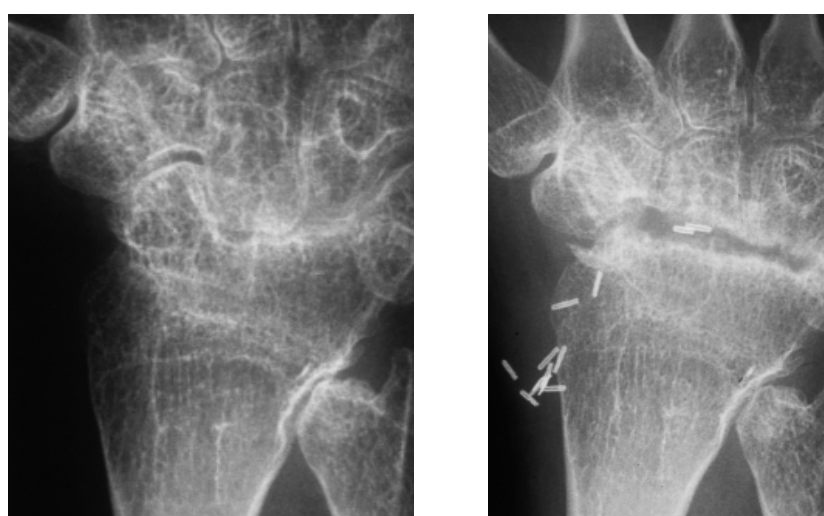

Fig. 8. Preoperative (left) and postoperative (right) $X$ ray of the wrist.

Pain. Each patient was asked to rate his or her preoperative and current pain status. The pain was rated as: none, mild, moderate and severe.

Two patients had severe preoperative pain. In one patient (with both wrists involved) preoperative pain was moderate. Postoperative in one of these patients pain disappeared. In the other patient postoperative pain was only mild. Surgery resulted in painfree wrists. None of the patients had any pain limiting their daily activities.

Motion. In all patients we achieved an increased wrist motion. Preoperative flexion/extension was absent in three out of four wrists. Postoperative the average arc of motion was $45^{\circ}$ (range $400-500$ ): $45^{\circ}$ of flexion, $0^{\circ}$ of extension (fig. $9 \mathrm{a}-\mathrm{b}$ ). In one patient flexion/extension increased from $45^{\circ} / 30^{\circ}$ to $50^{\circ} / 30^{\circ}$.
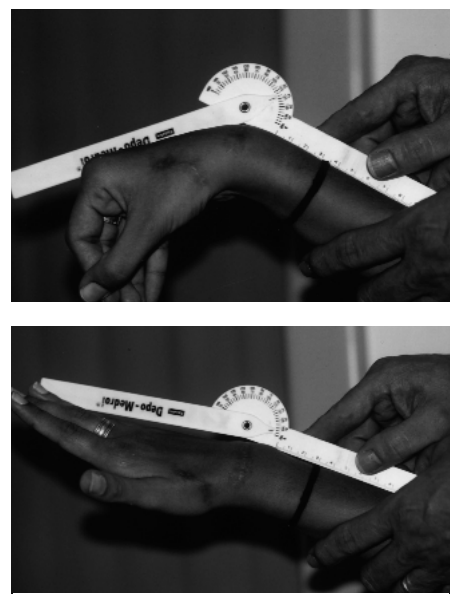

Fig. 9. Postoperative flexion and extension of the wrist 


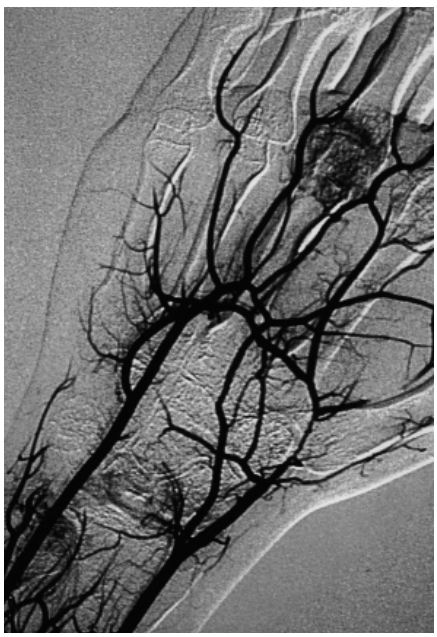

Function. All patients reported an increase of function and daily activities after surgery.

$X$-rays. Arteriograms at 18 months showed patent microvascular anastomoses and a dense vascular network in the free flap area. The articular space was maintained, and there were no signs of recurrent ankylosis during follow up.

Complications. No wound problems, such as infection, hematoma, delayed healing were present after surgery. All flaps survived, as proven by Doppler probe sign. No complications from anaesthesia were observed. None of the patients required a second operative procedure on the wrist up to the follow-up date.

\subsection{Discussion}

The treatment of rheumatoid wrist requires several different procedures according to different variations of laxity and destruction that occur in a patient with inflammatory arthritis.

In case of end-staged rheumatoid wrist, characterised by a wide articular destruction and fixed deformities, arthrodesis and total wrist arthroplasties are the surgical solutions to provide a painless functional wrist joint.

The disadvantage of a wrist arthrodesis is that it eliminates wrist motion, impairing function especially in those patients with significant involvement of more proximal joints. Wrist implants have been used by several authors ${ }^{(2)}$ showing inconsistent results. Long term follow-up shows a high failure rate due to fractures, dislocation of the prosthesis, recurrent deformities and revision for pain.

Straub and Ranawat first described a technique of stabilising the wrist without arthodesis utilising soft tissues ${ }^{(1)}$. A stiff wrist was avoided, however the stabilisation was not appropriate in patients with severe deformity in which soft tissues are compromised. Fifteen years later, Ryu et al. ${ }^{(12)}$ described a reconstruction of the rheumatoid wrist utilising an intentional fibrous non-union between the carpus and the radius. This fibrous hinge gives wrist stability while allowing painless motion at the fibrous radiocarpal hinge and at the less severely involved midcarpal joint. It is not a true pseudoarthrosis since the connection is fibrous and a synovial false joint is not formed.

Our method is inspired by the concepts underlying the fibrous non-union between the distal radius and the proximal row of the carpal bones by Ryu et al., providing a painless motion of the wrist. We use a well-vascularized tissue as temporalis fascia to replace the destroyed joint, hoping for a long vitality. The advantage of using a vascularized flap is the maintenance of the sliding surface instead of just a spacer as described by these authors. 
In this paper we propose a new procedure for wrist ankylosis and severe cases of rheumatoid wrists that should be considered as an alternative to the conventional solutions. This method overcomes some of the problems of the conventional techniques but it is indicated only in selected cases.

The free temporalis fascia is a versatile flap which has numerous applications. Its use in hand surgery has already been reported by Upton et al ${ }^{(13)}$ to cover exposed tendons, bone and neurovascular structures. In addition, dorsal capsule and retinaculum could be reconstructed using the free temporalis fascia. Using the free temporalis fascia to replace the joint we can achieve pain relief but no wrist stability. Wrist stability depends on the original ligaments which are repaired after insersion of the flap. Instability of the wrist may lead to a very weak grasp. Thus, only when the extrinsic (radiocarpal and ulnocarpal) and intrinsic (intercarpal) ligaments are good enough and not compromised by the disease, the free temporalis fascia can be successfully performed. Because the volar ligaments are the most important stabilizers of the wrist, we perform a dorsal approach to the carpus, avoiding any damage of these ligaments and preserving stability of the wrist.

To our opinion the procedure eliminates or postpones the indication for an arthrodesis or arthroplasty in selected cases with no wrist instability. In cases of end-staged wrist disease with a wide destruction of the ligamentous support, instability and severe dislocation of the wrist, arthodesis is still the solution of choice, providing pain relief and re-establishing support.

\subsection{References}

1. Straub LR, Ranawat CS. The wrist in rheumatoid arthritis. J Bone Joint Surg. \{Am\} 51A: 1, 1969.

2. Feldon P, Terrono AL, Nalebuff E A, Millender LH. Rheumatoid arthritis and other connective tissue diseases. In Green DP, Hotchkiss RN, Pederson WC, (Eds). Green's operative hand surgery, Vol. 2, 4th Ed Philadelphia: Churchill Livingstone, 1999.

3. Chantelot C, Fontaine C, Flipo RM, Migaud H, Le Coustumer F, Duquennoy A. Synovectomy combined with the Sauve'-Kapandji procedure for the rheumatoid wrist. J Hand Surg Br. 24B (4): 405, 1999.

4. Miller-Breslow A, Millender LH, Feldon PG. Treatment considerations in the complicated rheumatoid hand. Hand Clin 5: 279, 1989.

5. Barbier O, Saels P, Rombouts JJ, Thonnard JL. Long-term functional results of wrist arthrodesis in rheumatoid arthritis. J Hand Surg Br. 24 (1): 27, 1999.

6. Fourastier J, Le Breton Alnot Y, Langlais F, Condamine JL, Pidhorz L. La prothese totale radiocarpienne Guepar dans la chirurgie du poignet rheumatoide. A propos de 72 cas revus. Rev Chir Orthop Reparatrice Appar Mot 82 (2): 108, 1996.

7. Byrd HS. The use of subcutaneous axial fascial flaps in reconstruction of the head. Ann Plast Surg. 4: 191, 1980.

8. Brent B, Upton J, Acland RD, et al. Experience with the temporoparietal fascial free flap. Plast Reconstr Surg 76: 177, 1985. 
9. Smith R A. The free fascial scalp flap. Plast Reconstr Surg 66: 204, 1980.

10. Boeckx W. Clinical Microsurgery. In Marquet R, Hess F, Kort W, Boeckx W. Micro-surgery. Experimental techniques in the rat and clinical applications. Ghent, Belgium. European Press, 1976.

11. Harris GD, Finseth F, Buncke HJ. Posterior-wall-first microvascular anastomotic technique. $\mathrm{Br}$ J Plast Surg 34: 47, 1981.

12. Ryu J, Watson HK, Burgess RC. Rheumatoid wrist reconstruction utilizing a fibrous nonunion and radiocarpal arthrodesis. J Hand Surg 10A: 830, 1985.

13. Upton J, Rogers C, Durham-Smith G, Swartz W. Clinical applications of free temporoparietal flaps in hand reconstruction. J Hand Surg 11: 475, 1986. 
Chapter 6 - Horseshoe expanded scapular flap shows no venous congestion

F. De Lorenzi, R. R. W. J. van der Hulst, W. D. Boeckx

Br J Plast Surg 2001, 54(7): 604-9 


\section{Abstract}

The free scapular flap is a reliable solution when a relatively thin cutaneous flap is required, but its dimensions limit its use in large defects. The pre-transfer expansion of the flap has enlarged its clinical applications, but still with problems. In fact distal marginal venous congestion and subsequent partial necrosis of the flap can occur performing the conventional round shaped expansion of the flap.

In this paper we present a new pattern of flap pre-expansion: the "horse shoe" shaped expansion. The main reasons to perform this procedure and surgical details are described. Advantages and disadvantages over the conventional expanded free scapular flap are discussed. 


\subsection{Introduction}

In our experience the free scapular flap ${ }^{(1-5)}$ is a reliable solution when a relatively thin cutaneous flap is necessary to cover medium-sized defects. The flap has a constant vascular pedicle, which is of adequate length and diameter for microvascular anastomoses ${ }^{(1)}$. Flap dissection is quite easy. Donor site-morbidity is minimal since the donor area can be closed primarily to leave a scar that is cosmetically acceptable (although some widening occurs) and no functional deficiencies arise.

We performed scapular free flaps mostly for head and neck reconstructions ${ }^{(6)}$, where a relatively thin coverage is particularly desirable; the smallest flap measured $5 \times 20 \mathrm{~cm}$ and the largest $10 \times 25 \mathrm{~cm}$. The main indications were hypertrophic scars and scar contractures after burns.

However, although the flap colour and texture are suitable for burn repair, achieving a perfect colour match between the flap and the recipient area, flap dimensions are not sufficient in cases of extended burns. This limits the use of the scapular flap.

Nowadays, the scope of the scapular free flap is increased by using the principles of flap prefabrication ${ }^{(7)}$. Pre-transfer expansion of a flap generates additional specialised tissue and donor site morbidity can be reduced ${ }^{(8)}$. Pre-expansion of a scapular flap may be useful in selected patients in whom a large thin fasciocutaneous flap is required and where there is a sufficient time to allow flap expansion prior to transfer.

In our early experience we expanded the scapular flaps by using a round pattern of expansion, as described in the literature ${ }^{(8-11)}$. All flaps survived after transfer, but in three out of four flaps we observed marginal distal venous congestion and necrosis not related to the microvascular anastomoses. This complication has also been described by Russell et al. ${ }^{(11)}$.

No venous congestion and marginal distal necrosis were observed in our later cases in which an "horseshoe" pattern of expansion was used.

In this article, we present a refinement of the technique first proposed by Laitung and Batchelor in $1990{ }^{(9)}$ and largely used by Russell et al (11). The "horseshoe" pattern of scapular flap expansion is described and reasons for and advantages of using this procedure are discussed.

\subsection{Patients and methods}

Seven expanded scapular free flaps were performed (in six females and one male). The average age of the patients at the time of the first operation was 23,4 years (range: 8-34 years).

The flaps were used to cover defects in head and neck region in the majority of patients and the main indication was burn sequelae (Table 1). 


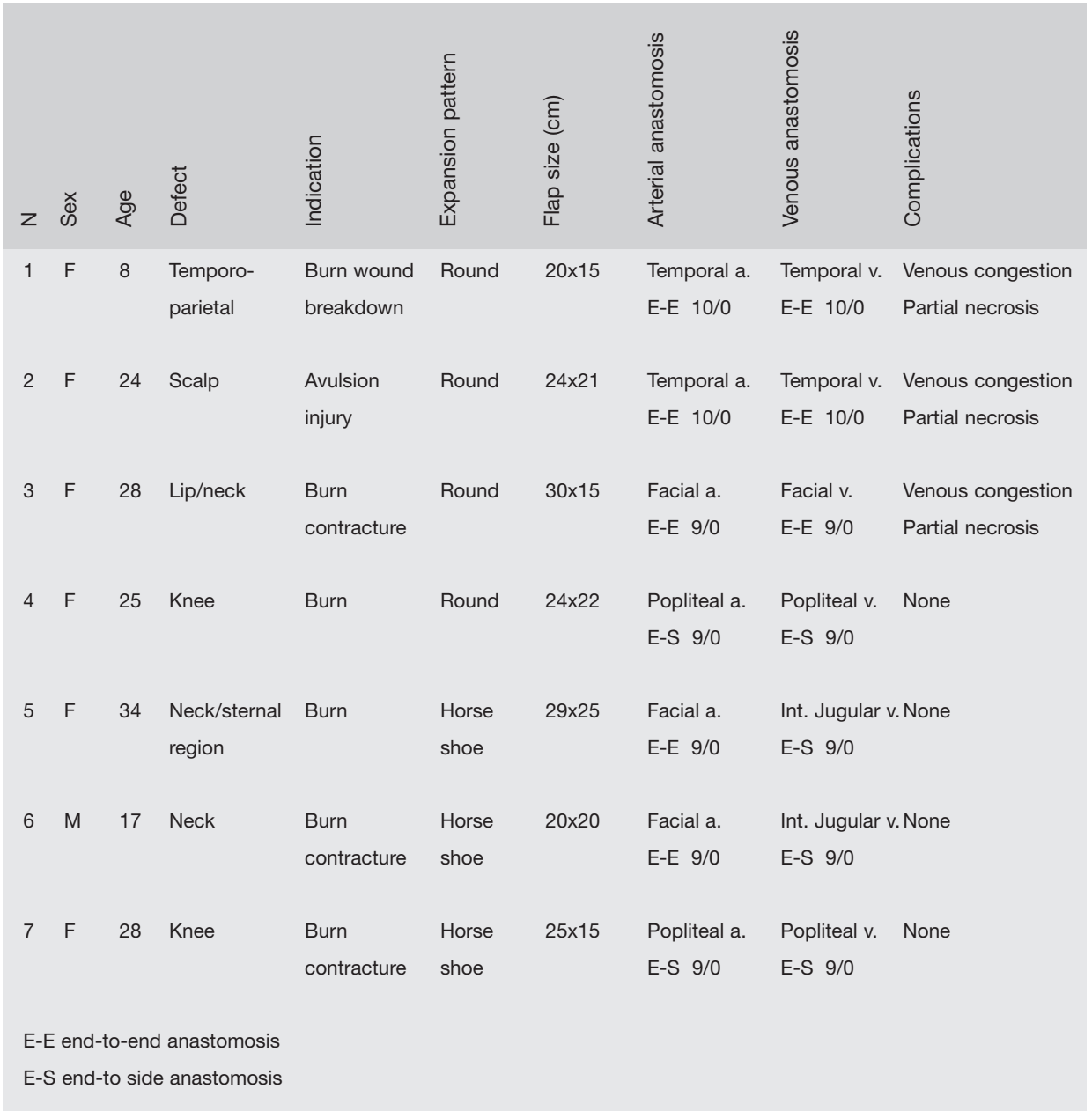

Tab. 1

The scapular flaps were expanded for 6 to 12 weeks prior to transfer with two different patterns: in four patients we performed a round shaped flap expansion and in three patients an "horseshoe" shaped expansion.

In the cases in which we used the round pattern of flap expansion, one round tissue expander was inserted into a subfascial pocket placed on top of the underlying latissimus dorsi, serratus and lower-back muscles, corresponding to the central part of the proposed scapular flap. A vertical midline incision was usually used to create the subfascial pocket.

In the cases of "horseshoe" shaped expansion, two or three different shaped tissue expanders were placed in the scapular region to create the "horseshoe" shape. They were croissant-shaped with sharp or blunt edges and were placed deep to the 

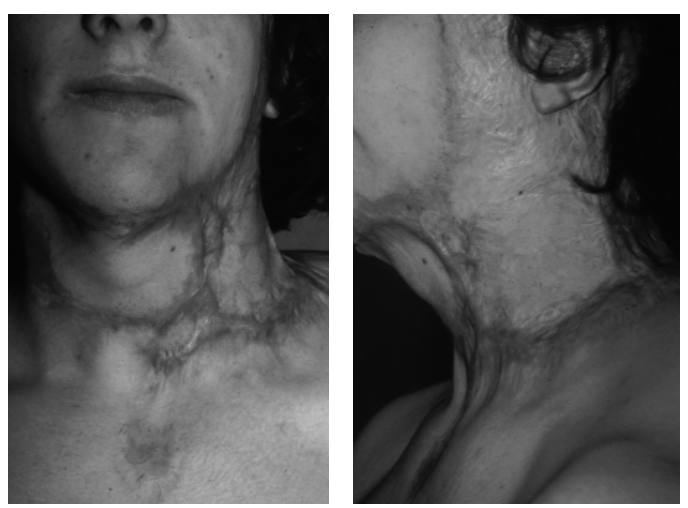

Fig 1. Preoperative views of a patient with severe neck contracture after burn injury.

superficial muscle fascia in an area corresponding to the peripheral borders of the conventional scapular flap. Two skin incisions, one medial and one lateral, were necessary to insert the expanders (Fig. 1).

In both series, the tissue expanders were placed without interfering with the vascular pedicle to be used for microvascular anastomoses.
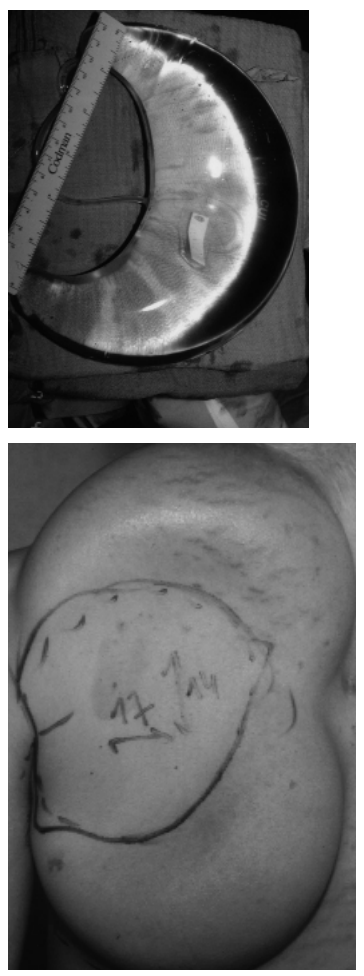
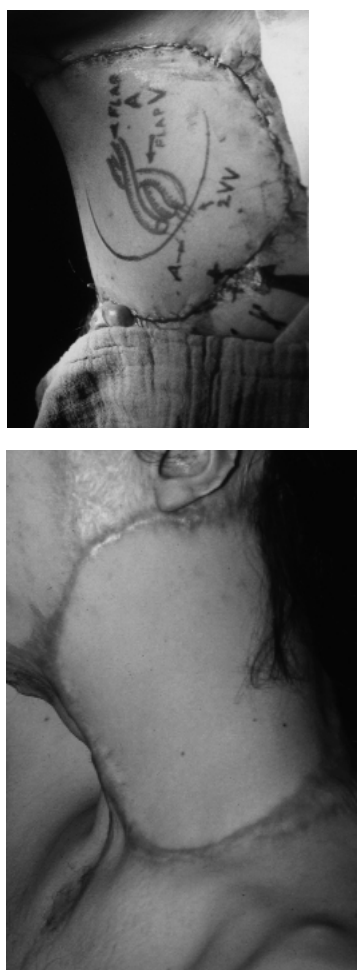

Fig. 1. (continued) The horseshoe-shaped tissue expander and after expansion. Immediate postoperative appearance and after 6 months. 
Expansion was begun 7 to 14 days after surgery with $50-100 \mathrm{ml}$ of saline added every 7 days, as tolerated by the patient. The flaps were over-expanded to create sufficient tissue for reconstruction and primary donor-site closure.

During the second surgical procedure, the scapular pedicle was first checked by a Doppler probe with the arm abducted 90o. The pedicle was dissected toward the circumflex scapular vessels which were used for microvascular anastomoses. Only when the scapular pedicle had been dissected for 4-5 cm and its distal branches had been visualised distally, did the dissection proceed at the distal pole of the flap. The capsule over the expander(s) was left attached to the inferior surface of the flap.

Different recipient vessels and different anastomotic techniques were used, as described in Table 1. Although the pedicle presented two comitant veins in four cases, one vein was dominant. In all cases, a single venous anastomosis was sufficient to guarantee good flap drainage. In all cases, we use a "posterior wall first" technique of anastomosis ${ }^{(12-13)}$. The donor area was closed primarily in all patients.

\subsection{Results}

Flap expansion was performed in all patients without complications.

All expanded free scapular flaps survived, but three out of four round-shaped expanded flaps experienced marginal distal venous congestion and, consequently, partial necrosis. None of the "horseshoe" expanded flaps showed venous congestion.

In patients who developed partial distal necrosis of the flap, secondary healing at the interface between the flap and the recipient area was achieved.

In all cases there were no complications related to the microvascular anastomoses that required surgical revisions of the anastomosed vessels. Regular Doppler probe monitoring of the anastomoses confirmed excellent flow.

During flap elevation, after expansion, we observed that an enlarged venous network
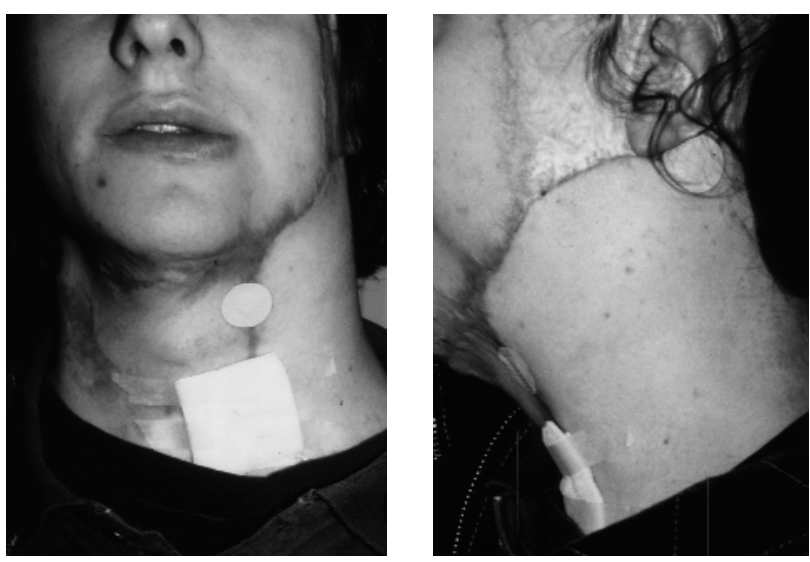

Fig. 1 (continued) Appearance after secondary scar correction 
was present in the distal and marginal portions of the round-shaped expanded flaps. Venous vessels were numerous but not large enough to be used for microvascular anastomoses. In practise, this resulted in a remarkable venous bleeding during dissection and the onset of venous congestion even before the pedicle was cut.

No increased venous bleeding was present during dissection of the marginal and distal parts of the "horseshoe" expanded flaps. In addition, we did not observed an enlarged venous network and there was no venous congestion when the flap was dissected free, within its pedicle still intact.

No complications were seen at the donor site after harvesting the expanded flaps.

\subsection{Discussion}

The clinical applications of flap prefabrication have largely increased reconstructive capabilities and overcome problems not solved satisfactorily by the available classical free flaps. Pre-transfer flap expansion enlarges the flap area and permits the transfer of a more extensive amount of tissue than in the case with the classical flap. Thus, much more extensive soft tissue defects can be repaired. In addition, donor site morbidity is reduced because, despite the large dimensions of the flap, primary closure is easily achieved. The clinical applications of these principles are supported by experimental studies in animals. Leighton et al. (1988) ${ }^{(14-15)}$ showed that axial pattern flap expansion augments arterial blood flow in pigs. They found that the maximum expansion occurs directly over the centre of the expander, and that the expansion decreases toward the periphery; the expanded skin has an increased vascularity. Angiography showed an enlargement of the vascular tree within the expanded flaps. Histology demonstrated a thinning in all soft tissue layers, which was more evident over the dome of the expanders and decreased toward the periphery. The adipose layer was most affected, being 30$50 \%$ thinner than the control flaps; , the epidermal thickness remained unchanged and thinning was minimal in the dermal layer. Moreover, the formation of new vessels was most apparent in the reticular dermis.

The venous network, largely studied by Taylor et al ${ }^{(16)}$, and its modification due to expansion have not been previously investigated. The venous network is a low-pressure vascular system and we suppose that the intraluminal pressure of the tissue expander compresses this network. The maximum amount of compression occurs directly over the dome of the expander, thus the venous drainage is interrupted in this area.

When performing a round-shaped flap expansion, the maximum amount of expansion occurs in the central portion of the flap, corresponding to the dome of the expander (Fig. 2). In this area the external physical forces associated with expansion compress venous vessels more strongly than in the periphery. Functionally, the venous drainage is partially or completely interrupted in the central part of the expanded flap, improving a centrifugal venous network. This is also seen in standard expanded flap where central infarction can occur. When the flap is harvested, the peripheral venous connections are interrupted and the major component of the venous drainage of the distal portion of the flap is lost. 


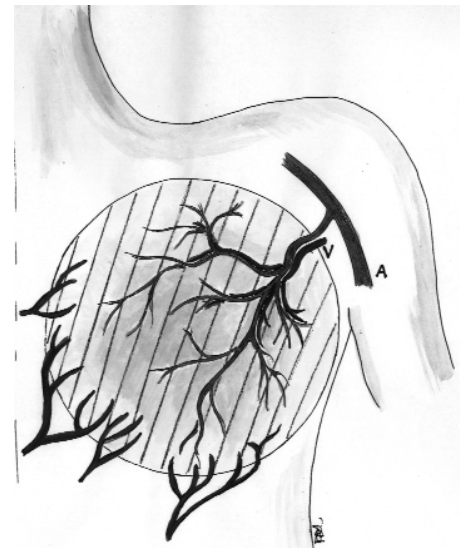

Fig. 2 Conventional round shape of expansion.
However, when performing a "horseshoe" shaped expansion of the scapular flap the maximum amount of expansion occurs at the periphery of the flap. This is the area of maximum venous compression, while in the central part of the flap no external forces interfere with venous network. Thus, this pattern of expansion reduces the centrifugal venous drainage of the flap and increases the axial venous return (Fig. 3), thereby acting as a delay phenomenon. In fact, if the peripheral venous connections are gradually interrupted by expansion, then when the scapular flap is harvested only a minimal part of the flap drainage is lost.

These theoretical ideas are confirmed by our intraoperative findings and clinical results. Bleeding is significant during the peripheral dissection of the round-shaped expanded flap. This is because the enlarged "centrifugal" venous network is interrupted, losing the main part of flap outflow. Bleeding is minor during peripheral dissection of the "horseshoe" expanded flap.

Three out of four round-expanded scapular flaps developed immediate venous congestion in the marginal distal portions even before the vascular pedicle was transected, resulting in distal partial necrosis over the subsequent postoperative days. None of the "horseshoe" expanded flaps showed this complication. Thus, in our opinion the main advantage of performing the "horseshoe" expanded scapular flap is improved flap viability, compared with the conventional method of central expansion.

A second advantage is that when a fasciocutaneous flap is "prefabricate" and inset without tension, less secondary contraction occurs. This is especially important when a concave surface has to be covered, as in neck region where previous burn scar contracture is often the indication for the free flap. Although flap viability is improved with the "horseshoe" expansion, the conventional round pattern of flap expansion is still preferred when a convex surface has to be reconstructed (as in scalp reconstruction, for example). This shape of expansion accurately reproduces the shape of the defect and perfectly fits the convex area. If distal partial necrosis occurs, secondary healing can be achieved by secondary contraction of the wound and secondary stretching of the flap (secondary 
expansion of the flap without tissue expanders). In future, we will perform a surgical delay of the round-expanded scapular flap to avoid distal marginal necrosis.

The main reason of expanding the scapular flap is to enlarge its area. The associated thinning of the flap is particularly useful in head and neck reconstructions, where a thin coverage is desirable, thus avoiding the need for subsequent liposuction or defatting. The main disadvantage of the "horseshoe" expanded flap is that the shape of the flap can be inconvenient if a convex area has to be covered. Another disadvantage is that the operative time is slightly longer if more than one tissue expander has to be inserted in the back to create the horseshoe-shape. In our opinion, these are minor problems.

In our series, alternative surgical solutions to repair such wide defects could be muscle flaps with skin grafts or myocutaneous flaps, such as latissimus dorsi or TRAM flap. We preferred the expanded scapular flap to muscle and myocutaneous flaps because the donor site morbidity is lower and a more satisfactory functional and aesthetic results can be achieved in head and neck region, avoiding the bulk of myocutaneous flaps, which cannot be reduced by liposuction or defatting. Here only debulking and a new split skin graft is possible.

The extended free scapular flap, first described by Thoma and Heddle in $1990{ }^{~(17)}$, and other technical variations (18-20) to lengthen the standard scapular flap are possible solutions if a relatively thin cutaneous flap is required.

\subsection{Conclusion}

In conclusion, the "horseshoe" expanded free scapular flap is a reliable solution for large defects. It overcomes the surgical inconveniences associated with the conventional round-shaped expanded scapular flap and the morbidity at the donor site is minimal. It is particularly recommended when a concave area has to be covered and secondary flap retraction has to be prevented.

\subsection{References}

1. Dos Santos LF. The vascular anatomy and dissection of the free scapular flap. Plast. Reconstr Surg 73(4): 599, 1984.

2. Barwick WJ, Goodkind DJ, Serafin D. The free scapular flap. Plast Reconstr Surg 69(5): 779, 1982.

3. Urbaniak JR, Koman A, Goldner RD, Amstrong NB, Nunley JA. The vascularized cutaneous scapular flap. Plast Reconstr Surg 69: 772, 1982.

4. Hamilton SGL, Morrison W A. The scapular free flap. Br J Plast Surg 35: 2, 1982.

5. Mayou BJ, Whitby D, Jones BM. The scapular flap; an anatomical and clinical study. Br J Plast Surg 35: 8, 1982.

6. Boeckx W, Fossion E, Guelinckx P, Demey R, Dewilde R. Free flaps in head and neck surgery. Acta Chir. Belg. 3: 219, 1982. 
7. Baudet J, Rivet D, Martin D, Boileau R. Prefabricated free flap transfers. In Proceedings of the 3rd Annual Meeting of the American Society for Reconstructive Microsurgery. San Antonio, Texas, Sept 12-13, 1987.

8. Khouri RK, Upton J, Shaw WW. Principles of flap prefabrication. Clin Plast Surg 19: 763, 1992.

9. Laitung JKG, Batchelor AG. Successful preexpansion of a free scapular flap. Ann Plast Surg 25:205, 1990.

10. Mayou BJ, Gault DT, Crock JG. Tissue expanded free flaps. Br J Plast Surg. 45: 413, 1992.

11. Russell RC, Khouri RK, Upton J, Jones TR, Bush K, Lantieri LA. The expanded scapular flap. Plast Reconstr Surg 96: 884, 1995.

12. Boeckx W. Clinical micro-surgery. In Marquet R, Hess F, Kort W, Boeckx W. Micro-surgery; experimental techniques in the rat and clinical applications. Ghent, Belgium. European Press, 1976.

13. Harris GD, Finseth F, Buncke HJ. Posterior-wall-first microvascular anastomotic technique. $\mathrm{Br}$ J Plast Surg 34: 47, 1981.

14. Leighton WD, Russell, RC, Marcus DE, Eriksson E, Suchy H, Zook EG. Experimental pretransfer expansion of free flap donor sites: I. Flap viability and expansion characteristics. Plast Reconstr Surg. 82: 69, 1988.

15. Leighton WD, Russell R C, Feller, AMDE, Eriksson E, Mathur A, Zook EG. Experimental pretransfer expansion of free-flap donor sites: II. Physiology, histology and clinical correlation. Plast Reconstr Surg 82: 76, 1988.

16. Taylor GI, Caddy CM, Watterson PA, Crock JG. The venous territories (venosomes) of the human body: experimental study and clinical implications. Plast Reconstr Surg 86: 185, 1990.

17. Thoma A, Heddle S. The extended free scapular flap. Br J Plast Surg 43: 709, 1990.

18. Batchelor AG, Bardsley AF. The bi-scapular flap. Br J Plast Surg 40: 510, 1987.

19. Angrigiani, C., Grilli, D. Total face reconstruction with one free flap. Plast Reconstr Surg 99: 1566, 1997.

20. Arnez ZM, Planinsek F, Ahcan U. Lateral extension of the free scapular flap. Br J Plast Surg 47: 268, 1994 
Chapter 7 - The free TRAM procedure in breast reconstruction: choice of vascular receptor site

W. D. Boeckx, F. De Lorenzi, P. N. Blondeel, R. R. W. J. van der Hulst

(submitted for publication) 


\section{Abstract}

In this study 70 consecutive cases of breast reconstruction with the use of a free Transverse Rectus Abdominal Myocutaneous (TRAM) flap were reviewed with respect to the type of recipient vessels. We describe our evolution of choice of the receptor vessels. The deep inferior epigastric artery was anastomosed to the thoracodorsal artery in 15 cases. In 55 cases the internal mammary artery was used as a recipient vessel. The deep inferior epigastric vein was anastomosed to the thoracodorsal vein in 15 cases, to the cephalic vein in eight cases, the external jugular vein in 16 cases and to the internal mammary vein in 31 cases. Total flap necrosis occurred in four cases. In an additional four cases there was partial necrosis requiring minor operative correction. In six cases venous outflow problems were the cause of flap necrosis. The external jugular vein $(n=3)$ and cephalic vein $(n=2)$ were relatively often involved in case of venous outflow problems. One flap could be rescued 5 days after surgery following venous thrombosis by applying a vein graft. The internal mammary artery and vein proved to be reliable and easy to access recipient vessels for anastomosing the vessels of the free TRAM. 


\subsection{Introduction}

Breast reconstruction after mastectomy has gone through a tremendous evolution over the last two decades. On the one hand the importance of the psychological impact of mastectomy has been acknowledged resulting in an increased demand for breast reconstruction. On the other hand new techniques have been developed which make it possible to reconstruct an aesthetically acceptable breast. One of these techniques is the Transverse Rectus Abdominis Myocutaneous flap (TRAM flap) which has found a definitive place within reconstructive breast surgery ${ }^{(1-4)}$. The procedure provides good aesthetic results and has a lower long term complication risk compared to the latissimus dorsi flap or the tissue-expansion procedure ${ }^{(5)}$.

In immediate reconstruction the TRAM procedure was shown to be aesthetically superior to other techniques ${ }^{(5)}$. Herniation, abdominal wall weakness and partial flap necrosis are less common in the free TRAM (FTRAM) compared to the pedicled TRAM flap. In addition shaping possibilities of the FTRAM are superior to the pedicled TRAM. For these reasons often the FTRAM flap is preferred ${ }^{(6-14)}$. The FTRAM method requires harvesting of a small part of the rectus abdominis muscle including the perforating vessels of the deep inferior epigastric artery and veins. In addition, the development of perforator flaps led to the DIEP (deep inferior epigastric perforator) flap which is a sophistication of the FTRAM flap ${ }^{(15-18)}$. Dissection of only the perforating vessels within the muscle diminishes the amount of muscle that has to be sacrificed, further decreasing donor morbidity ${ }^{(19-20)}$. The vessels of the FTRAM/DIEP flap have to be connected to recipient vessels in the thoracic area. There are several possible acceptor arteries and veins for the FTRAM ${ }^{21-26)}$. The thoracodorsal, subscapular, and internal mammary artery can be used as arterial receptors, whereas the thoracodorsal, cephalic, external jugular and internal mammary vein may serve as venous receptors. In this study we describe our evolution in the choice of the different vascular receptor arteries and veins. The advantages and disadvantages of the vascular receptor sites will be discussed.

\subsection{Material and Methods}

The files of all patients who underwent a FTRAM flap procedure between August 1988 and January 1998 in the Sint Pieter University Hospital in Leuven were retrospectively reviewed. There were no patients excluded from the study. In 64 patients 70 breast reconstructions by means of a FTRAM flap was performed. Mean age of the patients was 44 years and varied between 27 and 66 years (SD 8,2).

The following data were collected: type of anastomosis, operation time, smoking, and postoperative complications. Postoperative complications were classified as flap related or general complications Reasons for mastectomy, type of mastectomy, tumor classification, and previous radiotherapy or chemotherapy were also studied (Tab. 1). 


$\begin{array}{ll}\text { Tumour classification } & \text { Breasts } \\ \text { Carcinoma in situ } & 2 \\ \text { T1 } & 6 \\ \text { T2 } & 17 \\ \text { T3 } & 19 \\ \text { T4 } & 2 \\ \text { Unknown } & 24 \\ \text { Chemotherapy } & \\ \text { Yes } & 29 \\ \text { No } & 30 \\ \text { Unknown } & 11 \\ \text { Radiotherapy } & \\ \text { Yes } & 41 \\ \text { No } & 18 \\ \text { Unknown } & 11\end{array}$

Table 1. Tumour classification and adjuvant treatment.

A standard operative procedure was followed. The operation was performed in two teams. Whilst the first team removed the scar tissue and prepared the recipient vessels, the second team harvested the flap. Flaps were dissected with preservation of the periumbilical perforators and as much rectus fascia as possible. The amount of muscle included in the flap was kept small. The entire flap was used for reconstruction. After performing the microvascular suturing and positioning of the flap, the rectus abdominis muscle was fixed to the pectoralis major muscle. Final shaping of the breast was performed subsequently. Postoperatively, flaps were monitored clinically and by means of unidirectional Doppler flowmetry. Patients were mobilised on the first postoperative day, and external abdominal support was given for at least six weeks. In the beginning no Vicryl mesh were used. In the last 28 cases a Vicryl mesh was used to strengthen the abdominal wall.

\subsection{Results}

In 58 patients the reconstruction was unilateral. In the majority of the patients a delayed reconstruction was performed (62 cases). 68 times mastectomy was done because of breast cancer. Mastectomy was performed twice because of cystic mastopathy. Modified radical mastectomy was performed in 65 cases. The remaining patients were treated by radical mastectomy (2), subcutaneous mastectomy (1), and lumpectomy (2). 33 cases patients smoked at the time of the reconstruction. Tumour classification for the first 55 cases is shown in Table 1. In 13 cases tumour classification was not known or conflicting due to primary surgery elsewhere.

The abdominal sheath could be primarily closed in 42 cases. In 28 cases a mesh was 
used. Initially in three patients a Mersilene mesh was used. In the following 25 operations we used a Vicryl mesh to close the abdominal wall defect. The majority of the arterial anastomoses $(n=55)$ were performed on the internal mammary artery. Other anastomoses were done to the thoracodorsal artery. The vein was anastomosed to the internal mammary vein $(n=31)$, the thoracodorsal vein $(n=15)$, the cephalic vein $(n=8)$, and the external jugular vein $(n=16)$. Operation time varied from $4 \mathrm{~h} 10$ minutes to $10 \mathrm{~h}$ and 45 minutes, with a progressive decrease of operation time during the course of this study. Flap necroses occurred in four of 70 flaps (6.8\%). An additional four flaps showed signs of partial necrosis, requiring minor operative correction. In two of these cases total necrosis was prevented by reintervention. In one flap there was leakage of the cephalic vein that could be solved by an additional stitch. In the other case the internal mammary vein proved to be too small and a venous graft between the deep inferior epigastric artery and a more proximal dissected part of the mammary vein was used to overcome the problem. In the remaining two flaps with partial necrosis, reintervention was not performed. However, it was clear that venous congestion was the cause of the problem. In one case reintervention five days after surgery rescued the flap. Thrombosis of the venous anastomosis (internal mammary vein) was treated by extensive dissection and venous graft interposition again between the flap vessel and a more proximal internal mammary vein. The causes of total flap failure were: thrombosis of thoracodorsal artery, thrombosis of internal mammary artery, thrombosis of external jugular vein, and leakage of a cephalic vein anastomosis with hematoma and thrombosis of the vein. Taken total and partial flap necrosis, and flap rescue together, a total of nine flap related problems were seen in our series. Of these, flap failure was caused four times by insufficiency of the venous anastomosis. The external jugular vein was most frequently involved in causing flap necrosis (three out of 16 external jugular vein anastomosis, 19\%). The cephalic vein anastomosis was two times insufficient and resulted in flap necrosis (25\% of all external jugular vein anastomosis). In two cases the internal mammary vein was the cause of thrombosis (6\% of all internal mammary vein anastomosis). Only one mammary artery was involved in causing flap necrosis $(2 \%)$ and one case was attributed to the thoracodorsal artery (7\%) (Tab. 2).

Minor complications after the TRAM procedure were wound dehiscence in a patient with severe radiofibrosis, and one patient with a fistula due to osteomyelitis. In one patient partial fat necroses became apparent some weeks after surgery. Abdominal wall herniation was described in 6 cases. In one patients an abdominal wall seroma was observed which could be treated with needle puncture. Major complications were observed in four patients. Two patients were transferred to the intensive care unit because of pneumonia within four days after surgery. Both cases responded well to intravenous antibiotics. One patient was treated for lung-oedema and another patient developed an adrenal bleeding postoperatively which was treated conservatively. 


\begin{tabular}{|c|c|c|c|c|}
\hline $\begin{array}{l}\text { Arterial } \\
\text { anastomosis }\end{array}$ & $\begin{array}{l}\text { Venous } \\
\text { anastomosis }\end{array}$ & necrosis & Cause of failure & Revision \\
\hline Int mammary a & Ext jugularis & partial & Venous congestion & Minor correction \\
\hline Int mammary a & Ext jugularis & partial & Venous congestion & Minor correction \\
\hline Int mammary a & Int mammary $v$ & partial & Vein too small & $\begin{array}{l}\text { Successful revision with venous } \\
\text { graft }+ \text { secondary minor correction }\end{array}$ \\
\hline Int mammary a & Cephalic v & partial & Leakage vein & $\begin{array}{l}\text { Successful revision + secondary } \\
\text { minor correction }\end{array}$ \\
\hline Int mammary a & Cephalic v & total & $\begin{array}{l}\text { Kinking and leakage } \\
\text { vein }\end{array}$ & Primary closure \\
\hline Int mammary a & Ext jugularis $v$ & total & Calibre mismatch vein & Primary closure \\
\hline Thoracodorsal a & Thoracodorsal v & total & Torsion vessels & Latissimus dorsi \\
\hline Int mammary a & Cephalic v & total & Thrombosis artery & Latissimus dorsi \\
\hline Int mammary a & Int mammary $v$ & rescued & Thrombosis vein & Vein interposition \\
\hline
\end{tabular}

Table 2. Type of anastomosis and complications.

\subsection{Discussion}

Although initial reports demonstrated excellent results of the pedicled TRAM flap ${ }^{(1,2)}$, later publications showed a considerable complication rate ${ }^{(3,11)}$. In anatomical studies it was shown that the superior epigastric artery and vein do not sufficiently supply the lower abdomen, which explains the poor results of the pedicled TRAM flap ${ }^{(6,7)}$. The free TRAM flap in which the inferior epigastric artery is used to perfuse the flap was developed and showed a lower complication rate. The avoidance of torsion and traction of the vascular pedicle and the better anatomical distribution of the blood supply of the free TRAM has made this flap a reliable option for breast reconstruction nowadays.

Although the complication rate of the free TRAM is less compared to the pedicled TRAM, the free TRAM is not without complications, as demonstrated in our study. The total complication risk of $34 \%(22 / 64)$ is high, but included a majority of minor complications such as abdominal seromas treated with puncture. In addition, it is remarkable that a substantial number of postoperative complications were not directly related to the flap surgery itself. Three patients developed major pulmonary complications. In one of these patients bilateral reconstruction was performed. In another patient with bilateral reconstruction an adrenal bleeding complicated the postoperative course. The relative high rate of non-surgical complications in patients with bilateral reconstructions (2/6 in the bilateral group compared to $2 / 58$ in the unilateral group) indicates that the operation time increased the risk of developing postoperative non-surgical complications, and should be considered in making the operative plan.

We started to perform free TRAM procedures in 1988 using the internal mammary artery as receptor artery. The literature at that time showed that the internal mammary vein was not always suitable for anastomosis ${ }^{(27)}$ (Fig.1). 


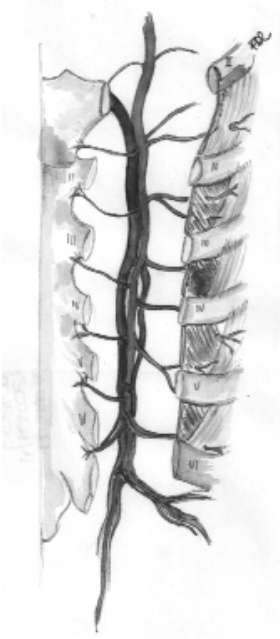

Fig 1. Schematic drawing of the internal mammary vessels.
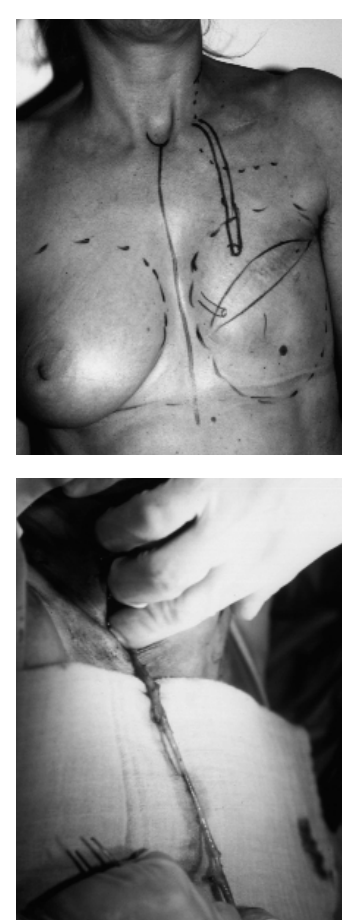

In the first 19 TRAM's in which the internal mammary artery (IMA) was used the venous anastomosis was performed using either the jugular vein or the cephalic vein (Fig. 2). This was however not always without problems as seen in the relatively high incidence of these veins in venous congestion problems. In 1993 we started using the internal mammary vein as a venous receptor vessel. At that time we still performed the dissection of the IMA and internal mammary vein (IMV) at the $6^{\text {th }}$ intercostal space. Until 1995 we frequently had problems because at this location we frequently found two relatively small veins. This was the main reason to adjust our technique and we started to perform dissection at the $4^{\text {th }}$ intercostal rib space. Although still in $70 \%$ of the cases there is a double venous system at this location the veins are bigger and it is easier to perform an anastomosis ${ }^{(25)}$. Nowadays, we therefore perform routinely anastomoses on the IMA and IMV at the $4^{\text {th }}$ intercostal space (fig 3). Only during immediate reconstruction we use the thoracodorsal system, because this is already dissected by the general surgeon.
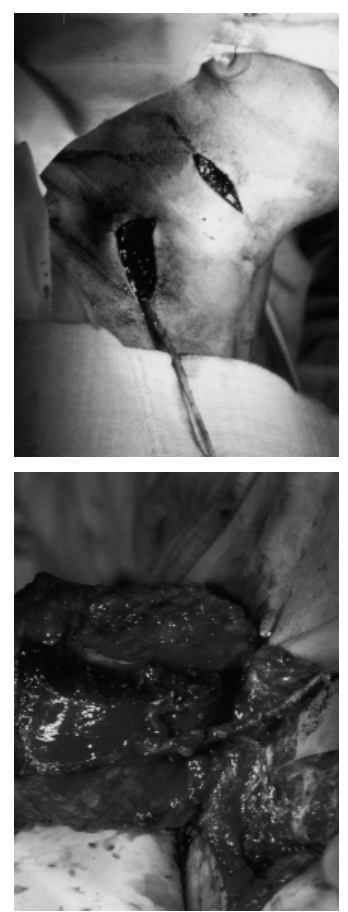

Fig. 2. A) Preoperative drawing in patient in which the external jugular vein is used. Excision of the mastectomy scar is marked as well as the internal mammary artery and external jugular vein. $B+C$ ) After dissection of the external jugular vein, it is tunnelled towards the sternum and sufficient length can be obtained. D) After anastomosis of the internal mammary artery and cephalic vein with the flap vessels. 


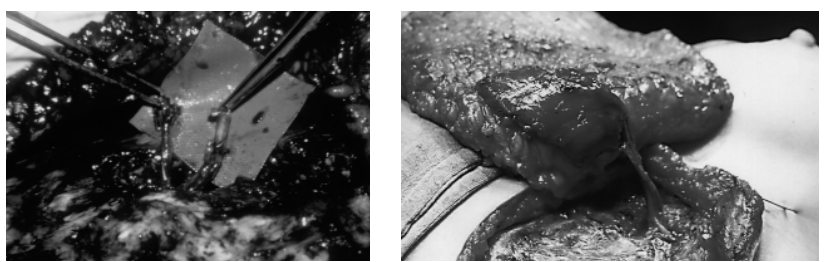

Fig. 3 The internal mammary artery and vein are shown after dissection. The TRAM flap is anastomosed to the internal mammary artery and vein.

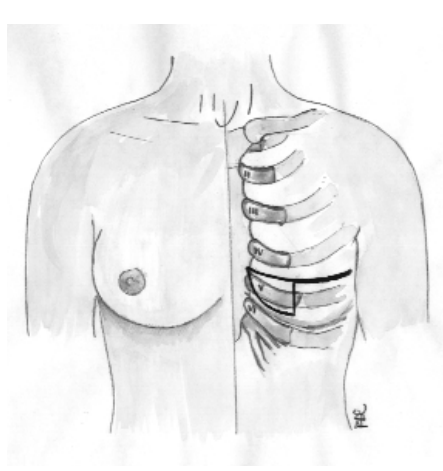

Fig. 4. Subcutaneous tissue and superficial muscle medially removed in the mastectomy scar.
The dissection of the IMA is performed in the following way. A small amount of skin, subcutaneous tissue and superficial muscle medially in the mastectomy scar is removed (Fig. 4).

Perforators from the IMA are identified to localise the vessels. Between the $3^{\text {rd }}$ and $4^{\text {th }}$ costal cartilage, lateral to the sternum, part of the intercostal muscles is removed (fig. 5).

We do not routinely perform a resection of the complete rib cartilage for exposure of the vessels, because this may result in pain complaints. We prefer to enlarge the intercostal space by partial resection of the cranial and caudal rib cartilages. Damage of the posterior perichondrium is avoided. Next, the posterior intercostal membrane is incised with a knife (fig. 6), giving access to the internal mammary vessels that lie very closely to this membrane (fig. 7 ).

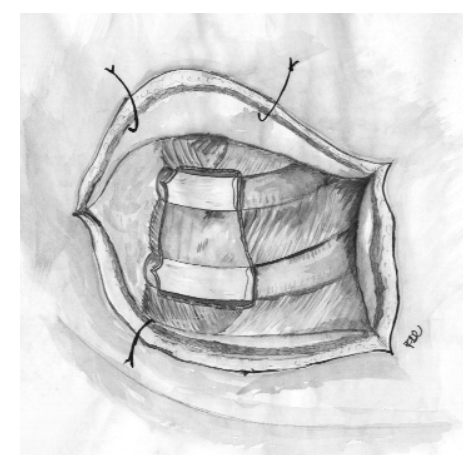

Fig. 5. Intercostal muscles are removed.

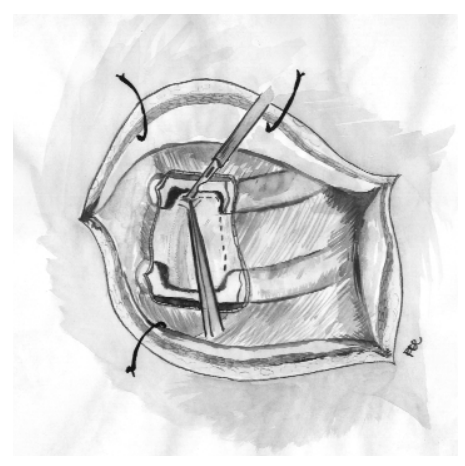

Fig. 6. Incision of the posterior intercostal membrane. 


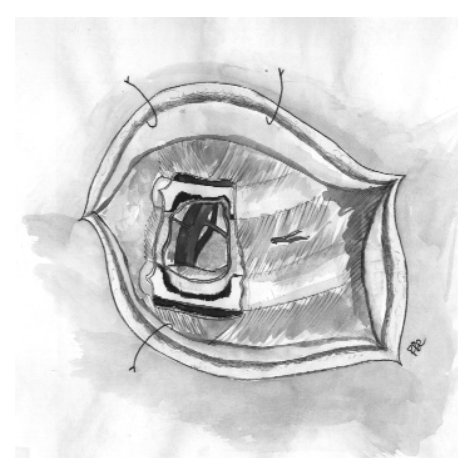

Fig. 7. Exposure of the internal mammary vessels.
This creates exposure of the vessels over a distance of about 3 centimeters. This allows easy placement of

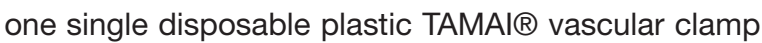
(Bear Co., Tokyo, Japan). We did not observe pleural problems in our series such as pneumothorax or hematothorax.

The central position of the anastomosis on the thorax offers a more comfortable and easy position for performing the microsurgical anastomoses without the need of repositioning the patient. In addition, the anatomy of the internal mammary vessels is constant and reliable ${ }^{(17)}$. Furthermore, the central position of the recipient vessels allows better shaping of the flap, making it possible to place the flap in horizontal as well

as in vertical direction. In most cases the flap was placed in a hammock shaped fashion allowing good projection and natural ptosis. This overcomes one of the inconveniences of using the thoracodorsal axis as receptor vessels. Lateral fullness and deficient medial fullness of the reconstructed breast frequently occur.

The operating time was not different for the different techniques used. In addition, the IMA anastomosis was shown to be a reliable alternative to the axillary vessels. Only in one case thrombosis of this artery was observed. It is remarkable to notice that venous failure was relatively more often observed after the use of the external jugular vein or cephalic vein compared to the internal mammary vein. When using an axillary approach (e.g. in immediate reconstruction) the comitant vein of the thoracodorsal artery is used as the venous recipient vessel. However, the major disadvantage of the axillary vessels is the possible damage after radiotherapy or dissection by the general surgeon. Therefore, in some cases the vein is not suitable and the cephalic vein has to be used. In our series the cephalic vein proved to be less reliable compared to the other recipient vessels. This is explained by the large diameter of the cephalic vein that leads to low flow conditions. The increase of vessel diameter behind the anastomosis will cause stasis and increase the risk of thrombosis. The external jugular vein can also be used as a venous recipient vessel. Dissection takes place through small incisions in the cervical region at regular distances. The vein is then tunnelled from one incision to another. The vessel is reliable although care has to be taken that kinking of the vessel cannot occur during the tunnelling of the vessel. Kinking is the most prominent disadvantage of this vein. The internal mammary vein was in our series most frequently used as recipient vessel. The vein is very reliable as demonstrated by the fact that thrombosis of this vein was only observed once. In most cases there are two internal mammary veins of which one is dominant. Only one venous anastomosis is sufficient to achieve satisfactory venous outflow. Rarely there is insufficient venous drainage that can be successfully overcome by performing an $\mathrm{Y}$ shaped anastomosis ${ }^{(28)}$.

In this study several recipient axis for the free TRAM were compared. In conclusion we state that the internal mammary vessels are suitable for anastomosing free abdominal 
flaps. Dissection of these vessels proves to be relatively easy and the vessels showed to be reliable recipient vessels. If, in immediate reconstructions, axillary vessels are prepared as part of a lymph node resection, these vessels are used as recipient vessels.

\subsection{References}

1. Hartrampf CR, Scheflan M, Black, PW. Breast reconstruction following mastectomy with a transverse abdominal island flap. Anatomical and clinical observations Plast Reconstr Surg 69: 216, 1982.

2. Hartrampf $\mathrm{CR}$, Bennet GK. Autogeneous tissue reconstruction in the mastectomy patient: $A$ critical review of 300 patients. Ann Surg 205: 508, 1987.

3. Watterson PA, Bostwick J, Hester TR, Bried JT, Taylor GI. TRAM flap anatomy correlated with a 10-year clinical experience with 556 patients. Plast Reconstr Surg 95: 1185, 1995.

4. Holmström $\mathrm{H}$. The free abdominoplasty flap and its use in breast reconstruction. Scand J Plast Reconstr Surg 13: 423, 1979.

5. Kroll SS, Baldwin BJ. A comparison of outcomes using three different methods of breast reconstruction. Plast Reconstr Surg 90: 455, 1992.

6. Taylor GI, Corlett RJ, Boyd JB. The versatile deep inferior epigastric (inferior rectus abdominis) flap. Br J Plast Surg 37: 330, 1984.

7. Boyd JB, Taylor GI, Corlett, R. The vascular territories of the superior epigastric and deep inferior epigastric system. Plast Reconstr Surg 73: 1, 1984.

8. Friedman RJ, Argenta LC, Anderson R. Deep inferior epigastric free flap for breast reconstruction after radical mastectomy. Plast Reconstr Surg 76: 455, 1985.

9. Arnez ZM. Free TRAM flap for breast reconstruction (letter). Plast Reconstr Surg 84: 1009, 1989.

10. Feller AM, Horl, H. W., Biemer, E. The transverse rectus abdominis musculocutaneous free flap: A reliable alternative for delayed autologous tissue breast reconstruction. Ann. Plast. Surg. 25: 425, 1990.

11. Grotting JC, Urist MM, Maddox W A, et al. Conventional TRAM flap versus free microsurgical TRAM flap for immediate breast reconstruction. Plast Reconstr Surg 87: 470, 1991.

12. Elliott LF, Eskenazi L, Beegle, PH, Podres PE, Drazan L. Immediate TRAM flap breast reconstruction: 128 consecutive cases. Plast. Reconstr Surg 92: 217, 1993.

13. Baldwin BJ, Schusterman MA, Miller MJ, Kroll SS, Wang B. Bilateral breast reconstruction: conventional versus free TRAM. Plast. Reconstr. Surg. 93: 1410, 1994.

14. Banic A, Boeckx WD, Greulich M, Guelinckx P, Marchi A, Rigotti G, Tschopp H. Late results of breast reconstruction with free TRAM flaps: a prospective multicentre study. Plast Reconstr Surg 95: 1203, 1995.

15. Blondeel Ph, Boeckx, WD. Refinements in free flap breast reconstruction: the free bilateral deep inferior epigastric perforator flap anastomosed to the internal mammary artery. Br J Plast Surg 47: 495, 1994.

16. Allen RJ, Treece P. Deep Inferior Epigastric Perforator flap for breast reconstruction. Ann Plast Surg 32: 32-8, 1998.

17. Blondeel Ph. One hundred free DIEP flap breast reconstructions: a personal experience. $\mathrm{Br} \mathrm{J}$ 
Plast Surg 52: 104-111, 1999.

18. Hamdi M, Weiler-Mithoff EM, Webster MH. Deep inferior epigastric perforator flap in breast reconstruction: experience with the first 50 flaps. Plast Reconstr Surg 103: 86-95, 1999.

19. Blondeel Ph, Boeckx WD, Vanderstraeten Lysens R, Van Landuyt K, Tonnard P, et al. The fate of the oblique abdominal muscles after free TRAM flap surgery. Br J Plast Surg 50: 315-21, 1997

20. Blondeel PhN, Vanderstraeten GG, Monstrey SJ, Van Landuyt K, Tonnard P, Lysens R, et al. The donor site morbidity of free DIEP flaps and free TRAM flaps for breast reconstruction. Br J Plast Surg 50: 322-30, 1997.

21. Arnez ZM, Valdatta L, Tyler MP, Planinsek F. Anatomy of the internal mammary veins and their use in free TRAM flap breast reconstruction. Br J Plast Surg 48: 540, 1995.

22. Ninkovic M, Anderl H, Hefel L, Schwabegger A, Wechselberger G. Internal mammary vessels: a reliable recipient system for free flaps in breast reconstruction. Br J Plast Surg 48: 533, 1995.

23. Hefel L, Schwabegger A, Ninkovic M, Wechselberger G, Moriggl B, Waldenberger P. Internal mammary vessels: anatomical and clinical considerations. Br J Plast Surg 48: 527, 1995.

24. Dupin CL, Allen RJ, Glass CA, Bunch R. The internal mammary artery and vein as a recipient site for free-flap breast reconstruction: a report of 110 consecutive cases. Plast Reconstr Surg 98: 685, 1996.

25. Clark CP, Rohrich RJ, Copit S, Pittman E, Robinson J. An anatomic study of the internal mammary veins: clinical implications for free-tissue-transfer breast reconstruction. Plast Reconstr Surg 99: 400, 1997.

26. Feng LJ. Recipient vessels in free-flap breast reconstruction: a study of the internal mammary and thoracodorsal vessels. Plast Reconstr Surg 99: 405, 1997.

27. Shaw WW. Breast reconstruction by superior gluteal microvascular free flaps without silicone implants. Plast Reconstr Surg 72: 490, 1983.

28. Boeckx W. Clinical micro-surgery. In Marquet R, Hess F, Kort W, Boeckx W. Micro-surgery. Experimental techniques in the rat and clinical applications. Ghent, Belgium. European Press, Pp. 192-194, 1976. 


\section{Chapter 8 - Free flaps in burn reconstruction}

F. De Lorenzi, R. van der Hulst, W. Boeckx

Burns 2001, 27: 603-12 


\section{Abstract}

In this paper we present our experience of free flap reconstructions in burned patients. It allows the preservation of otherwise unsalvageable deep burn injuries and secondary correction of contracted burn scars.

We analyse the indications of different free flaps, according to different anatomic regions and defects: depth and width of the loss of tissue, different colour skin, texture and thickness of the receptor area, weight-bearing or not weight-bearing surface.

Free flap reconstructions were successful in 50 of 53 cases (94\%). They provide good aesthetic and functional results with low morbidity both in acute deep burn injuries as in delayed reconstructions. 


\subsection{Introduction}

The majority of acute burn wounds undergoing surgical treatment require the excision of burn eschar and split skin grafting ${ }^{(1)}$. However, the introduction of free microvascular tissue transfer has allowed the preservation of otherwise unsalvageable deep burn injuries, when vital tissues such as nerves, arteries, veins, bones, tendons or joints are exposed ${ }^{(1-3)}$. Moreover, free flaps can be essential in secondary correction of contracted burn scars.

In burn injuries large areas of skin may be damaged, scarred or retracted, due to the specific wound healing and contraction after burn injury. Hypertrophic scar formation is a common sequel, beginning about 3 weeks after final wound closure and being most exuberant by the 3rd till the 6th month.

In reconstructive burn surgery, full thickness grafts or local skin flaps can be used. Reconstruction of burned scars is often difficult, due the lack of skin elasticity at the site of the contraction, avoiding rotation or transposition of local tissue. Thus, burn sequelae can be safely treated with "en block" resection and resurfacing using a free flap ${ }^{(1,4,5,6)}$. Tissue expansion offers an alternative procedure for resurfacing ${ }^{(7)}$, but it is not always available.

In this study we wanted to analyse the precise indications for 53 free flap burn reconstructions in 39 patients in the period of 1976-1996. In this period 2,400 acute burns were treated, only $1,8 \%$ requiring free flap burn reconstructions.

\subsection{Materials and methods}

Between 1976 and 1996, 39 patients with burn injuries underwent soft tissue reconstruction of different regions with 53 free flaps.

The patients, 28 men and 11 women, ranged in age from 7 to 62 years (mean 30,4 years) (Table 1).

Indication for surgery included acute burn injuries with vital tissues exposure in four patients and reconstructive procedures after contracture release in 35 patients.

\begin{tabular}{|c|c|c|}
\hline & Numbers of flaps & Numbers of patients \\
\hline$<10$ years & 6 & 4 \\
\hline $11-20$ year & 8 & 5 \\
\hline 21-30 year & 9 & 8 \\
\hline $31-40$ year & 15 & 14 \\
\hline $41-50$ year & 11 & 5 \\
\hline $51-60$ year & 2 & 2 \\
\hline \multirow[t]{2}{*}{$61-70$ year } & 2 & 1 \\
\hline & $n=53$ & $\mathrm{n}=39$ \\
\hline
\end{tabular}


The defects were placed in the majority of cases in the hand, inferior limb-foot and head and neck region (Table 2).

\begin{tabular}{llll} 
Hand: & $\mathrm{n}=24$ & $\begin{array}{l}\text { Bone exposed: } 8 / 24 \\
\text { Retracted joint: } 16 / 24\end{array}$ & $\begin{array}{l}33 \% \\
66 \%\end{array}$ \\
& & Hair loss: $1 / 15$ & $6 \%$ \\
Head and neck: & $\mathrm{n}=15$ & Scar contraction: $11 / 15$ & $73 \%$ \\
& & Loss of nose: $2 / 15$ & $13 \%$ \\
& & Osteomyelitis: $1 / 15$ & $6 \%$ \\
\hline Lower leg: & $\mathrm{n}=11$ & Bone exposed: $9 / 11$ & $81 \%$ \\
& & Contracted scar: $2 / 11$ & $18 \%$ \\
Upper limb: & $\mathrm{n}=3$ & Bone exposed: $2 / 3$ & $66 \%$ \\
& & Retracted joint: $1 / 3$ & $33 \%$ \\
\hline
\end{tabular}

Table 2. Indications for free flap cover in burn reconstructions.

We performed different free flaps according to different anatomic regions and defects: depth and width of the loss of tissue, different colour skin, texture and thickness of the receptor area, weight-bearing or not weight-bearing surface (Table 3).

Follow up ranged from 18 months to 10 years.

\begin{tabular}{|c|c|c|}
\hline Type of flap & n (total 53) & Receptor area \\
\hline \multirow[t]{2}{*}{ Arterialized venous flap } & \multirow[t]{2}{*}{17} & Hand (16/17) \\
\hline & & Upper limb (1/17) \\
\hline \multirow[t]{3}{*}{ Temporalis fascia } & \multirow[t]{3}{*}{11} & Leg and foot $(7 / 11)$ \\
\hline & & Hand $(3 / 11)$ \\
\hline & & Head and neck (1/11) \\
\hline \multirow[t]{3}{*}{ Scapular } & \multirow[t]{3}{*}{6} & Head and neck (4/6) \\
\hline & & Hand (1/6) \\
\hline & & Foot $(1 / 6)$ \\
\hline \multirow[t]{3}{*}{ Expanded scapular } & \multirow[t]{3}{*}{5} & Head and neck $(3 / 5)$ \\
\hline & & Thorax (1/5) \\
\hline & & Inferior limb (1/5) \\
\hline \multirow[t]{2}{*}{ Latissimus dorsi } & \multirow[t]{2}{*}{3} & Foot $(2 / 3)$ \\
\hline & & Upper limb (1/3) \\
\hline \multirow[t]{2}{*}{ Lateral arm } & \multirow[t]{2}{*}{3} & Hand $(2 / 3)$ \\
\hline & & Upper lip (1/3) \\
\hline Lateral forearm (Chinese) & 4 & Head and neck (4/4) \\
\hline 2nd toe transfer & 2 & Hand (2/2) \\
\hline Tensor fascia lata & 1 & Neck (1/1) \\
\hline Gracilis muscle & 1 & Upper limb (1/1) \\
\hline
\end{tabular}

Table 3. Different free flaps for different recipient areas. 
In the Head+Neck area: 15 free flaps were performed in 15 patients. All flaps were secondary reconstructions.

In seven cases a reconstruction of a contracted neck burn scar was performed using a scapular free flap.

Seven scapular flaps were used from which three had been expanded 3 months prior to their transfer.

Four radial forearm flap (Chinese flaps) were performed.

In 11 out of 15 cases, a contracted neck burn scar was the indication for the free flap. 10 large size flaps were necessary (average 20 by $15 \mathrm{~cm}$ ), therefore the expanded scapular free flap was used three times, together with four scapular free flap and four Chinese free flaps. A single tensor fascia lata flap had to be defatted twice.

Circumferential scar contracture around these free flaps required further $Z$ plasties and defatting especially at the posterior edges of the flaps.

In the lower leg: 11 free flaps were used.

In nine cases the bone was exposed.

The temporal fascia was used in seven out of 11 cases because it being the thinnest flap available.

Covering the flap with a split skin graft in the lower leg did not result in a contracted scar but improved the contour of the foot and leg, especially on the heel and dorsum of the foot.

A latissimus dorsi free flap without skin island but covered with a split skin graft was used in high tension electrical burn of the foot.

In the upper limb three cases were treated with a muscle free flap when a high tension electrical burn had exposed the bone.

In hand burns: (24 cases) there were eight cases of electrical burns only two being a high voltage burn, requiring a second toe transfer.

Low voltage hand burn contractures or palmar burns were treated with a lateral arm or temporal fascia free flaps (five cases). When electrical finger burns were encountered in six cases out of six a venous free flap was used.

In contracted MCP, PIP joints the venous free flap was the flap of choice in 10 out of 16 cases. On dorsal MCP joints involving the II till V finger a $14 \mathrm{~cm}$ long antebrachial venous free flap was used successfully. A $28 \mathrm{~cm}$ long saphenous venous free flap was used to correct an adducted wrist and first webspace, palm of the hand and retracted MCP II till $\mathrm{V}$ lesion. Here in the distal part the skin was lost requiring a new split skin graft 3 weeks later.

\subsection{Operative technique}

Basic microvascular technique.

In order to transfer a free flap safely, it should include an arteriovenous network nourished by a feeding artery and a draining vein. Ideally this arteriovenous capillary network should have vessels suitable for microvascular anastomoses, this means having 
preferably a 2 to $3 \mathrm{~mm}$ diameter. The longer the vascular pedicle, the more opportunities exist to find suitable recipient vessels for microvascular anastomoses.

Recipient vessel dissection.

In burn reconstruction the overlying tight skin is often hypertrophic and may be very thick, especially the dermal layer which contains the contraction bands of the scar. In many cases, however, deeper to this layer in the subcutaneous fat or between the muscles, recipient vessels can be found with suitable diameter for microvascular anastomoses.

It is essential to divide all contraction bands down to healthy tissue and to outline the area which the flap has to cover first. Then the recipient vessels should be dissected free. Only when the quality and length of the recipient pedicle has been assessed the final planning of the free flap should be done.

\section{Microvascular anastomoses.}

The type of the microvascular anastomoses depends on the diameter of the vessels, on the discrepancy of diameter between donor and recipient vessels and on the natural vascular territory of the recipient artery and vein. If the radial artery is dissected as a

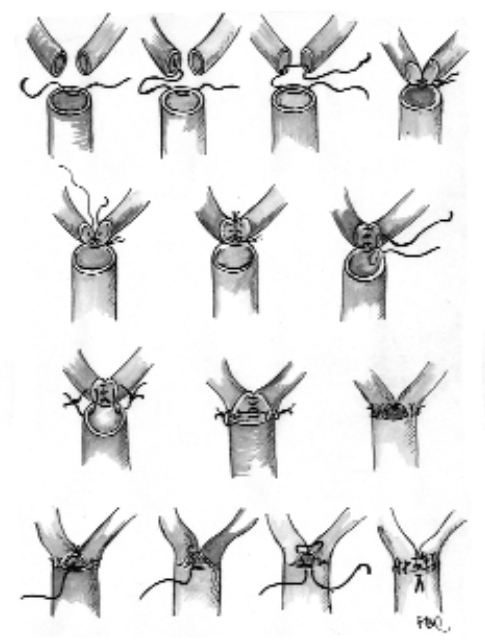
recipient vessel in a patient without a communicating arcade of the hand, it requires an end-to-side anastomosis in order not to compromise the vascularization of the hand. An Allen test should be done prior to the operation. Incongruent anastomoses may be performed using mattress stitches to narrow the larger vessel $^{(8)}$.

Y-shaped anastomoses ${ }^{(9)}$ (fig. 1), especially venous ones, may offer an alternative procedure to improve flap blood supply by linking two draining vessels to one flap vein. This applies specifically for the lower third of the leg and for the foot or for the venae comitantes of the radial forearm flap.

In all cases we use a "posterior wall first" technique of anastomosing ${ }^{(10,11)}$.

Fig. 1 Y shaped microvascular anastomosis

The choice of the flap.

Different free flaps can be used for coverage of deep burn defects or released contracted burn scars. Several surgical solutions are described in literature $e^{(3,12,13,14,15,16,17}$, ${ }^{18,19,20)}$ and most of the times the choice depends on surgical experience of the surgeon and his personal ideas. 
In addition we take into consideration the type and size of the defects, the anatomic region and aim for limited donor site morbidity.

For large and deep defects we perform the latissimus dorsi muscle flap with split thickness skin grafts or the combined latissimus dorsi and serratus anterior muscle flaps (Table 3).

If a thin free flap is required, at the moment our choice is a fascial flap with split skin grafts: the temporalis fascia can cover areas up to 8 by $12 \mathrm{~cm}$ in size, for larger areas a serratus anterior fascia flap can be harvested.

The lateral arm fasciocutaneous flap and the radial forearm flap (Chinese flap) offer a good skin quality with a thin layer of subcutaneous fat for medium size defects up to 10 $x 15 \mathrm{~cm}$. The morbidity of the Chinese flap may be more pronounced than the lateral arm flap.

When a larger cutaneous flap is required, the scapular or parascapular flap can be performed. If this unit is not large enough, a pre-expanded scapular flap can be prepared. It will take 2-3 months between the implant of the tissue expander and harvesting the flap. The pre-expansion of a free flap increases the tissue surface useful for transfer and reduces its thickness, reducing tension on the margins. Moreover, it allows an easier closure of the donor area ${ }^{(21-23)}$.

For hand burn contraction release we prefer the temporalis fascia flap with skin grafts. It's a thin flap and hand movements are not compromised. For first webspace or for small defects (15 cm maximum in length, only $2-3 \mathrm{~cm}$ in width) also an arterialised venous free flap is useful. Of course, a lateral arm or lateral forearm flaps can be used. For resurfacing the dorsum of the foot and heel, a temporalis fascia flap with split skin grafts is our first choice; a gracilis, rectus abdominis or latissimus dorsi myocutaneous flap or muscular flap covered with skin grafts is selected for resurfacing of the plantar surface, especially when bones are exposed.

Finally, the tensor fascia lata myofascial flap is useful when shearing forces must be avoided and a good connection between skin and the deeper structures is required.

\subsection{Results}

The free flaps were successful in 50 of 53 cases (94\%).

One nasal reconstruction with a Chinese flap failed and also one upper lip reconstruction with a lateral arm free flap. One venous free flap failure is due to a too long gradient of viability.

In all these cases wound healing was achieved by a new free flap transfer.

Flap complications included flap loss (three cases),venous congestion and partial loss (four flaps), grafts loss (two flaps), infection (two times) and minor wound dehiscence at the flap-recipient area interface (four patients). No recurrent ulceration occurred. All patients in whom this technique was successful, achieved and adequate and stable coverage.

Donor site complications included a partial skin graft loss in the forearm after Chinese 
flap harvesting. No hematoma formation has been described.

During follow-up, four patients underwent a minor secondary revision of the flap reconstruction. In order to improve the final aesthetic and functional result (especially in the hand), they underwent defatting procedures and Z-plasties.

The results were classified subjectively according to both patient and surgeon opinion. Good-to-fair results were obtained.

There were no recurrences of scar contractures and good function was gained in the majority of patients after contracture release.

\subsection{Clinical applications}

Several applications of free flaps in burn reconstruction are presented:

Case 1

A 2 year old Negro girl fell in a fire and sustained a 25\% TBSA burn involving her face
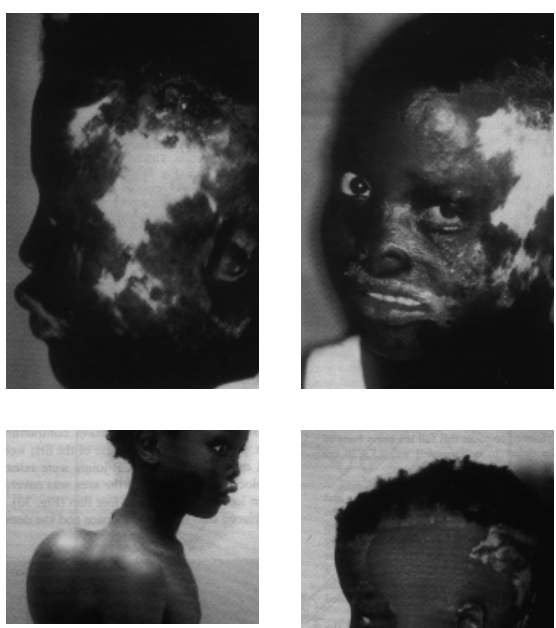

Fig. 2. Case report 1

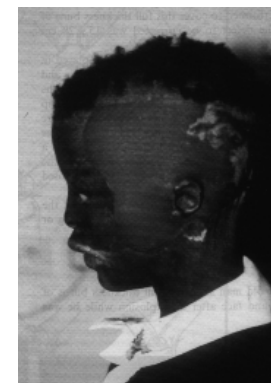
and the left side of the skull. More than 12 operations had been performed, however at the age 9 she presented a continuous breakdown of the temporal skin and infection of the temporal bone. Part of the bone was missing. The skin over the left side of the face and the skull was completely white, missing all pigment. The ear remnants were retracted. No primary skin transplantation had been performed to cover this full thickness burn of the face. The defect to be corrected was 15 by $20 \mathrm{~cm}$ (fig. 2a, b).

A 1200 cc rectangular tissue expander was placed in the right scapular area during a first operation time and a good expansion was achieved over a three months period (fig. 2c). Thus, an expanded scapular free flap was harvested and microvascular anastomoses were performed between the circumflex scapular and the superficial temporal vessels.

In the middle of the flap a $3 \mathrm{~cm}$ diameter hole was made to allow passage of the remnant of the ear (fig. 2d). The donor area was closed directly.

The post operative healing was uneventful and the colour-match was perfect. No hypertrofic scarring or keloid formation was found (fig.2d).

\section{Case 2}

A 47 year old man sustained full thickness burns of both hands and face after an explosion while he was working on a oil drilling platform in the North Sea. 
Only 5 weeks postburn split skin grafts had been applied to the hands, however without proper splinting, postoperative immobilisation and application of pressure garments. An adduction contracture of the thumb, of the first webspace and the palm of both hands developed. Boutonniere deformities developed on all long fingers in both hands, the nails were destroyed in a varying degree. The metacarpo-phalangeal joints (MCPs) of all long fingers were fixed in extension (fig. $3 a, b, c)$.
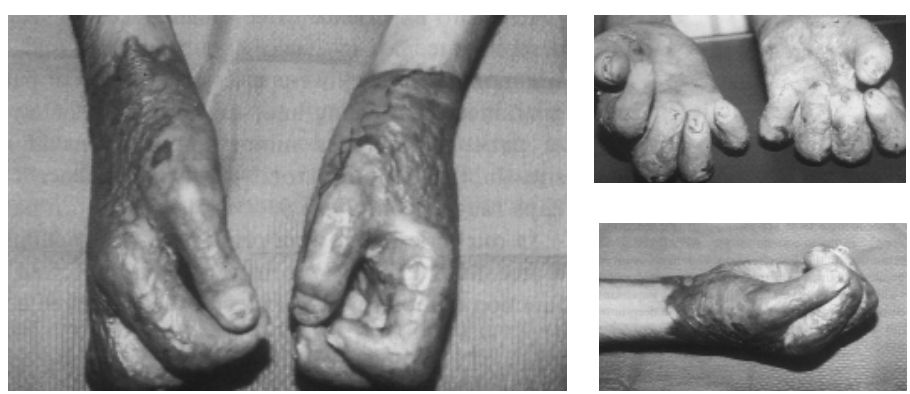

Fig. 3. Case report 2: a-c, post burn contracture of both hands

At 5 months postburn the patient was presented to us, requesting restoration of hand function, by increasing the span of the first webspace, extension of the long fingers and mobilisation of the metacarpophalangeal joints. Several reconstructive procedures were planned.

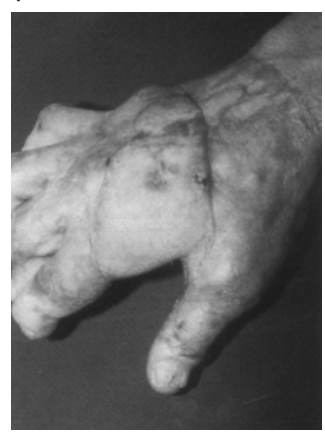

On the right hand, the flexion contracture of the palm, the adduction contracture of the first web and the fixed extension of the MCP joints were released after "en bloc" scar excision and the area was covered with a $23 \mathrm{~cm}$ long saphenous venous free flap (fig. 3d). The flap was placed into the first webspace and the dorsal aspect of the hand. The distal end of the long saphenous vein was connected to the radial artery and the proximal side to a dorsal vein. A venous congestion of the flap appeared

Fig. 3 (continued) d, A saphenous venous free flap in the first days after the operation, especially to replace the first webspace and the dorsal aspect over the 4th and 5th MCP joints. The first of the hand webspace was kept in abduction for one week by a K-wire. Secondary healing had taken place overlying the 3rd, 4th and 5th MCP joints, however not requiring any further surgery. No further defatting of the flap was necessary. The span of the first webspace indicated a thumb to index nail distance of $12 \mathrm{~cm}$, which is quite normal.

On the left hand the contracted burn scar was excised and the adduction contracture of the thumb released. The long fingers were stretched. The defect was covered by a superficial temporal fascia free flap with a full thickness skin graft. The anastomoses 
were performed to the radial artery and to a dorsal vein, making a tunnel from the volar to the dorsal aspect of the hand in the first webspace.

One year postoperatively good mobility of the fingers was achieved with complete opening of the palm (Fig. 3e f).
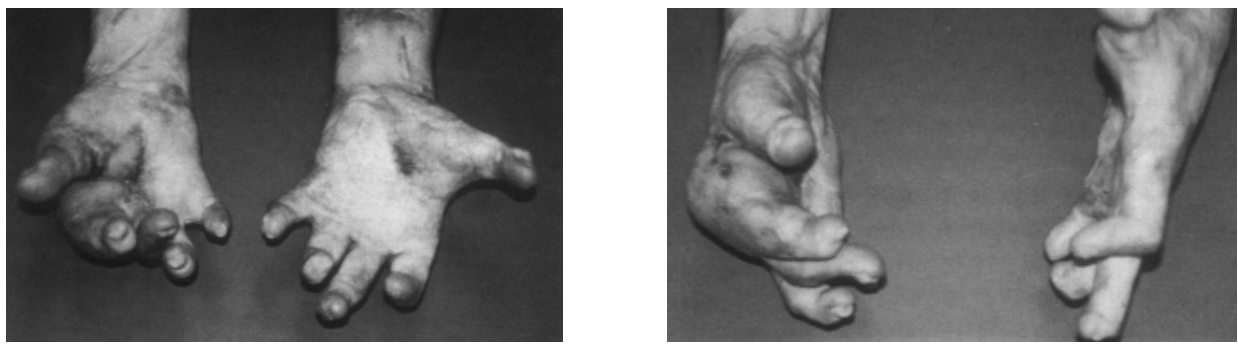

Fig. 3 (continued) e-f, postoperative results.

\section{Case 3}

A 72 year old man had fallen into a fire, due to toxic smoke inhalation. This resulted in a fourth degree burn of the left knee (fig. $4 \mathrm{a}$ b). During debridement the whole patella was
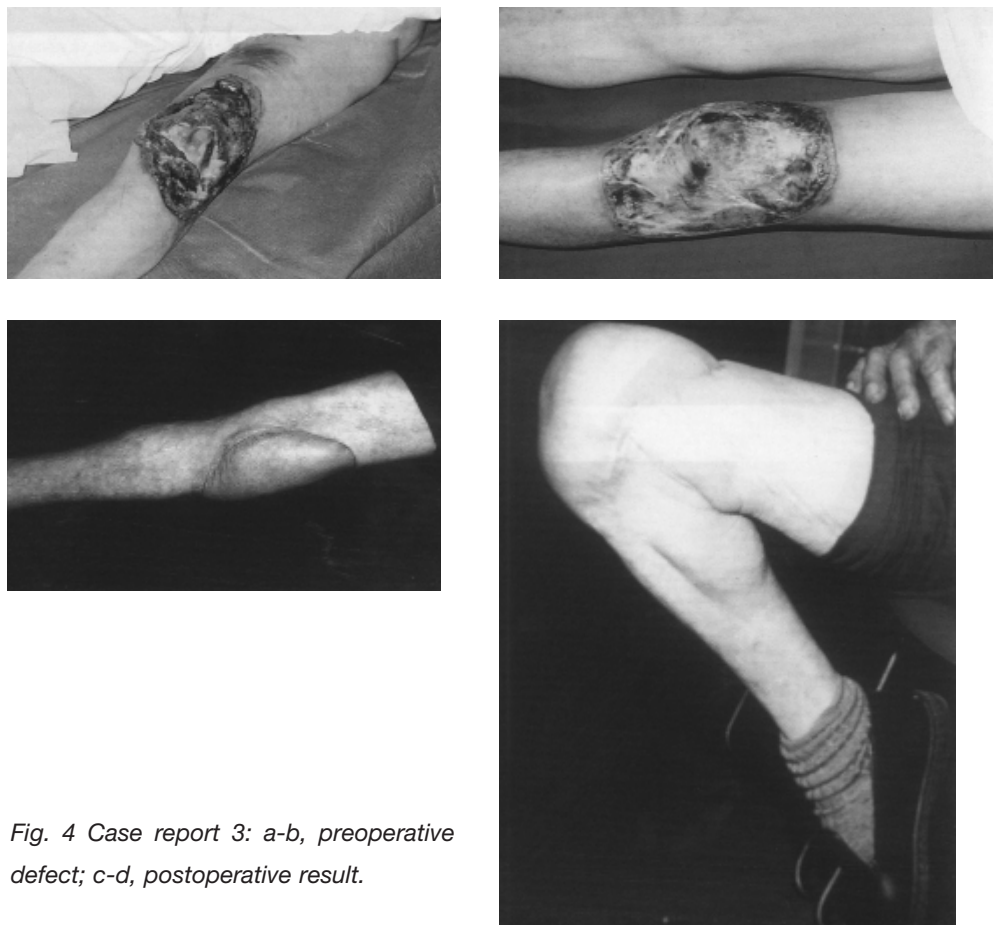

Fig. 4 Case report 3: $a-b$, preoperative defect; c-d, postoperative result. 
removed and the continuity between the quadriceps muscle and the tibia was lost. The collateral and cruciate ligaments of the knee joint were maintained.

The defect was reconstructed using a non-vascularized fascia lata slip of 15 by $12 \mathrm{~cm}$ to achieve patella tendon continuity and further coverage with a latissimus dorsi myocutaneous flap of 25 by $15 \mathrm{~cm}$.

Six months postoperatively a 1540 of knee flexion and full extension was achieved, enabling the patient to resume his hobby as a 65 plus cyclist (fig. $4 \mathrm{c} \mathrm{d}$ ).

\subsection{Discussion}

The majority of burn patients require only excision of burned tissue and split skin grafting. Free flaps, to our belief, play a marginal role in the management of burn patients. Similar to Platt et al. ${ }^{(1)}$, only 1,8 per cent of patients admitted to our Burn Unit required a free tissue transfer. However, free flaps are essential in selected cases.

Expertise in microvascular surgery has offered great opportunities to the burn surgeon and has improved the quality of burn reconstruction. Free microvascular flaps allow the preservation of functionally important structures such as nerves and vessels in acute deep burn injuries and the resurfacing of contracted burn scars when local tissue is not available.

In our experience free microvascular transfers demonstrated an high success rate and minimal donor site morbidity. They were successful in $94 \%$ of patients, guaranteeing a lasting and stable coverage. Only $2.2 \%$ of patients developed minor complications at donor site. In the literature total survival incidence of free flaps ranges from $78 \%{ }^{(1)}$ to $91,7 \%{ }^{(13)}$ in burn patients.

In our series $10 \%$ were primary reconstructions with a free flap. Primary reconstruction is preferred when functional impairment is expected. We achieved a stable one-stage coverage and early rehabilitation of the function. This concept is particularly important in hand burns, where more than for any other body part management of burns must strive for restoration of function. Our goal was to prevent the need of reconstruction, making early closure of vital tissues with free flaps thus preserving complex movements of joints and tendons.

Functional results are not satisfactory when traditional methods for reconstruction are used.

Our protocol consists of radical debridement of all questionably non viable tissues except visibly intact tendons, nerves and bones and early wound coverage by homografts to achieved a biological coverage and prevent further damage of the remaining tissues. After two or three weeks, when the wound is cleaned and the patient stabilised, a free flap is performed. This management is combined with proper splinting and early mobilisation and gave us good long-term results.

Bulky flaps can be avoided using a thin fascia transfer and skin grafts ${ }^{(13)}$. However, a secondary surgical revision (defatting, liposuction) can be performed if the flap is still bulky. 
We performed $90 \%$ delayed burn reconstructions with a free flap, when severe functional and aesthetic deformities due to contracted scars were present and local tissue was not available.

Skin contracture can recur even after wide and complete release and full-thickness skin grafting ${ }^{(22)}$. Recurrence is partly due to the inherent difficulties in both early postoperative immobilisation and the required long-term splinting.

The timing of free flap reconstruction however has to take into consideration the normal pattern of healing of a burn wound. Hypertrophic scarring and contraction increases in the first six months and maturation of the burn scar involves often the first two years postburn. Thus, time of surgery is preferable delayed after a complete maturation of the burn scar. However, the loss of function due to severe contraction is an indication for early contraction release ${ }^{(24)}$.

In our series free flaps gave good functional outcomes without any skin contracture recurrence in $100 \%$ of patients.

Regarding aesthetic results, other authors often choose other surgical procedures (skin graft, tissue expansion), suggesting that a flap is excessive thick and bulging ${ }^{(7)}$. We do not agree with this opinion because different type of flaps are available and the choice of a thin or thicker flap depends on the variable characteristics of the defect (depth, size, skin colour, texture, weight-bearing surface or not weight-bearing surface) and the flap itself.

A perfect colour match between the flap and recipient area is not always achieved, neither with skin grafts. Good results are achieved with tissue expansion: local expanded skin is similar in colour, texture and thickness to the area to be reconstructed and no new scars will be added since the expanded skin is adjacent to the defect. Otherwise, tissue expansion is not always applicable next to burn tissue and two operation times are necessary. Moreover, we think that in a burn patient the difference in skin colour or a not perfect colour match are not relevant, because of a mixture of different colour and texture are present, due to secondary healing and grafting.

\subsection{Conclusion}

This paper demonstrates the efficacy of free tissue transfer in burn surgery in providing a successful, one-stage reconstruction with low morbidity both in acute deep burn injuries with vital structures exposure as in delayed reconstructions for contracted burn scars. Free flaps are a versatile procedure, using different flaps according to different characteristics of the recipient area (colour skin, texture, thickness, weight-bearing or not weight-bearing surface). 


\subsection{References}

1. Platt AJ, McKiernan MV, McLean NR. Free tissue transfer in the management of burns. Burns 22(6): 474-476, 1996.

2. O'Shaughnessy M, Zinn AG, Vidal P, Milling MA. The problem of bilateral foot reconstruction after severe burns. Br J Plast Surg 49(4): 233-236, 1996.

3. Shen TY, Sun YH, Cao DX, Wang NZ. The use of free flaps in burn patients: experiences with 70 flaps in 65 patients. Plast Reconstr Surg 81(3): 352-357, 1998.

4. Angrigiani $\mathrm{C}$. Aesthetic microsurgical reconstruction of anterior neck burn deformities. Plast Reconstr Surg 93(3): 507-518, 1994.

5. Lo LJ, Yang JY, Wei FC. Free flap transfer in burn reconstruction. Chang Keng I Hsueh. 14(1): 8-14, 1991.

6. Mast BA, Newton ED. Aggressive use of free flaps in children for burn scar contractures and other soft tissue deficits. Ann Plast Surg 36(6): 569-575, 1996.

7. Adant JP, Bluth F, Jacquemin D. Reconstruction of neck burns. A long term comparative study between skin grafts, skin expansion and free flaps. Acta Chir Belg 98(1):5-9, 1998.

8. Boeckx W, Vereecken R, Depuydt K. Microsurgery for intra-abdominal testicular retention. Eur J Obstet Gynaecol 81:191, 1998.

9. Boeckx W. Clinical micro-surgery: end to end venous anastomosis. In Marquet R, Hess F, Kort Boeckx W. Micro-surgery. Experimental techniques in the rat and clinical applications. Ghent, Belgium. European Press, pp. 193-194, 1976.

10. Boeckx W. Clinical micro-surgery: finger remplantation. In: Marquet R, Hess F, Kort W, Boeckx W. Micro-surgery: experimental techniques in the rat and clinical applications. Ghent, Belgium European Press, pp. 219-220, 1976.

11. Harris GD, Finseth F, Buncke HJ. Posterior-wall-first microvascular anastomotic technique. $\mathrm{Br}$ J Plast Surg 34: 47, 1981.

12. Achauer BM. Reconstructing the burned face. Clin Plast Surg 19:623, 1992.

13. Chowdary RP, Chernofsky MA, Okunski WJ. Free temporoparietal flap in burn reconstruction. Ann Plast Surg 1990; 25(3): 169-173, 1990.

14. Economides NG, Ferrell TH. Neck resurfacing with free TRAM flap. Microsurgery 13:240, 1992.

15. Fried $\mathrm{M}$, et al. Electrical burn injury of the scalp. Bone regrowth following application of latissimus dorsi free flap to the area. Burns 17: 338, 1991.

16. Grotting J, Walkinshaw M. The early use of free flaps in burns. Ann Plast Surg 15:127, 1985.

17. Hammer H, Bugyl I, Zellner PR. Soft tissue reconstruction of the anterior surface of the lower leg in burn patients using a free latissimus dorsi muscle flap. Scand J Plast Reconstr Surg 20(1): 137-140, 1996.

18. Maillard GF, Montandon D. Reconstructive surgery of deep burns of the lips. Clin Plast Surg 11(4): 655, 1984.

19. Silverberg $B$ et al. Microvascular reconstruction after electrical and deep thermal injury. $J$ Trauma 26: 128, 1986.

20. Stamatopoulos $\mathrm{C}$, et al. Use of free flaps in the aesthetic reconstruction of face and neck deformities. Microsurgery 13: 188, 1992.

21. Hallock GG. Preexpansion of free flap donor sites used in reconstruction after burn injury. J 
Burn Care Rehabil 16(6): 646-653, 1995.

22. Kenney JG, Di Mercurio S, Angel M. Tissue-expanded radial forearm free flap in neck burn contracture. J Burn Care Rehabil 11(5):443-445, 1990.

23. Santanelli F, Grippaudo FR, Ziccardi P, Onesti MG. The role of pre-expanded free flaps in revision of burn scarring. Burns 23(7-8):620-625, 1997.

24. Robson MC, et al. Making the burned hand functional. Clin Plast Surg 19:663, 1992 
Chapter 9 - Nostril reconstruction with ear helix free flap

F. De Lorenzi, R. van der Hulst, W. Boeckx

Eur J Plast Surg (2001) 24: 253-255 


\section{Abstract}

Many different techniques have been described in the past for nose reconstruction. Of these, nasolabial and forehead flaps are most frequently performed. The disadvantage of local flaps is that they do not accurately reproduce the alar rim contour, despite secondary surgical revisions. We present a full-thickness nostril reconstruction after a dog bite injury using a microvascular free ear helix composite flap.

The flap dissection is described and surgical details are underlined. The indications and advantages are compared to those with other surgical solutions. 


\subsection{Introduction}

In cases of large full-thickness defects of the lower half of the nose, local skin flaps cannot completely reproduce the tip projection and the alar rim contour, despite several secondary procedures. Attempts to achieve tip prominence and alar rim contour have centred on the creation of a skeletal framework. Skeletal elements in the form of composite chondromucosal or chondrocutaneous grafts harvested from the nasal septum or the ear concha have been used in the past. However, all composite grafts carry the inherent risk of incomplete revascularization, which may results in loss of mass and definition together with collapse of the skeletal framework due to cartilage reabsorption and retracted scar.

In 1985 Parkhouse and Evans ${ }^{(5)}$ described nasal ala reconstruction using a composite free flap from the anterior part of the pinna to replace the free alar margin and the external nasal skin with the hairless pre-auricular skin. The flap consists of the helix cartilage and the overlying tissue, and it is supplied by auricular branches arising from the superficial temporal artery. In 1989 Shenaq et al. ${ }^{(7)}$ described the same flap for nasal ala reconstruction, and more recently Pribaz and Falco ${ }^{(6)}$ and Tanaka et al. ${ }^{(8)}$ presented further refinements.

We present a clinical application of the free ear helix flap and discuss surgical details and advantages over other reconstructive procedures.

\subsection{Case report}

A 18-year-old boy was admitted to our Unit 3 months after a dog bite resulting in a total

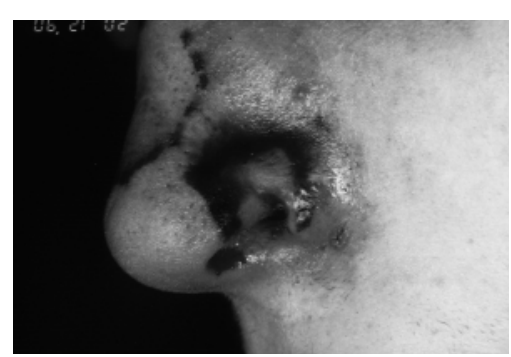

Fig. 1 Preoperative view. A total alar defect 3 months after a dog bite. left alar defect (Fig.1). This initially healed spontaneously. A $2.5-\mathrm{cm}$-wide free helix flap from the right ear was planned to repair the composite tissue loss. Before planning the free helix flap, we first identified the superficial temporal artery by digital palpation and Doppler probe sign. A pattern of the defect was made, taking particular care to place the free alar margin correctly. This pattern was marked out on the ascending helix of the contralateral ear, positioning the alar margin on the free posterior edge of the helix crus.

Under general anaesthesia, the incision began a few millimeters anterior to the tragus and continued upward following the course of the superficial temporal artery. Skin flaps were carefully undermined in the dermohypodermic plane and the superficial temporal artery was easily exposed. Numerous small arteries supplied the upper helix, however one single arterial vessel was identified as the dominant pedicle. This vessel arose as a direct branch from the superficial temporal artery and ran upward and backward to the helix crus. An accompanying vein, 
draining into the superficial temporal vein, was present. The superficial temporal vessels were then ligated and divided distally to the origin of the helix crus pedicle. Thus the auricular flap was based only on the superficial temporal vessels, because the connections to the temporal frontal branch had been tied off.
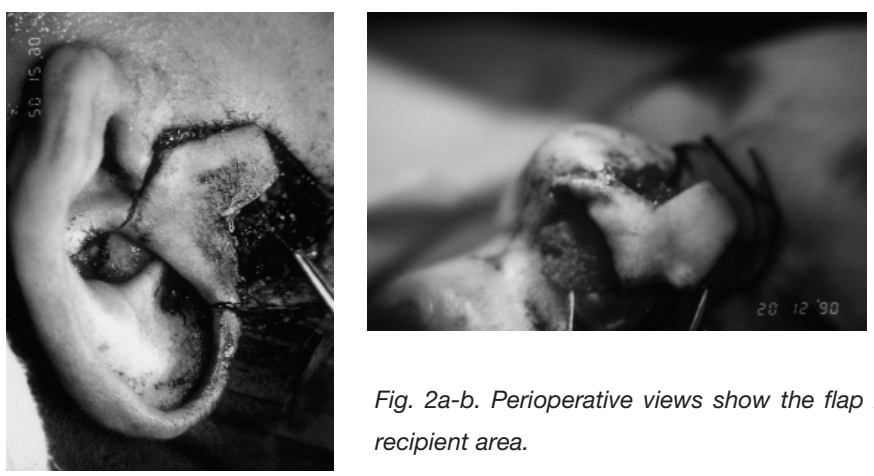

Fig. 2a-b. Perioperative views show the flap harvested and transferred to the recipient area.

The dissection was then performed on the posterior border of the flap. The incision began from the posterior auricular surface and continued to the free edge of the helix. A full-thickness incision separated the flap from the remaining helix at the upper border, the dissection continued posteriorly detaching the helix crus from the temporal bone. The flap and its pedicle were thus harvested in this way (Fig.2a). The vascular pedicle could be lengthened by following and dissecting the superficial temporal vessels proximally toward the parotid gland. In the recipient area the facial artery and vein were exposed and dissected free in the nasolabial fold. The flap was transferred to the recipient area (Fig.2b). An end-to-end microvascular anastomoses was performed ("posterior wall first" technique ${ }^{(2,4)}$ ) between the facial and the superficial temporal vessels without the use of any vein graft. The ear defect was repaired with an advancement and rotation flap from the remaining helical rim.

Recovery was uneventful without postoperative complications. The patient required a
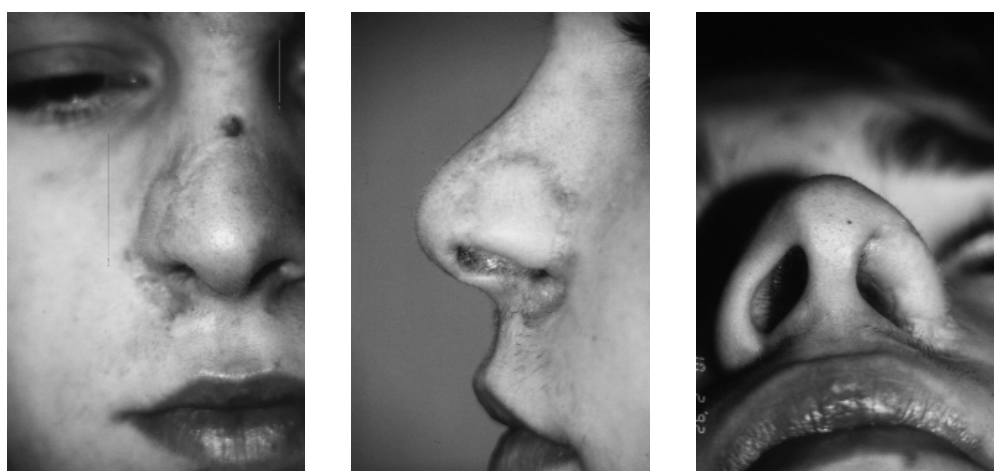

Fig. 3a-c. Postoperative result after 1 year. The free alar margin is accurately aligned and the entire nasal defect correctly reconstructed. 
secondary revisional procedure (minor scar corrections and debulking of the pedicle of the flap). The late result, 1 year after the reconstructive procedure, was very satisfactory (Fig.3a-c). The free alar margin was accurately aligned and the entire nasal defect correctly reconstructed.

\subsection{Discussion}

In 1946 Brown and Cannon ${ }^{(3)}$ first described the use of free composite grafts of skin and cartilage from the ear, and since then the auricle has been considered a tissue bank for nose reconstruction. Composite chondrocutaneous grafts can be used to repair small full-thickness defects of the distal part of the nose. Instead, reconstruction of large fullthickness nasal defects is impossible to be treated by free composite grafts, since a composite graft has to be limited in width to guarantee complete survival. A cartilage framework can also be used as a skeletal element to achieve projection of local skin flap reconstructions. However, local flap techniques involving folding to reproduce the alar margin leave a bulky structure which is difficult to thin secondarily. In addition, local flaps produce a scar in a visible area of the face. In 1985 Parkhouse and Evans ${ }^{(5)}$ first described the reconstruction of the ala of the nose using a composite free flap from the pinna. The flap consists of the helix cartilage and the overlying tissue and it is supplied by auricular branches arising from the superficial temporal artery. Other authors ${ }^{(6,7,8)}$ have since performed and refined the same flap, pointing out several advantages over conventional technique of nose reconstruction.

First, the skin of the helix crus is of the same colour, texture and thickness as that of the normal nose, allowing excellent aesthetic results. In fact the ascending helix of the ear and the distal portion of the nose are both laminated structures composed of cartilage bounded on each side by a thin layer of skin ${ }^{(6)}$. Thus, the upper part of the helix consists of an ideal donor site for nasal reconstruction. In our patient we could achieve very satisfactory results, as shown in photographs taken 1 year after the reconstruction.

We think this technique is a reliable solution for nose reconstruction since a constant pedicle arises from the superficial temporal system, as demonstrated by several anatomical studies ${ }^{(1,5)}$. Various arterial patterns have been described regarding the relationship between the origin of the vascular pedicle of the free auricular flap and the level of superficial temporal artery bifurcation ${ }^{(1,5)}$. The anatomy of the preauricular region permits freedom of design of the composite free helix flap, allowing reconstructions of nasal defects having different sizes and shapes. The flap can include a part of skin from the preauricular area or a skin island from the ear concha if complex defects have to be repaired (defects of the tip, columella, ala and/or dorsum of the nose) (1). Thus, this flap represents a versatile solution for different nasal defects. Donor site morbidity is minimal. No additional scars are present in the central portion of the face. The ear defect can be repaired with an advancement and rotation flap from the remaining helical rim; the ear becomes slightly shorter but its natural shape is preserved.

Anatomical findings demonstrated that constant anastomoses are present between the 
anterior frontal branch of the superficial temporal system and the supraorbital and supratrochlear arterial systems ${ }^{(1)}$. Thus, the same flap can be used as an island unit in a reverse vascular flow fashion, as described by Baudet et al. (1). We prefer the microsurgical transfer of the flap, that permits a "one stage" reconstruction. The main inconvenience of the island transfer is related to the fact that the pedicle is left "bridging" over the middle face at least for two weeks and a second operative procedure is required for its division. This is inconvenient for the patient.

In conclusion, we think that the ear helix free flap is an ideal, reliable and versatile solution for large full-thickness defects of the distal portion of the nose. It can be performed in patients who are anxious of further scarring in the central part of the face or patients which have undergone unsuccessful previous attempts of reconstruction with more conventional methods.

\subsection{References}

1. Bakhach J, Conde A, Demiri E, Baudet J. He reverse auricular flap: a new flap for nose reconstruction. Plast Reconstr Surg 104 (5): 1280, 1999.

2. Boeckx W. Clinical micro-surgery. In: Marquet R, Hess F, kort W, Boeckx W. (eds) Micro-surgery. Experimental techniques in the rat and clinical applications. European, Ghent, 1976.

3. Brown JB, Cannon B. Composite free grafts of skin and cartilage from the ear. Surg Gynecol Obset 82: 253, 1946.

4. Harris GD, Finseth F, Buncke HJ. Posterior-wall-first microvascular anastomotic technique. $\mathrm{Br}$ J Plast Surg 34: 47, 1981

5. Parkhouse N, Evans D. Reconstruction of the ala of the nose using a composite free flap from the pinna. Br J Plast Surg 38: 306, 1985.

6. Pribaz J, Falco N. Nasal reconstruction with auricular microvascular transplant. Ann Plast Surg 31 (4): 289, 1993.

7. Shenaq SM, Dinh TA, Spira M. Nasal ala reconstruction with an ear helix free flap. J Reconstr Microsurg 5: 63, 1989

8. Tanaka Y, Tajima S, Tsujiguchi K, Fukae E, Ohmiya Y. Microvascular reconstruction of nose and ear defects using composite auricular free flaps. Ann Plast Surg 31:298, 1993. 
Chapter 10 - Arterialised venous free flaps for soft tissue reconstruction of digits: a 40 cases series

F. De Lorenzi, R. R. W. J. van der Hulst, W. F. A. den Dunnen, J. J. Vranckx, B. Vandenhof, C. Francois, W. D. Boeckx 


\section{Abstract}

When there is not sufficient local tissue available for reconstructions of one or multiple digits defects, distant flap reconstructions are required. Available thin flaps with defined arterial inflow and venous outflow are limited and require the sacrifice of an arterial pedicle. In addition, a functional limitation can occur at the donor site.

During the last decades, experimental and clinical attempts have been made at using venous flaps, just based on the venous network for in- and outflow.

A 40 cases series of arterialised venous free flaps in soft tissue reconstruction of digits and hands is presented. Neovessel formation induced by an intact venous plexus within the flap clinically proves to be the survival mechanism. Postoperative congestion was present in all flaps and subsided within 14 days, $92 \%$ of all flaps eventually survived. In $57,5 \%$ of cases total flap survival was observed. In $17.5 \%$ of flaps a superficial epidermolysis occurred, not requiring further surgery. In $17,5 \%$ of flaps a full-thickness skin necrosis developed, requiring grafting (minor complication). In 7,5\% of reconstructions total flap necrosis was observed. Thus, in our experience, when conventional local flaps are not available, arterialised venous free flaps prove to be a successful solution for soft tissue reconstruction in digits and hands.

In this paper the authors present main indications and advantages of arterialised venous free flaps, pointing out essential technical steps and main pitfalls in treatment. 


\subsection{Introduction}

In soft tissue reconstruction of fingers and hands a multitude of surgical solutions have been described, such as dorsal metacarpal flaps, neurocutaneous island units, cross finger flaps, advancement flaps, kite and flag flaps and reversed radial forearm flaps ${ }^{(1-7)}$. All flaps are based on a conventional vascular pedicle with an afferent arterial inflow, a capillary system and an efferent venous outflow. For distal defects of fingers, however, these flaps might be limited, depending on size, orientation and location of the defect, the length of the pedicle needed and magnitude of the fingers to be treated.

A new concept for skin transfer, which could decrease the donor site morbidity and increase the amount of useful donor sites, is represented by venous free flaps. They rely only on the venous system for flap perfusion. Nakayama first described this ideas in 1981 on a rat model ${ }^{(8)}$, using abdominal skin flaps and showing that the arterial inflow through the venous system nourished the distal part of the flap and could function as a pedicle in a free flap. Later, several researchers described venous free flaps in animal models ${ }^{(9-17)}$. These experiments stimulated the clinical use of these flaps ${ }^{(18-23)}$. Wolff et al. concluded that arterialised venous free flaps are the safest form of venous free flaps, whereas venous island flaps carry a high risk of partial or total necrosis (24).

The arterialised venous flap is perfused with arterial blood by anastomosing the afferent subcutaneous vein of the flap to a recipient artery (arterialisation of a vein). In this way the venous network in the venous flap, nourishing the tissue, is oxygenated with arterial blood. The flap consists of skin and subcutaneous fat, an axial vein in subcutis, while no artery and arteriovenous network are included.

In this paper we present our experience with 40 reconstructions of digits and hands using arterialised venous free flaps. Main indications and surgical technique are described, advantages and complications discussed.

\subsection{Material and methods}

Between 1990 and 1998 we performed 40 arterialised venous free flaps for soft tissue reconstructions of hands and digits. The follow-up period ranged from one to four years postoperatively. The average age of the patients ( 36 males and 4 women) was 32 years with a range of 3 to 66 years.

Indications were burn scars with contracture in 16 patients, avulsion injuries in 12 patients, crush injuries in eight patients and recurring Dupuytren disease in four cases. In 37 patients the forearm region was the donor site, using the antebrachial vein. In the remaining, the long saphenous vein was used.

Preoperatively, the subcutaneous vein was marked. Only when not clearly visible, a Doppler probe was used. Secondly, flap shape was marked over the superficial vein. Flap dimensions varied between 1,5 by $2 \mathrm{~cm}$ and 15 by $3 \mathrm{~cm}$ or 9 by $6 \mathrm{~cm} .6 \mathrm{~cm}$ was the maximum of width in order to close the donor site primarily. A drainage system was left in place at the donor side for approximately two days. 
With regard to recipient site dissection, the interdigital artery was used in 34 reconstructions as recipient artery. In the other six cases, the dorsal branch of the radial artery was used. Arterial-venous anastomoses were preferably performed in end-to-end fashion when existing traumatic arterial stumps or terminal arterial branches (digital artery). They were performed with end-to-side technique when existing uninterrupted vessels (mostly interdigital artery).

Veno-venous anastomoses were performed on one of the dorsal hand veins at metacarpal-phalangeal level in 36 out 40 reconstructions. In two cases they were performed at wrist level and in two cases at forearm level. We preferably used an endto-side way of anastomosing; only distally (proximal phalanx level) we used an end-toend technique. Ethilon 10/0 was used for suturing in all cases.

Postoperatively, antibiotics and Rheomacrodex (Dextran 40) at $30 \mathrm{cc} / \mathrm{h}$ were administered for five days. Monitoring of the free flap was performed by Doppler probe analysis of the pulsate flow through the anastomoses.

\subsection{Results}

In early post-operative time, after the release of tourniquet, all flaps became ischemic and white. Paleness resolved in about 30 minutes, showing a good capillary refill in 37 out 40 flaps. A clear Doppler probe signal, as in arterio-venous fistula, was present at the anastomosis site in 32 flaps. In eight reconstructions, including the three pale flaps, this sign was unclear.

Few days postoperatively all flaps showed venous congestion. It was present at flap margins and not at flap axis. In 30 of them this congestion spontaneously recovered after three to five days and the flaps became pink.

23 flaps $(57,5 \%)$ survived completely. 14 flaps (35\%) had a partial necrosis. Of this group of transfers, seven units $(17,5 \%)$ showed a superficial epidermolysis not requiring further surgery. Seven units $(17,5 \%)$ showed a full-thickness skin necrosis requiring an additional split-thickness skin graft for coverage (minor complication). The second operation was performed within 14 days after first surgery, when enough granulation tissue was formed. Three flaps did not survive at all and were replaced by another arterialised venous free flap in one patient and by other flaps in the remaining two patients.

Age seems to be related to the percentage of viability of arterialised venous free flaps. In the group of necrotic flaps (group A) the average age of patients at time of surgery was 52 years (SD 14.01). In the group of partial necrosis of the flap (group B) the average age was 40 (SD 8,62). In the remaining group - total survival (group C) the average age was 32 (SD 15,39). The difference between group $B$ and $C$ was significant (T-test: $p=0.017$ ), however group A consisted of only three patients, which is too small for adequate statistical analysis (Tab. 1).

A simple scoring system was used to evaluate the relationship between flap survival and recipient defect: 2 points for complete flap survival, 1 point for partial survival and 0 for 
total flap necrosis. In burns $(n=16)$ the average score was 1,375 ; in avulsion injuries $(n=12) 1,5$; in crush injuries $(n=8) 1,75$ and in recurrences of Dupuytren disease $(n=4) 1,5$. The differences between the scores, however, were not significant (Tab. 2).

After 3 to 4 years post-operatively, arterialised venous free flaps were examined by Laser-Doppler. At the anastomosis site the signals obtained were unchanged when compared with early postoperative examinations.

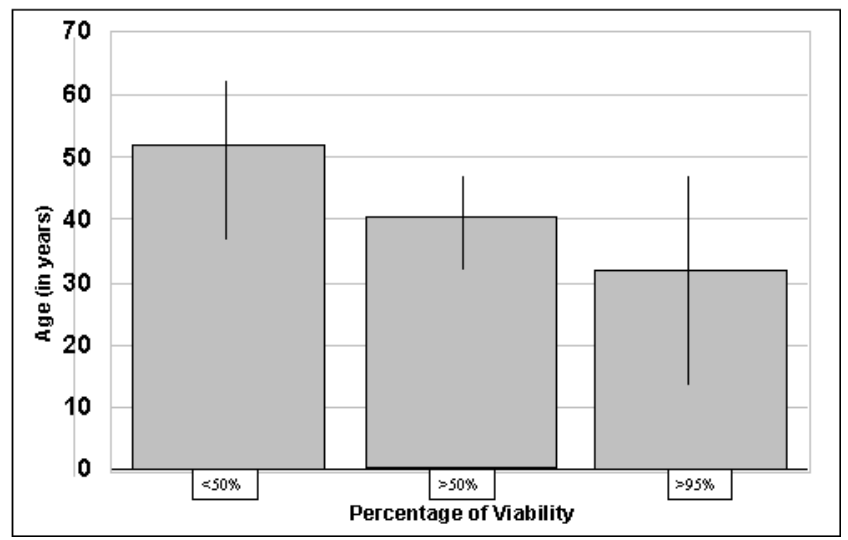

Table 1. Age related to necrosis of flaps. Group A total necrosis of flap. Group B partial necrosis. Group $C$ total survival. Age was lower in patients without necrosis (B versus $C p<0.05$ ).

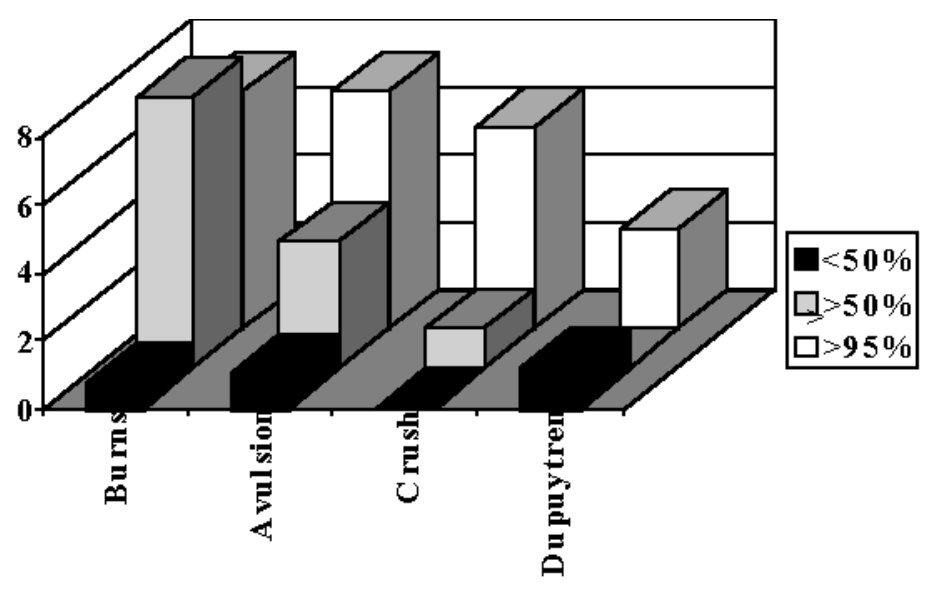

Table 2. A scoring system was used to compare type of defect and survival of flaps. 2 points was given for total survival, 1 point for partial necrosis and 0 in case of total flap necrosis. There were no significant differences between the different types of defects and the risk of developing necrosis. 


\subsection{Discussion}

Several procedures have been performed in patients with skin defects of fingers and hands, in which vital tissues such as bones, tendons, vessels and nerves are exposed. The high success rate of this study shows that arterialised venous free flaps can be successfully used in case of avulsion, crush and burn injuries as well as in recurrences of Dupuytren disease. In fact, in $75 \%$ of reconstructions a good coverage of the defects was achieved in one operation time. In $17,5 \%$ of flaps a full-thickness skin necrosis occurred but vital tissues remained covered by viable fat tissue, requiring only additional skin grafting.

Before showing our results and main advantages of these flaps, we would discuss basic steps and surgical details, giving emphasis to pitfalls in the treatment.

With regard to donor area, although different superficial subcutaneous veins can be harvested with surrounding soft tissues, our venous free flap of choice is the one including the distal volar antebrachial skin. We prefer to use the ipsilateral forearm region since it lies in the same operative field of the defect to be covered. It contains several veins, assuring good venous drainage. On the contrary, removing a large caliber vein

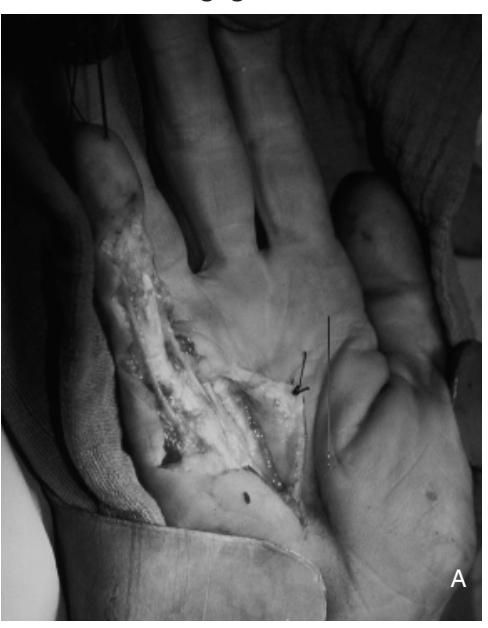
from the lower extremity (for example, long saphenous vein) may lead to prolonged oedema of the leg and venous hypertension ${ }^{(21)}$. In our study we achieved good aesthetic results at the donor site and in all cases the donor area was primarily closed. Moreover, the skin of the forearm region is pliable and of the same thickness of the skin of fingers and hand, achieving good functional results at the recipient site.

Case 1. A, Tissue defect after excision of recurrent Dupuytren's. $B$, Indicating excision of the venous free flap from the lower arm. $C$, Clinical results after 1 week; venous stasis in the arterialized venous flap is normal.
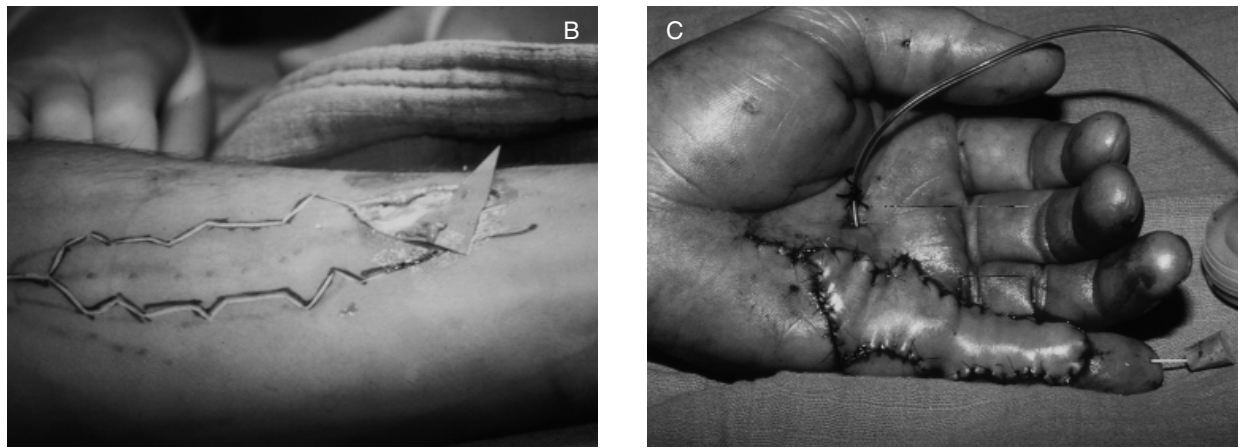

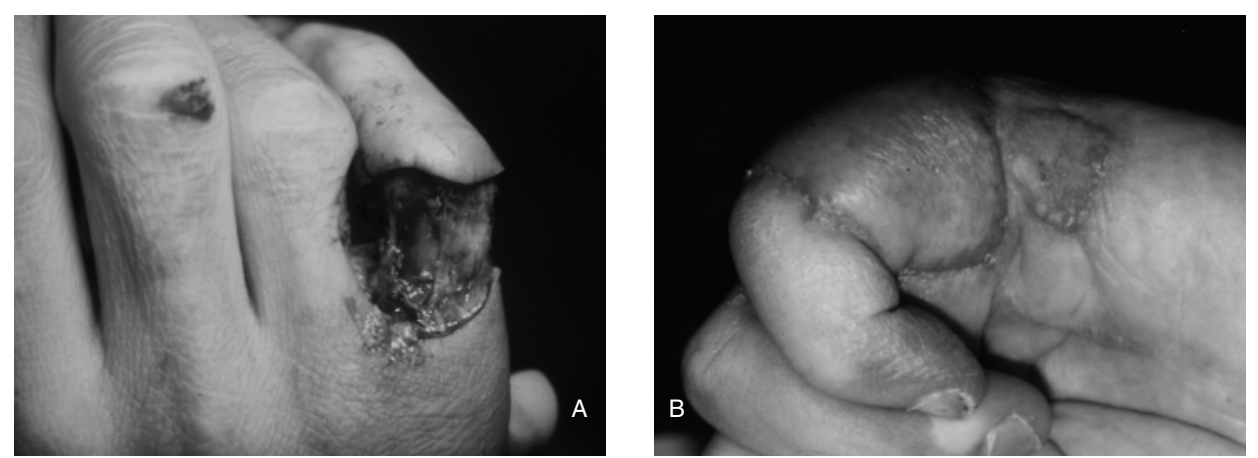

Case 2. A, Electrical burn injury after excision of burned tissue. B, Result 3 months postoperatively; note that full extension and flexion are possible.

Besides the donor area itself, some remarks should be made with regard to flap location. We advise to mark the flap shape so that the vein runs centrally and longitudinally on the flap. The distal flap vein is anastomosed to the recipient artery and the proximal flap vein to the recipient vein. In this manner a normal flow direction is maintained through the flap and the venous valves inside the flap become insufficient.

Concerning flap dissection, the transverse distal flap margin is first dissected. The vein has to be located centrally at the flap base. The distal vein is arterialised and we usually use as short as possible. Secondly, the transverse proximal margin of the flap is dissected. The proximal vein is used for venous drainage and extra length is required. After dissection of the afferent and efferent vein, flap elevations continues superficial to the fascia.

With regard to arterio-venous anastomosis, we advise to perform an oblique end-to-side anastomosis, unless an amputation stump is present. We perform a longitudinal incision in the recipient artery and cut obliquely the afferent vein. We prefer to perform the anastomosis under tourniquet, without using microvascular clamps. The afferent vein has to be as short as possible to place the flap base very close to the arterio-venous anastomosis.

The efferent vein is distally turned back under the flap and tunnelled to a proximal bigger recipient vein on the dorsal side of the hand or wrist. The veno-venous anastomosis is performed best to in an end-to-side fashion on a relatively large caliber vein, in order to prevent thrombosis. In this manner, a high flow arterio-venous fistula is created, which is sufficient for the survival of the arterialised venous free flap. This is in contrast to the opinion that multiple veins are necessary, as Tsai et al. ${ }^{(11)}$ suggested.

Inoue et al. (20) showed that in six out of ten arterialised venous free flaps the arteriovenous fistula had to be ligated distal to the flap because the vein in the flap was dilating and readily palpable. It occurred 6 to 12 weeks post-operatively. This further procedure was not necessary in any flap of our series. Moreover, at examination three to four years postoperatively, the Laser Doppler signals were the same as one week post-operatively, indicating an unchanged flow pattern, pointing at an unchanged vein caliber. In our 
opinion, venous dilation might be caused by the fact that a relatively long vein segment was used: $2 \mathrm{~cm}$ proximal to the flap, a variable length inside the flap, as well as 5 to 8 $\mathrm{cm}$ distal to the flap. In this manner the resistance is higher and the drop in intravascular pressure per unit length smaller.

Concerning our results, it seems to be a tendency that increasing age will lead to less flap viability, but group A consisted of only three patients, which is too small for adequate statistical analysis. In contradiction with the idea that a good recipient bed is essential for venous free flap survival, in this 40 cases series, exposed bone and traumatised borders as recipient beds associated with good flap survival are described. Others ${ }^{(19,25)}$ reported that these flaps well survive at sites where even bone is exposed. We didn't find any significant relationship between different types of recipient defect and flap survival.

In conclusion, we would like to summarise main properties of arterialised venous free flaps:

- They are "cheap flaps", requiring the sacrifice of only a subcutaneous vein and no artery. The flap includes skin and superficial fat tissue, resulting minimal donor morbidity.

- They are long narrow flaps, characterised by an exceptional length-width ratio (4:1 to 8:1).

- They are the thinnest free flaps, fascia is not included in the transfer.

- Their innervation is possible by including volar antebrachial nerves in parallel with the vein.

- Donor site dissection is very easy and quick

- Microvascular anastomoses are reliable by using these flaps.

- Post-operative evolution is unreliable: all flaps show venous congestion which generally subside after ten to 14 days. In most of the cases post-operative course is uneventful; other times partial necrosis occurs and delayed healing is frequent. In our series total failure rate is $8 \%$.

- When a "perfect" functional result is required at the recipient area, other surgical solutions as neurovascular island units are more acceptable. On the other hand, arterialised venous free flaps are a successful solution for soft tissue defects of digits and hands when local tissue are not available.

\subsection{References}

1. Earley MJ, Milner RH. Dorsal metacarpal flaps. Br J Plast Surg, 40. 333, 1987.

2. Bertelli JA, Khoury Z. Neurocutaneous island flaps in the hand: anatomical basis and preliminary results. Br J Plast Surg, 45: 586, 1992.

3. Dautel G, Merle M. Direct and reverse dorsal metacarpal flaps. Br J Plast Surg, 45: 123, 1992.

4. Atasoy, E. Reversed cross finger subcutaneous flap. J Hand Surg 7: 481, 1982.

5. Cavanagh S, Pho RW. The reserve radial forearm flap in the severely injured hand: an anatomical and clinical study. J Hand Surg, 17B: 501, 1992. 
6. Joshi BB A sensory cross finger flap for use on the index finger. Plast Reconstr Surg 58: 210, 1976.

7. Yu,N , Elliot D. Dorsal V-Y advancement flap in digital reconstruction. J Hand Surg 19: 91, 1994.

8. Nakayama Y, Soeda,S, Kasai Y. Flaps nourished by arterial inflow through the venous system: an experimental investigation. Plast. Reconstr. Surg 67: 328, 1981.

9. Baek SM, Weinberg H, Song Y. Experimental studies in the survival of venous island flaps without arterial inflow. Plast Reconstr Surg 75: 88, 1985.

10. Thatte M, Kamdar N, Khakkar D. Static and dynamic computerised radioactive tracer studies on vital dye staining and theoretical mathematical calculations to ascertain the mode of survival of single cephalad channel venous island flaps. Br J Plast Surg 42: 405, 1989.

11. Tsai TM, Matiko J. Venous flaps in digital revascularization and replantation $\mathrm{J}$ Reconstr Microsurg 3: 113, 1987.

12. Serafin D, Shearin JC, Georgiade N. The vascularisation of free flaps. Plast. Reconstr. Surg 60: 233, 1977.

13. Tsur H, Daniller A, Strauch B. Neovascularisation of skin flaps: route and timing. Plast Reconstr Surg 66: 85, 1980.

14. Gencosmanoglu R, Ulgen O, Yaman C. Mechanisms of viability in rabbit flank venous flaps. Ann Plast Surg 30: 60, 1993.

15. Mundy JC, Panje WR. Creation of free flaps by arterialisation of the venous system. Arch. Otolaryngol 110: 221, 1984.

16. Nichter L, Haines P. Arterialised venous perfusion of composite tissue. Am J Surgery 150: 191, 1985.

17. Voudikis T. An axial pattern flap based on the arterialised venous network: an experimental study in rats. Br J Plast Surg 35: 524, 1982.

18. Honda T, Nomura S, Yamauchi, S. The possible applications of a composite skin and subcutaneous vein graft in the replantation of amputated digits. Br J Plast Surg 37: 607, 1984.

19. Chavoin JP, Rouge, D, Vachaud M. Island flaps with an exclusively venous pedicle. A report of 11 cases and a preliminary haemodynamic study. Br J Plast Surg 40: 149, 1987.

20. Inoue G, Suzuki K. Arterialised venous flap for treating multiple skin defects of the hand. Plast Reconstr Surg 91: 299, 1993.

21. Galumbeck M, Freeman, B. Arterialised venous flaps for reconstructing soft-tissue defects of the extremities. Plast Reconstr Surg 94: 997, 1994.

22. Xiu ZF, Chen ZJ Clinical applications of venous flaps. Ann. Plast Surg 34: 518, 1995.

23. Thatte M, Thatte R. venous flaps. Plast Reconstr Surg 91: 747, 1993.

24. Wolff K, Telzrow T, Rudolph K. Isotope perfusion and infrared thermography of arterialised, venous flow-through and pedicled venous flaps. Br J Plast Surg 48: 61, 1995.

25. Fouscher G, Norris R. The venous dorsal digital island flap or the neutral flap. Br J Plast. Surg 41: 337, 1988. 


\section{Chapter 11 - Development of a new arterialised venous}

flap in the rabbit ear

F. De Lorenzi, J. W. van der Steeg, W. D. Boeckx, R. R. W. J. van der Hulst

(submitted for publication) 


\section{Abstract}

Since Nakayama ${ }^{(6,7)}$ first described an arterialised venous flap with arterial inflow through the venous system, several clinical applications and experimental models have been developed. However, nowadays the mechanism of arterialised venous flap survival and circulation is still not completely understood. Especially the reason of the initial appearance of edema and congestion that slowly resolves between the fifth and the tenth postoperative days is unknown. We developed a new model in the rabbit ear to investigate the microcirculatory changes in the arterialised venous flap immediatly after the creation of the arteriovenous switch and during the period of acclimatization. 


\subsection{Introduction}

In plastic, reconstructive and hand surgery severe skin defects occur regularly, due to burns, tumor excisions, infections and trauma. They require grafting or coverage with flaps, depending on different locations and anatomic characteristics of the defect. A more recent developed technique of coverage is the venous free flap transfer, in which no artery has to be sacrificed at the donor site, decreasing morbidity. There are different types of venous flaps: the "pure" venous flap and the arterialised venous flap. The "pure" venous flap is defined as a flap in which blood flows into the flap through a vein and exits through veins. Since 1985 , several studies ${ }^{(1,2,3,4,5)}$ investigated the circulating mechanism of the pure venous free flaps in animal models. Venous flaps reliability was low and the majority of flaps had partial or total skin necrosis. As a consequence of the poor reliability of the "pure" venous flaps, the arterialised venous flap was developed. The arterialised venous flap is perfused with arterial blood by anastomosing the afferent vein of the flap to a recipient artery. In this way the venous network in the venous flap, nourishing the tissue, is oxygenated with arterial blood.

In 1981 Nakayama et al. ${ }^{(6,7)}$ first described an arterialised venous flap with arterial inflow through the venous system. They concluded that arterial inflow had an enormous effect on the survival in comparison with flaps with "purely" venous inflow. Nowadays the mechanism of arterialised venous flap survival is still not completely understood. Especially the cause of initial appearance of edema and congestion that slowly resolves between the fifth and the tenth postoperative days, is unknown. Pittet en al. ${ }^{(8)}$ thought it reasonable to hypothesize that the resolution of venous congestion in the flap is either due to neovascularisation or to an adaptation of the vascular network within the flap. However, the pathophysiological changes in the arterialised venous flaps are scarcely investigated. The time direct after the anastomosis between the recipient artery and the afferent vein of the flap till the acclimatization of the flap on the recipient bed determines the survival changes for the flap. Especially during this acclimatization period several questions are still unsolved. Main questions which have to be solved are: how does the arterialised venous flap acclimatize to its new blood supply especially to the high pressure in the venous system? Is it possible to decrease the postoperative edema and congestion which will increase the flap survival? How important is the angiogenesis in the flap survival and is it possible to influence this?

To study the microcirculatory changes we developed a model of the arterialised venous flap in the rabbit ear. The rabbit ear has a central artery and vein for blood supply. It is possible to anastomose the artery on the vein (arteriovenous switch). Moreover, through a previous created window long-term microscopical observations on the microvasculature and surroundings tissues can be obtained and the flow can be investigated.

Our study is derived from the study Suzuki et al..$^{(9,10)}$ performed in 1994 . They created an arterialised venous flap in the rabbit ear distally to venous shunts and followed the microcirculatory changes six hours after the arteriovenous switch. The relevant difference between this model and the new one we developed is that we used a more 
proximal venous arcade of the rabbit ear and completely disconnected blood vessels "from and to" the designed flap by dissecting the flap all around. In this manner, we reproduced an arterialised venous free flap which is similar to the clinical situation. We investigated microcirculatory changes occurring one hour after the arteriovenous switch. Our aim was to develop a model suitable for studying microcirculation in the arterialised venous flaps.

\subsection{Materials and methods}

Three adult male New Zealand White Rabbits weighing 4000-4500 g were used on both sides. After shaving the hair on the ear, the rabbit ear chamber was implanted six centimeters from the top of the ear adjacent to the central vessels. The chamber we used was described by Pollock et al. ${ }^{(11)}$.

The rabbit was anaesthetized using ketamine (Nimatek) $0.5 \mathrm{ml} / \mathrm{kg}$ i. m. and xylazine (Sedamun) $0.25 \mathrm{ml} / \mathrm{kg}$ i. m. For antibiotic prophylaxis the animal was given Pentrexyl $1.25 \mathrm{ml} \mathrm{i.} \mathrm{m}$. After these injections the ear was shaved and the window implantation place marked with ink. Two Thermanox cover-slips were prepared. The rabbit was positioned, the ear was disinfected and draped as a sterile field. Using a dissecting microscope, a circle of ventral skin (10 mm diameter) was scored using knife 15 . The underlying cartilage was removed. With a $30 x$ magnification the remaining thin fibrous layer was removed to create a good view on the vascular network. The minimal bleeding was controlled and flushed with $\mathrm{NaCl} 0.9 \%$. At the border two incisions were made. The skin and the cartilage of the border were raised as a unit. A cover-slip is then rinsed with normal saline and carefully placed over the vascular bed. The two Thermanox coverslips (with eight anchoring holes) were secured with eight $4 / 0$ Ethilon stitches. The pressure between the cover-slips should be adjusted so that the circulation beneath the window is not compromised. The implantation is now complete (fig. 1).

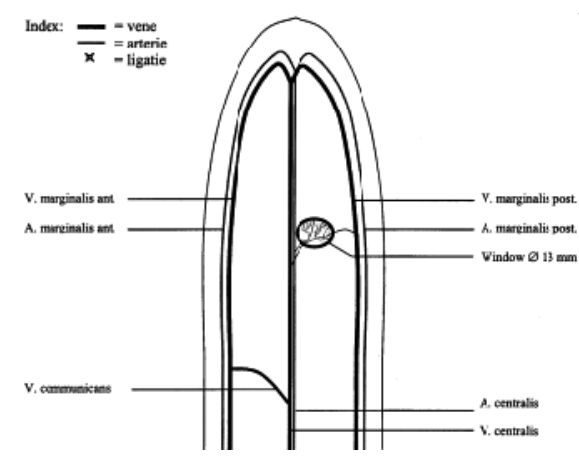

FIG. 1 Schematic drawing of the rabbit ear with window used in our experiment. 
In the first rabbit ear we didn't use the dorsal cover-slip. Directly after the experiment there was formation of oedema, which stabilized after four days. This oedema didn't allow us to have a microscopic view of the vascular bed through the window. The next five windows were placed successfully. In the first week no other surgical procedures were done to allow the rabbit ear to recover after surgery. Within the first week 1 of these five chambers became infected.

One week after the implantation of the window the rabbit was anaesthetized again. The "physiological" microcirculation was observed by transluminating the window with microscopic magnifications ranging from 50 to 550 times normal. The microcirculation was recorded with a Panasonic video monitor and a camera. A map of the window was created with a Mitsubishi video printer at 200 times normal. On this map areas to be observed were marked.

After analysing the "physiological' microcirculation the anaesthetized rabbit was prepared for the arteriovenous anastomosis. The flap $(2 \times 2 \mathrm{~cm})$ was marked with ink on the ear. This area ranched from the central artery and vein to 2 centimeters from the posterior border. The rabbit was positioned, the ear disinfected and sterile draped. At the base of the ear an incision was made. The central artery and vein were identified and dissected. The artery was distally ligated with a $4 / 0$ Ethilon wire, the vein proximally. With microsurgical instruments and a 10/0 Ethilon wire the central artery and the central vein were anastomosed and checked for leaking. The wound was closed.

Later the marked venous flap was cut through the skin till the cartilage. At this point the artery was identified and cut proximally and distally to the venous flap. The vein was kept undamaged. With a bipolar coagulator the venous flap margin was coagulated to be sure no connections, except for the arteriovenous shunt, were present. With a few stitches at the margins of the flap the skin was fixed on the ear (fig. 2).

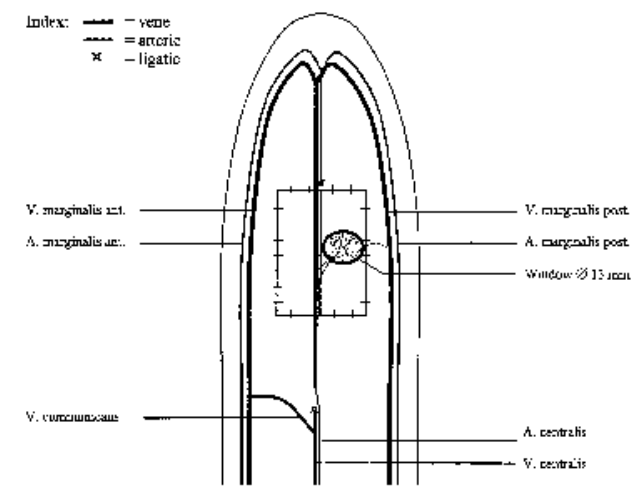

Fig. 2 Schematic drawing of the rabbit ear with window and arterialised venous flap used in our experiment. 
One hour after the arteriovenous shunt the microcirculation was observed by transluminating the window with microscopic magnifications ranging from 50 to 550 times normal. The microcirculation was recorded with a video monitor and a camera.

\section{Microcirculation and Experiments}

\section{Overview}

With a video printer we created an overview of the microcirculation in the window with microscopic magnification 50 times normal, one week after the implantation of the window. On this overview we indicated the arteries, the veins, the flow direction and the areas we would analyze directly after the anastomosis between the artery and the recipient vein (arteriovenous switch).

\section{Flow}

With a video we recorded the microcirculation with microscopic magnification 220, 325 and 550 times normal. We defined a network with a divergent flow pattern as arterial and a network with a convergent flow pattern as venous. Three arteries and three veins were selected to be compared before and after the arterio-venous switch, each vessel with the three magnifications during five minutes.

On-line

With BDO (a Bi-Directional Optical three-stage prism grating system for on-line measurement of red blood cells velocity in microvessels) and fiber optic light we tried to measure the blood velocity in the selected vessels on line.

\section{Off-line}

We analyzed the obtained video material with CapiFlow (capillary flow measurement). In this way we tried to measure the blood velocity off-line in the six arteries and veins.

Microangiography

Immediately after rabbit sacrifice (28 days after flap creation), microangiography was performed to visualize the vascular network of the arterialised venous flap. The rabbit ear was amputated and a small catheter was placed into the central vein to inject télébrix, 350 (a mixture of Natriumjoxitalamaat and Megluminejoxitalamaat). Two X-rays were made.

\section{Histology}

After rabbit sacrifice, the ears containing the arterialised venous flaps were preserved in Formaline for one day. The next day tree pieces were taken, which contained both normal skin and venous flap skin. These pieces were embedded, sliced and HE and EvG (Elastine von Gieson) coloured. 


\subsection{Results}

\section{Microcirculation}

The vascular network of the rabbit ear is complex. Arteries and veins resemble each other, many arterio-venous shunts are present and the blood flow is variable. Nevertheless it was possible to distinguish the venous and arterial network in the window (fig. 3a). The venous network is situated superficial in the dorsal skin with regard to the arterial network. The arteries have a pulsating flow, the veins a more constant flow. In the larger vessels the flow is to fast to be visualized. Only in venules, arterioles and capillaries flow is visible.

One hour after the arterio-venous switch the haemodynamic behavior gradually changed. Directly after the switch a "to and fro" flow pattern was visible in the switched vein. The arterial inflow and the outflow through the distal vein were unchanged. Slightly the "to and fro" flow was replaced by a one way inflow, although the blood was shunted directly to the outflow vein. This resulted in a inefficient circulation. Gradually, after two hours the blood flew into a large area of vascular system (fig. 3b), probably due to a decreasing vasospasm in the switched vein.

Finally we could observe three flow systems:

- One arterial inflow system (three main arteries)

- One venous inflow system (one A-V switched vein)

- One venous outflow system (two main veins)

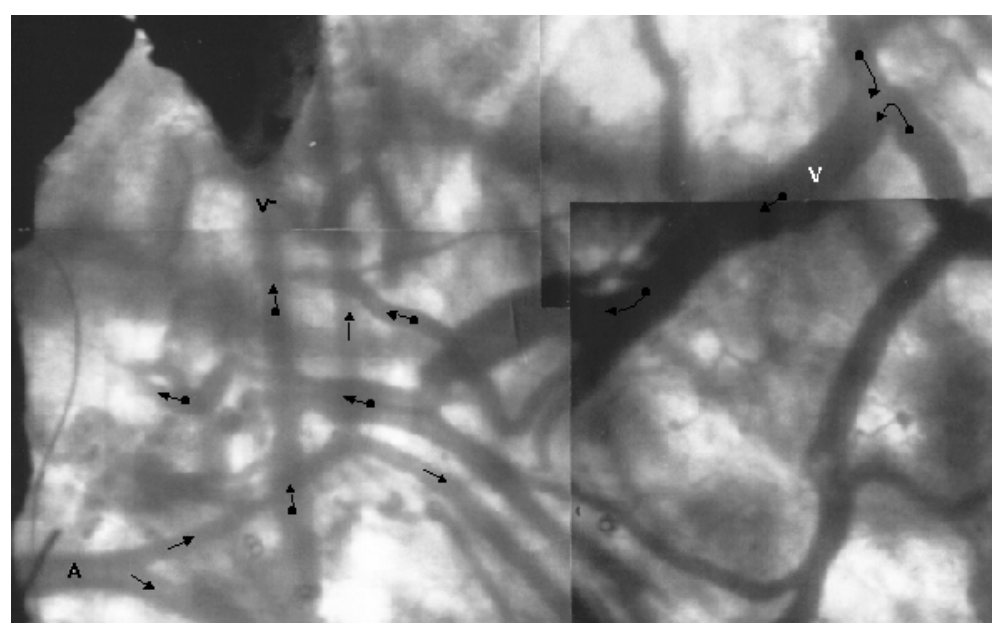

FIG. 10a Overview of a part of the vascular network, before the arterio-venous switch. 


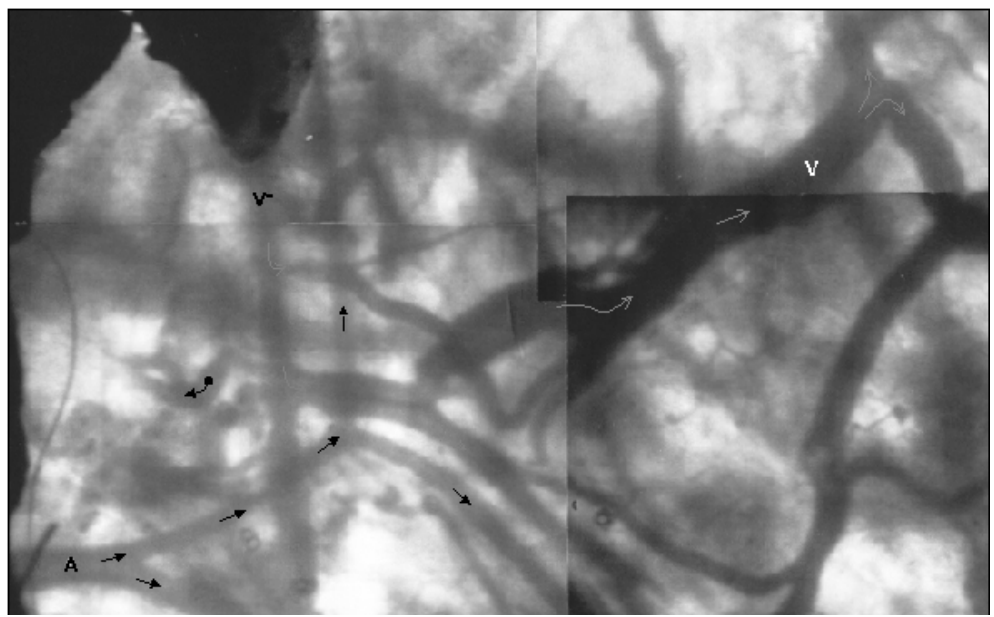

FIG. 3b Overview of a part of the vascular network, two hours after the arterio-venous switch. FIG. 3a,b- A-artery, V-vein, $V^{*}$-anastomosed vein, arrows-flow (

\section{Macroscopy}

\section{The window}

No blood was seen in the vascular network in the window directly after the implantation. This was probably due to the increased pressure between the two cover-slips. One day after the implantation vessels were visible, the window was well fixed. The rabbit did not seem to be troubled by the window. There were only marginal signs of acute inflammation. One week later vascular network in it had acclimatized.

\section{The venous flap}

There was capillary refill in the arterialised venous flap directly after creation. One day later the flap became oedematous and purple/pink coloured. The ear was drooping. Within a week flap had a normal pink colour, although the oedema was still visible. Flap necrosis did not occur. Four weeks after the flap creation the flap had grown into the rest of the ear.

\section{Microangiography}

The X-rays showed us an increased vascular density in the flap region. New vessel were grown into the venous flap. This showed that neovascularization already appeared within 28 days (fig. $4 a, b)$. The circle is where the window implanted. Many vessels have grown into the AV-flap (straight white lines to window). The arrows show examples of the neovascularisation into the arterialised venous flap.

\section{Histology}

In the HE slides a moderate inflammation was visible in the area near the cover-slip. There was an increased amount of vessels in the flap compared to the normal skin, 
probably due to neovascularisation. The central artery was obliterated. In the EvG the central vein didn't show the expected transformation due to adaptation to the arterial pressure.
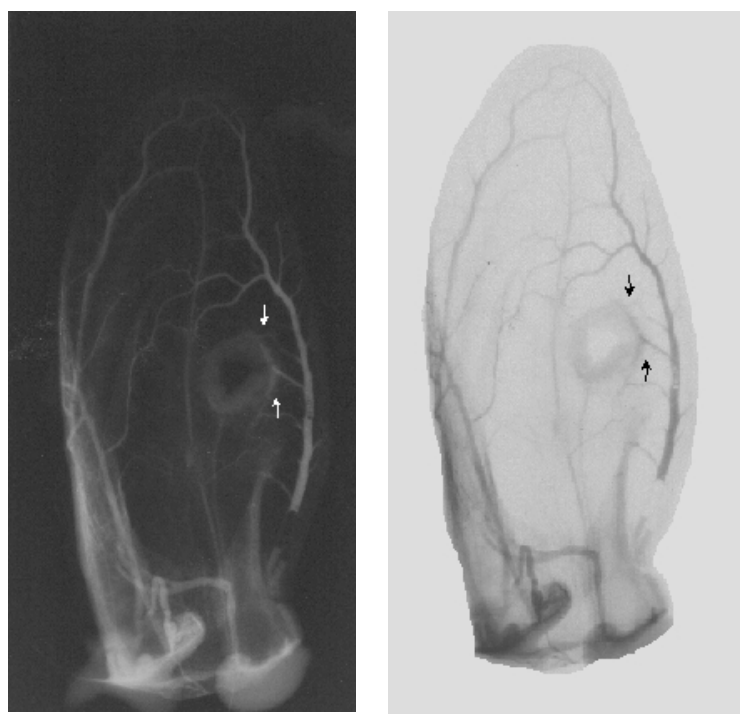

Fig 4-a

Fig 4-b

FIG.4a X-ray of the rabbit ear four weeks after the AV-switch and the AV-flap creation.

FIG.4b The same X-ray in negative.

The arrows indicate an increased vascular density in the flap region.

\subsection{Discussion}

Since Nakayama ${ }^{(6,7)}$ first reported an arterialised venous flap with arterial inflow through the venous system, several clinical applications have been described. In all situations, congestion and edema sustained for 3 to 6 weeks and resulted in partial or total necrosis. Nowadays the mechanism of arterialised venous flap survival and circulation is still not completely understood despite of several experimental models. This study was designed to develop a new model in the rabbit ear to study the microcirculatory changes in the arterialised venous flap immediatly after the creation of the arteriovenous anastomosis and during the period of acclimatization.

The rabbit ear has several attributes that make it a suitable model for an arterialised venous flap, including a consistent vascular anatomy with various hemodynamic pathways, a lack of valves in the veins, and its peripheal location, allowing easy access and monitoring. Suzuki et al. ${ }^{(9)}$ proved that although the rabbit ear model has no valves, it is still comparable to a human venous flap. With a ligature on the central vein they simulated competent venous valve function and demonstrated how the blood flow can 
circumvent the competent venous valve to perfuse the distal part of the rabbit ear. The implantable window we used is the one described by Pollock. It allows repeated visualization of networks of preformed arterioles, venules and anastomotic channels. It is well tolerated and implantation is relatively easy and quick.

Inspired by the study of Suzuki et al. ${ }^{(9,10)}$, this rabbit model introduces important modifications. The first modification was the implantation of the window over a more proximal venous arcade in the rabbit ear close to the central vein. The second was the design of the venous flap. We used a part of the ear instead of the whole ear. Third, the essential change was that we dissected the flap all around, disconnecting all blood vessels from the designed flap, except of the central vein. This is similar to arterialised venous flaps used in clinic and avoids any other vessel ligation at the base of the ear, as performed by Suzuki.

Already in the first two hours after the arteriovenous switch the haemodynamic behaviour was investigated. Directly after the switch a "to and fro" pattern was visible in the switched vein. The arterial inflow and the outflow through the distal vein were unchanged. Progressively the blood flow through the anastomosed vein was increasing from a sluggish intermittent flow to a more steady flow in a constant direction. In addition, the blood was shunted directly in the outflow vein and resulted in a inefficient circulation. Gradually, after two hours the blood flew into a large area of vascular system, probably due to or increasing vasodilatation or decreased resistance to arterial pressure in the vein. This finding may be interpreted as meaning that the vasoactivity in the anastomosed vein plays a role in the initial haemodynamic acclimatization. Influencing this vasoactivity might influence the flap survival.

Macroscopically, one day after the arteriovenous switch the flap became oedematous and congested; however the absence of flap necrosis showed us that our work was successful.

Microangiography performed 28 days after switch creation showed an increased vascular density in the flap region. New vessels were grown into the venous flap. Histological findings confirmed this results showing an increased amount of neovascularisation. This neovascularisation could be necessary for the long term survival of the flap, although we can not exclude that the neovascularisation might be induced by the moderate inflammation.

The absence of the transformation of the central vein was not conform our expectations. We expected a more obvious proliferation of the intima and the media in the central vein after exposure to the arterial pressure.

This study showed that our model is feasible to study the circulation in the arterialised venous flap. To prove reproducibility the number of rabbits has to increased. Although we made some interesting observations we can not make conclusions regarding flow changes in the venous flap. 


\subsection{References}

1. Baek SM, Weinberg $\mathrm{H}$ and Biller HF. Experimental studies in the survival of venous island flaps without arterial inflow. Plast Reconstr Surg Vol. 75, No. 1; 88-95, 1985.

2. Yuan R, Shan $Y$ and Zhu S. Circulating mechanism of the "pure" venous flap: direct observation of microcirculation. J Reconstr Microsurg, Vol. 14, No.3; 147-152, 1998.

3. Yilmaz M, Adnan M and Barutçu C. Effects of the number of pedicles on perfusion and survival of venous flaps: an experimental study in rabbits. Ann Plast Surg, Vol. 39, No. 3; 278-286, 1997.

4. Xiu ZF and Chen ZJ. The microcirculation and survival of experimental flow-through venous flaps. Br J Plast Surg, Vol. 49; 41-45, 1996.

5. Matsushita K, Firrell JC and Tsai TM. Blood flow and tissue survival in the rabbit venous flap. Plast Reconstr Surg, Vol.91, No. 1; 127-135, 1993.

6. Nakayama $Y$, Soeda $S$ and Kasai $Y$. Flaps nourished by arterial inflow through the venous system: An Experimental investigation . Plast Reconstr Surg, Vol. 67, No. 31; 328-334, 1981.

7. Nakayama $Y$, Soeda $S$ and Kasai $Y$. The importance of arterial inflow in the distal side of the flap: an experimental investigation. Plast Reconstr Surg, Vol. 69, No. 1 ; 63-67, 1982

8. Pittet $B$, Chang $P$ and Cram AE. The role of neovascularization in the survival of an arterialized venous flap. Plast Reconstr Surg, Vol. 97, No. 3; 621-629, 1996.

9. Suzuki $\mathrm{Y}$, Suzuki $\mathrm{K}$ and Ishikawa K. Direct monitoring of the microcirculation in experimental venous flaps with afferent arteriovenous fistulas. Br J Plast Surg, Vol. 47; 554-559, 1994.

10. Suzuki Y, Suzuki K and Ishikawa K. Tissue transfer with a distal to proximal arteriovenous anastomosis for venous drainage: microcirculatory analysis on the rabbit ear model. Scan J Plast Reconstr Hand Surg, Vol. 28; 15-18, 1994.

11. Pollock FE, Smith TL and Smith BP. Decreased microvascular perfusion in the rabbit ear after six hours of ischemia. J Orthopaedic Res, Vol. 12; 48-57, 1994. 


\section{Chapter 12 - Discussion}

Although microvascular surgery now exists for more than four decades, we still do not have the ideal solutions for all situations. This thesis consists of several descriptive studies in which technical and/or clinical problems are attacked. In a period in which evidence based medicine is the standard, a major drawback is that these studies are not double blind randomised trials. However, in these kind of studies it is impossible to perform such a study due to several reasons. First, the surgeon confronted with a technical problem has to find an instant solution depending on the specific situation. It is impossible to predict the kind of situations in which techniques described in this thesis have to used. Second, it is typical in plastic surgery that there are several ways to solve a clinical problem. There is no standard treatment in the majority of clinical cases. This makes the design of trials impossible. Third, if the above mentioned topics could be solved, there remains an ethical problem. The experience of the surgeon prohibits the use of inferior techniques. To our opinion, although the studies are descriptive, they can contribute to a further development in reconstructive surgery.

Making a microvascular anastomosis remains a technical challenge. The purpose of improving the microvascular surgical techniques is both the decreased time required to make the anastomosis and the lowered risk of thrombosis at the anastomosic site. There are several ways to achieve these goals. First, the technical skills of the surgeon have to be maximised. For this reason education of microsurgery should be well organised and the possibility for residents to practise microsurgery should be optimised. Second, the instruments and materials should be of outstanding quality. Since the introduction of microsurgery there has been a tremendous development in quality of the instruments and suture materials for microsurgery ${ }^{(1-13)}$. In difficult situations, however, we still don't have structural solutions.

Improving tissue and flap engineering and modifying the microcirculatory properties of composite tissues are important goals of this thesis. Examples of these are the horseshoe expanded free flaps and the venous free flaps. In this way we can go beyond the limits of the "care as usual".

First by changing the microcirculation in a free flap we are able to develop a complete new era of reconstructive surgery. Interfering with the natural properties of the blood vessels and changing their properties allows us to perform tissue engineering not only in the sense of shaping the tissues but in the sense of developing new angiogenesis controlled properties (angiosomas). Extensive interference in microcirculation is shown by the arterialisation of the venous network. It is possible to rearrange microcirculation in such a way that without using arterial network a flap will survive.

In the example of the horse shoe expansion we relocated venous drainage by using unconventional expansion. By expanding the tissue in a specific way, vascular reorganisation will occur which in this case overcomes the clinical problem of venous congestion. This is a typical example by which the use of a new concept can overcome a clinical problem. Other ways to change vascular supply of tissue can also developed 
in the future. An example might be staged surgery in which specific vascular supply is increased by endoscopic ligation of secondary pedicles.

The size of the tissue to be transplanted can also be augmented. This should be done without increasing donor site morbidity. The horse shoe expanded flap again is a good example of this. Another way to increase size is to interfere with the metabolic properties of the vascular network. E.g using vasoactive substrates like nitric oxide may increase the angiosoma.

Third specific tissue properties can be changed. By expansion e.g. the overlying tissue is thinner making the flap not only useful for "care as usual". Another example of changing tissue properties could be the development of tissue to replace a diseased joint. The use of the temporalis fascia may be an initial step towards the development of this joint prefabrication in the wrist. It has been shown that this technique can be used with good results. The technique may be further developed by using transplanted cultivated chondrocytes on this well vascularized fascia and folding the fascia in the original joint architecture. This may open the way towards a future with complete reconstruction of a joint. The use of specific growth factors may also be used to modify and precondition a free tissue transfer. It might be possible to increase the amount of fat in the tissue transferred e.g. in breast reconstruction. Another application in the future would be the stimulation of precursor cells to transform into chondrocytes and or osteocytes which can be used for joint and bone repair. The whole concept of prefabrication of tissues will be one of the most interesting areas of plastic surgery in the near future.

Finally, it is important to perform basic studies. Our investigation of the microcirculation in the rabbit ear was used as a pilot study in the development of tissue engineering models with microsurgical techniques. Creation of a new arterial axis line, arising from a venous channel, was studied in the rabbit ear. This in a first step of studying the basic mechanism of angiogenesis in prefabricated free flaps, with the aim to further improve our understanding how development of arterial input can be stimulated. Other experimental works were performed in our laboratory as the application of microsurgical tubular anastomoses in the rabbit using the VCS staples to increase the speed of surgery with minimal tissue trauma ${ }^{(14)}$. Exploring the basic factors of microsurgical tissue trauma prevention improves our knowledge of wound healing by studying the factors involved in surgical trauma and its decrease by the use of refined microsurgical techniques. "Noli me tangere", been one of the basic principles in infertility microsurgery, can be applied to a broader range of microsurgical techniques, further limiting tissue trauma by using the benefits of high power magnification to better identify the quality of our surgery, to better understand the extent of our tissue trauma, leading us to the detection of factors that can be eliminated in order to improve rapid primary wound healing, decreasing the risk of postoperative lesions or microvascular thrombosis. 
This thesis illustrates several new areas of development in reconstructive and microvascular surgery. It is possible that not all the described techniques will survive, however everything described will contribute to further improvement of microvascular techniques or the development of new clinical applications with improved outcome.

\section{References}

1. Salmon PA, Assimacopoulos A. A pneumatic needle holder suitable for microsurgical procedures. Surgery 55: 446, 1964.

2. Buncke HJ jr, McLean DG. The advantage of a straight needle in microsurgery. Plast Reconstr Surg 47: 602, 1971.

3. O’Brien BM, Hayhurst KW. Metallized microsutures and a new micro-needle holder. Plast Reconstr Surg 52: 673, 1973.

4. Acland RD. New instruments for microvascular surgery. Br J Surg 59: 181. 1972.

5. Acland RD. Microvascular anastomosis: a device for holding stay sutures and a new vascular clamp. Surgery 75: 185, 1974.

6. Acland RD. A flat bodied needle for microvascular surgery. Plast Reconstr Surg 61: 793, 1978.

7. Daniel RK, Olding M. An absorbable anastomotic device for microvascular surgery: experimental studies. Plast Reconstr Surg 74: 329, 1984.

8. Hoerenz P. The operating microscope. I. Optical principles, illumination systems and supporting system. J Microsurg 1: 364, 1980.

9. Hoerenz P. The operating microscope. III. Accessories. J Microsurg 2: 22, 1980.

10. Lang WH, Machel F. Zeiss Microscopes for microsurgery. Springer Verlag, Berlin, 1981.

11. Cham RB, Peimer CA, Howard CS, Walsh WP, Eckert BS. Absorbable versus non-absorbable suture for microneurorrhaphy. J Hand Surg 9: 434, 1984.

12. Krag C, Larsen J, Reumert T. Handling properties and trombogenicity and microsutures. J Microsurg 2: 202, 1981.

13. Pitt TTE, Humphries NLM. Microarterial anastomosis in the rat: the influence of different suture materials on the patency, strength and the electron microscopic appearance of the vessels. $\mathrm{Br}$ J Plast Surg 35: 150, 1982.

14. Boeckx W, Darius O, Van den Hof B, Vandevoort M. Scanning electron microscopic analysis of the stapled microvascular anastomosis in the rabbit. Ann Thorac Surg 63: 128, 1997. 


\section{Summary}

This thesis discusses new techniques, applications and refinements in microvascular surgery with the purpose to overcome current limitations and practical problems. The first three chapters describe novel developments in basic microvascular anastomosis techniques. One major problem in performing microvascular anastomosis is the discrepancy in diameter of the vessels. There are several solutions to overcome this problem. One of these is the use of the so called $Y$ anastomosis which is discussed in chapter 2. The $Y$ anastomosis is an end-to end anastomosis between three vessels: two small one on one side and a larger vessel on the opposite side. This type of anastomosis is recommended when a vessel discrepancy exists of more than 2-3:1 ratio. Used in such cases reliability and patency rate are comparable with conventional techniques. For minor size discrepancies, less than 1,5-2:1 ratio, the mattress anastomosis is described in chapter 3 . This technique is used to decrease the larger vessel diameter adjusting it to the smaller one. The interrupted mattress suturing technique is a quick, safe and reliable solution for mild incongruent end-to-end anastomoses.

In chapter 4 a new technique to make microvascular anastomosis with the use of individual titanium staples is described in clinical practise. The possibility to individually staple each small segment of an anastomosis, comparable to suture type anastomosis, allows performing both venous and arterial anastomoses. This is an advantage over the predefined and not adjustable type of anastomoses when using the UNILINK or 3M anastomotic device. The technique is discussed and proved to be useful in selected cases.

The fifth and the sixth chapters discus new applications in microsurgery.

In chapter 5 a new indication for free temporalis fascia transfer is discussed. It is used to create a neo wrist by making a pseudo-articular surface in wrist ankylosis. It's application significantly increased function of the wrist in young patients affected by juvenile rheumatoid arthritis. To our opinion the procedures eliminates or postpones the indication for an arthrodesis or arthroplasty in selected cases with no wrist instability. In the chapter 6 a new technique of tissue-expanding is presented. Horseshoe expansion makes it possible to modify the microvascular properties and the venous drainage of a free flap. In this case a horse shoe expansion of the scapular flap is described. The main advantages are: increased flap survival, better shape and augmented size of tissue to be transplanted.

The following chapters describe refinements and experiences of microsurgery. In chapter 7 the selection of different recipient vessels for free tissue transfer in breast reconstruction are compared. The use of the mammary artery and vein as recipient vessels is shown to be superior compared to the axillary system. In chapter 8 the selection of different free flaps and timing of reconstruction in burned patients is discussed. In chapter 9 we describe the reconstruction of the ala of the nose using a composite free flap from the ear helix.

In the last part of the thesis the arterialised venous free flaps is discussed in clinical 
practice (chapter 10) and in an animal model (chapter 11). The arterialised venous flap makes it possible to transfer free tissue without using an artery. This is advantageous, because donor site morbidity can be reduced. Indications, techniques and results are discussed. In the last chapter an animal model to study microcirculation in arterialised flaps is described.

\section{Riassunto}

Nella tesi sono discusse nuove tecniche, nuove applicazioni e raffinatezze in microchirurgia per superare i limiti e i problemi della pratica clinica.

I primi tre capitoli descrivono alcune novità che riguardano le tecniche anastomotiche di base. Uno delle evenienze più frequenti è la discrepanza di calibro fra i vasi da anastomizzare. Per superare questo problema esistono diverse soluzioni: fra queste nel secondo capitolo è descritta l'anastomosi Y. Si tratta di una anastomosi terminoterminale fra tre vasi: due di calibro minore da un lato e uno di maggior diametro dall'altro, indicata per incongruenze superiori a 2-3:1. In questi casi l'anastomosi $Y$ ha mostrato una affidabilità e una percentuale di pervietà del tutto sovrapponibile alle tecniche convenzionali. In caso di incongruenze inferiori a 1,5-2:1, nel terzo capitolo è descritta l'anastomosi "a materassaio", costituita cioè da singoli punti staccati "a materassaio", grazie ai quali il diametro del vaso maggiore è ridotto fino a raggiungere quello del vaso di calibro minore. Questa anastomosi è veloce, sicura e affidabile per incongreunze moderate in caso di suture termino-terminali.

$\mathrm{Nel}$ quarto capitolo è descritto l'utilizzo di singole graffette in titanio per effettuare anastomosi microchirurgiche nella pratica clinica. La peculiarità di applicare singolarmente le graffette, così come sono applicati i singoli punti nelle anastomosi classiche, fa si che questa metodica di sutura sia possibile sia per le arterie che per le vene, a differenza di quanto accade con altri dispositivi meccanici predefiniti come UNILINK o $3 \mathrm{M}$ device. In casi selezionati la tecnica è risultata essere utile e sicura. Il quinto e il sesto capitolo descrivono due nuove applicazioni della microchirurgia. Nel quinto capitolo è descritto il trasferimento della fascia temporale superficiale per ricreare l'articolazione del polso, mimando la superficie articolare. Essa previene la rigidità articolare e l'immobilità in giovani pazienti affetti da artrite reumatoide. Questa metodica elimina o ritarda la necessità di dover effettuare una artrodesi o artroplastica in casi clinici selezionati che non presentano instabilità del polso.

Nel sesto capitolo è descritta una nuova metodica di espansione tissutale, a "ferro di cavallo" che permette di modificare il microcircolo e il drenaggio venoso dei lembi liberi. Ciò permette di migliorarne la sopravvivenza, la forma e di aumentarne le dimensioni. I capitoli successivi descrivono l'evoluzione della microchirurgia. Nel settimo capitolo sono analizzati i diversi siti riceventi in caso di ricostruzione mammaria con lembi liberi; i vasi mammari interni sono risultati essere migliori rispetto a quelli ascellari. Nell'ottavo capitolo sono presi in considerazione la selezione dei diversi lembi liberi disponibili e il tempo della ricostruzione in pazienti ustionati. Nel nono capitolo descriviamo la 
ricostruzione dell'ala nasale con un lembo libero composto prelevato dall'orecchio.

Nella parte finale della tesi, è analizzato l'utilizzo dei lembi liberi venosi arterializzati nella pratica clinica (capitolo 10) e in un modello animale (capitolo 11). Lo scolpimento di questo lembo permette il trasferimento dei tessuti a distanza senza sacrificare alcun asse arterioso, riducendo pertanto la morbidità della regione donatrice. Sono descritte le indicazioni, la tecnica chirurgica e i risultati. Nell'ultimo capitolo l'allestimento di un nuovo modello animale permette di studiare il microcircolo dei lembi venosi arterializzati.

\section{Samenvatting}

Dit proefschrift beschrijft nieuwe technieken, toepassingen en verfijningen in de microchirurgie. Het doel hiervan is een aantal van de beperkingen en praktische problemen van de microvasculaire chirurgie op te lossen.

De eerste drie hoofdstukken beschrijven nieuwe ontwikkelingen in de basale microchirurgische anastomose technieken. Een belangrijk probleem bij het maken van een anastomose is het verschil in diameter van de vaten. Er zijn verschillende oplossingen voor dit probleem. Eén hiervan is het gebruik van de zogenaamde $Y$ anastomose welke in hoofdstuk 2 bediscussieerd wordt. De $Y$ anastomose is een zogenaamde end to end anastomose tussen drie vaten: twee kleine aan een kant en een grote aan de andere kant. Dit type anastomose wordt geadviseerd bij een vaat discrepantie van meer dan 2-3:1. Wanneer in deze gevallen de $\mathrm{Y}$ anastomose techniek gebruikt wordt is de betrouwbaarheid vergelijkbaar met een "routine" microvasculaire anastomose. Bij kleinere diameter discrepanties, kleiner dan 1,5-2:1, kan gebruik gemaakt worden van de matras anastomose, welke in hoofdstuk 3 beschreven wordt. Deze techniek wordt gebruikt om het grotere vat te verkleinen en aan de diameter van het kleinere vat aan te passen. Deze techniek is snel, veilig en betrouwbaar bij milde diameter verschillen.

In hoofdstuk 4 wordt het gebruik van titanium nietjes beschreven in de microvasculaire chirurgie. De mogelijkheid om individueel elk segment van de anastomose te nieten, vergelijkbaar met hechten, maakt het mogelijk zowel een veneuze als arteriële anastomose te maken. Dit in tegenstelling tot andere "geautomatiseerde" microvasculaire technieken zoals UNILINK of $3 \mathrm{M}$. De toepassing wordt beschreven in klinische gevallen.

Het vijfde en zesde hoofdstuk behandelen nieuwe toepassingen in de microchirurgie. In hoofdstuk 5 wordt een nieuwe indicatie voor de vrije fascia temporalis transplantatie beschreven. De fascie wordt gebruikt om een nieuw gewricht te maken bij ernstige verstijving van de pols. Deze toepassing verbetert de functie van de pols aanzienlijk in jonge mensen welke een ernstige verstijving van de pols hebben zoals dit voorkomt bij juveniele rheumatoide arthritis. Naar onze mening maakt deze ingreep een arthrodese of arthroplastiek in gevallen zonder pols instabiliteit minder snel noodzakelijk.

In hoofdstuk 6 wordt een nieuwe manier van weefsel expansie beschreven. De zogenaamde hoefijzer expansie wordt gepresenteerd. Hoefijzerexpansie maakt het 
mogelijk microvasculaire eigenschappen en veneuze drainage van een vrije lap te beïnvloeden. In dit geval wordt hoefijzerexpansie bij de scapula flap gepresenteerd. De belangrijkste voordelen zijn: verbeterde flap overleving, betere vorm, en toename weefsel te gebruiken voor reconstructie.

De volgende hoofdstukken beschrijven verfijningen en ervaringen in de microchirurgie. In hoofdstuk 7 wordt de keuze tussen de verschillende acceptorvaten bij borstreconstructie middels vrije weefsel transplantatie besproken. De arteria en vena mammaria blijken superieur aan het axillaire systeem. In hoofdstuk 8 wordt de keuze en timing van vrije flappen bij secundaire brandwond reconstructie beschreven. Hoofdstuk 9 bediscussieert de reconstructie van de ala van de neus middels een vrije lap van de oorhelix.

In het laatste deel van het proefschrift wordt het gebruik van de gearterialiseerde veneuze lap bediscussieerd in de kliniek (hoofdstuk 10) en in een diermodel (hoofdstuk 11). De gearterialiseerde veneuze lap is een vrij lap welke van bloed voorzien wordt via het veneuze vaatbed. Het gebruik van deze lap maakt het mogelijk weefseltransplantatie te verrichten zonder een arterie op te hoeven offeren. Hiermee kan de donor morbiditeit beperkt worden. De indicaties, techniek en resultaten worden getoond. In het laatste hoofdstuk wordt een diermodel beschreven waarin het mogelijk is microcirculatie te bestuderen in een gearterialiseerde veneuze lap. 


\section{Acknowledgements}

The clinical and experimental research performed around this thesis was performed in the Department of Plastic and Reconstructive Surgery of the University Hospital of Maastricht (chief: Prof. Dr. W. Boeckx). This work could not have been completed without the help of a large number of co-workers and friends. I am indebted to all of them and I wish to express my feelings of gratitude and respect to everybody who helped me to achieve my goal.

Prof. Dr. Willy Boeckx, my promoter, has been the key person in the development of this thesis, offering his endless energies, creative ideas and all the data included in the thesis. Thanks for believing in my clinical work and research, for supporting me every moment I spent in Maastricht and for the pleasant working atmosphere you created. You taught me how to write a scientific article and how to improve my microsurgical skills, pointing out tricks and pitfalls.

Dr. René van der Hulst, co-promoter of this thesis and a good personal friend. His friendship is something very precious and highly appreciated. Thank you for supporting, constructing and planning my work, for reviewing and analysing my data and findings in the scientific way, for co-writing the scientific data. You encouraged me to go on during the dark moments.

I wish to express my profound feeling of gratitude to Dr. Grazia Salimbeni (former teacher of Plastic Surgery, Pisa) for training me and moulding me into a plastic surgeon. Her open-minded disposition provided me with all the opportunities a young surgeon needs and guided me through my training. She introduced me to the international plastic surgery community and organised my stay in Maastricht, which gave me the opportunity of writing this thesis.

Also the efforts of the different members of the degree committee are highly appreciated: Prof. dr. Evers, chairman, Prof. dr. Jacobs, Dr. Hagen, Prof. dr. Van Kerrebroeck, Prof. dr. Asko-Seljavaara. Especially Dr. Hagen and Prof. dr. Asko-Seljvaara do deserve my gratitude for their suggestions to the thesis. I thank this committee and the Dean of the Faculty of Medicine of the University of Maastricht, Prof. dr. Nieuwenhuijzen Kruseman. My gratitude also goes to my friend Massimo Sangiorgi for making the layout of the thesis and to John Sawor being my paranymph.

Finally I would like to thank my husband Sanni and my family for their support and for being patient when I was busy with the thesis. 


\section{Curriculum vitae}

Francesca De Lorenzi was born on November 13th, 1970 in Lucca, Italy. She graduated in 1989 from the "Vallisneri- scientific lycee" in Lucca. She continued her studies at the Medical Faculty of the University of Pisa and she received her medical degree in 1995 (cum laude). In November 2001 she received her qualifying diploma in Plastic and Reconstructive Surgery at the University of Milan. During her study she worked as a staff member at the Department of Plastic and Reconstructive Surgery in San Donato Milanese (Milan) and as a resident in training in the Academic Hospital Maastricht, The Netherlands. Since March 2002 she has been working as a staff member at the European Institute of Oncology, Milan, Italy. 
